\title{
One Dimensional, Transient Model of Heat, Mass, and Charge Transfer in a Proton Exchange Membrane
}

\author{
Brandon M. Eaton \\ Thesis Submitted to the Faculty of the \\ Virginia Polytechnic and State University \\ In partial fulfillment of the requirements for the degree of \\ Master of Science \\ in \\ Mechanical Engineering \\ Dr. Michael R. von Spakovsky, Chair \\ Dr. Michael W. Ellis \\ Dr. Douglas J. Nelson
}

May 9, 2001

Blacksburg, Virginia

Keywords: PEMFCs; polymer membranes; transient heat, mass, and charge transfer

Copyright 2001, Brandon M. Eaton 


\title{
One-Dimensional, Transient Model of Heat, Mass, and Charge Transfer in a Proton Exchange Membrane
}

\author{
Brandon M. Eaton
}

\begin{abstract}
(Abstract)
A transient, one-dimensional, model of the membrane of a proton exchange membrane fuel cell is presented. The role of the membrane is to transport protons from the anode to cathode of the fuel cell while preventing the transport of other reactants. The membrane is modeled assuming mono-phase, multi-species flow. For water transport, the principle driving forces modeled are a convective force, an osmotic force (i.e. diffusion), and an electric force. The first of these results from a pressure gradient, the second from a concentration gradient, and the third from the migration of protons from anode to cathode and their effect (drag) on the dipole water molecules. Equations are developed for the conservation of protons and water, the conservation of thermal energy, and the variation of proton potential within the membrane.
\end{abstract}

The model is solved using a fully implicit finite difference approach. Results showing the effects of current density, pressure gradients, water and heat fluxes, and fuel cell startup on water concentration, temperature, and proton potential across the membrane are presented. 


\section{AKNOWLEDGEMENTS}

I would like to express my gratitude to my advisor and chair of my committee, Professor Michael R. von Spakovsky, for his guidance during my time here at Virginia Tech.

I would also like to thank the other members of by examining committee, Professor Michael Ellis, Professor Douglas Nelson, and Dr. Benoit Olsommer for the time and effort they have spent advising me. In addition, I would like to thank Nathan Siegel for the assistance he has provided me since joining the project.

Lastly, I would like to thank the U.S. Department of Energy for funding my research through a Gate Fellowship. 


\section{Table of Contents}

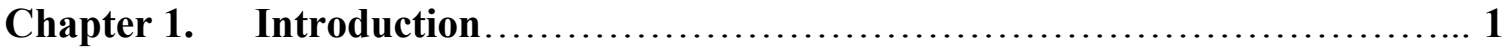

$1.1 \quad$ Fuel Cells ....................................................... 1

1.2 Proton Exchange Membrane Fuel Cells (PEMFCs) $\ldots \ldots \ldots \ldots \ldots \ldots \ldots \ldots . . \ldots$

$1.3 \quad$ Fuel Cell Performance Objectives..................................... 8

1.4 Thesis Objectives............................................... 10

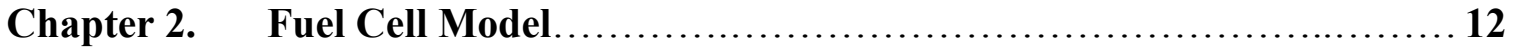

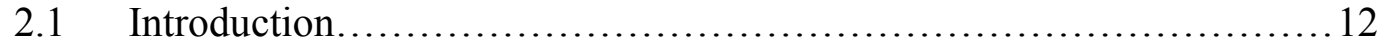

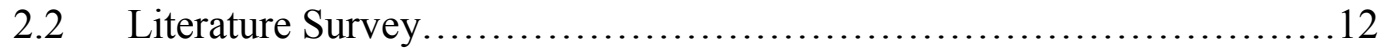

2.3 Mathematical Model................................................... 18

2.3.1 Model Overview ......................................... 18

2.3.2 Component Summary Models................................. 18

Chapter 3. Membrane Model..................................................

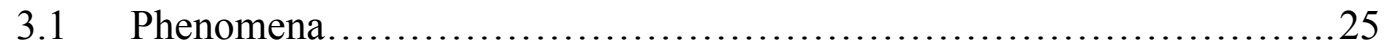

3.2 Structure and Resulting Assumptions ...............................26

3.3 Governing and Constitutive Equations.............................2 27

3.3.1 Mass or Species Conservation................................ 28

3.3.2 Momentum Equation...........................................

3.3.3 Conservation of Energy Equation................................ 31

3.3.4 Conservation of Current........................................32

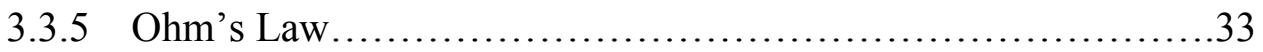

3.3.6 Mixture Pressure Relation......................................33

3.3.7 Interface Water Activity Relation...............................34

3.3.8 Membrane Water Activity Relation...............................34

3.4 Boundary and Initial Conditions ................................... 35

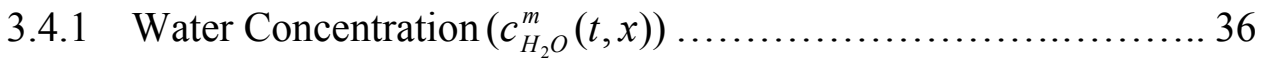

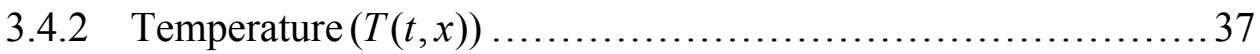

Chapter 4. Model Solutions...........................................................

$4.1 \quad$ Finite Difference Approach........................................ 38

4.1.1 Difference Operators..........................................

4.1.2 Implicit versus Explicit Schemes..............................41

4.1.3 Variable Coefficients............................................. 44

4.1.4 Boundary Conditions..................................... 48

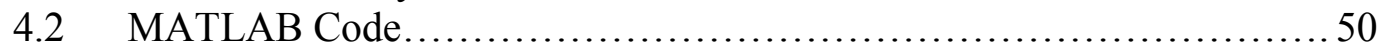

4.2.1 Function Descriptions ......................................51

4.2.2 Program Flow............................................... 58

4.2.3 Code Validation.............................................. 62

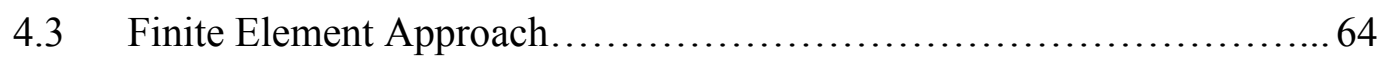

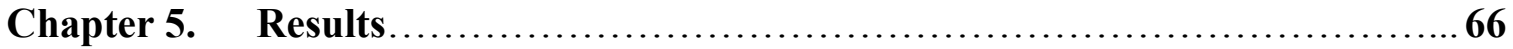

5.1 Influence of Transient Bounday Conditions............................66 66

5.2 Water Management Within the Membrane..............................66

5.2.1 Effects of Electric Drag...................................... 69 
5.2.2 Effects of Pressure Gradients ............................... 70

5.2.3 Effects of Water Flux Entering and Exiting...................... 71

5.3 Temperature Profiles within the Membrane.............................75

5.4 Simulated Start-up of a Fuel Cell..................................77

Chapter 6. Conclusions and Recommendations............................81

6.1 Conclusions................................................... 81

6.2 Recommendations............................................... 82

Bibliography........................................................ 84

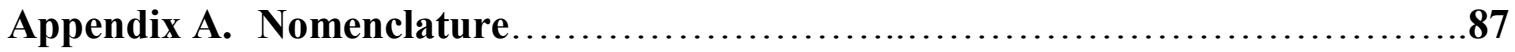

Appendix B. Mathematical Model............................................. 89

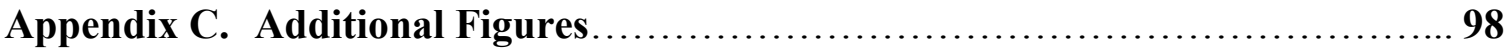

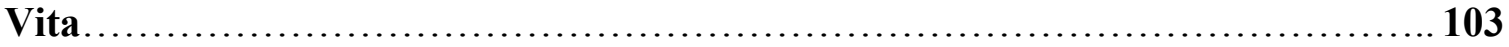




\section{List of Multimedia Objects}

Figure 1.1 Average exergy efficiencies of the principal types of Energy conversion systems...........................................................

Table 1.1 Types of fuel cell systems .................................................

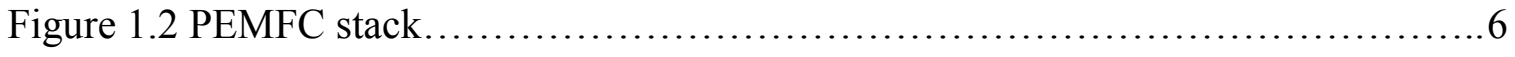

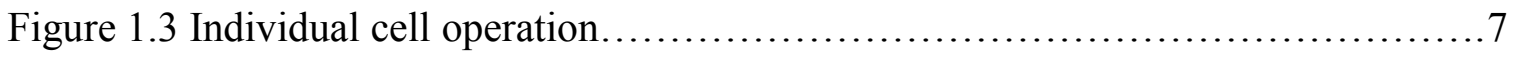

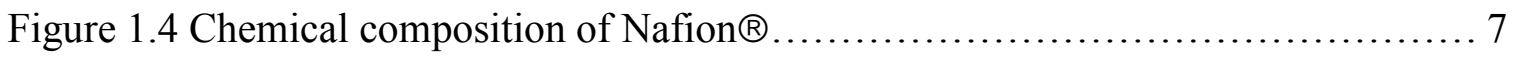

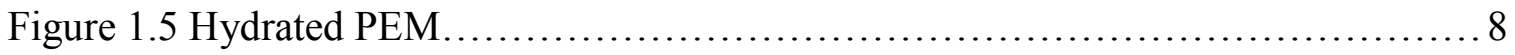

Figure 3.1 Membrane Transport Phenomena.......................................25

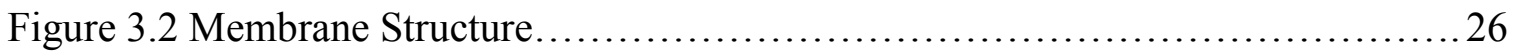

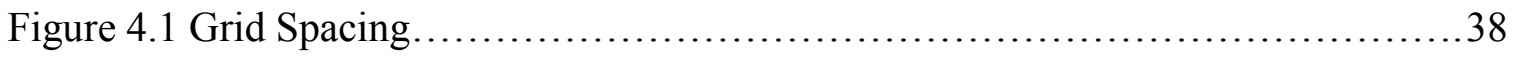

Figure 4.2 Implicit formulation and solution technique.............................43

Figure 4.3 Dirichlet Boundary Conditions.........................................49

Figure 4.4 Outline of the MATLAB code developed to build and

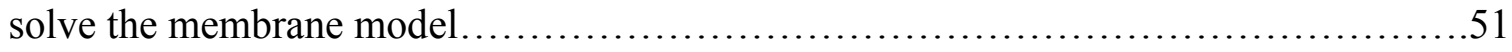

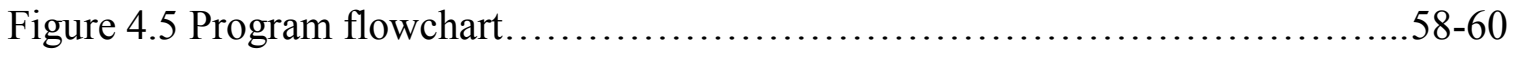

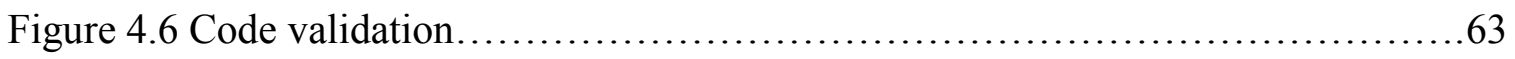

Table 5.1 Initial and boundary conditions used to generate results in

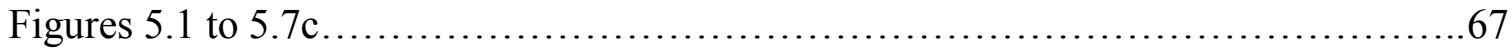

Figure 5.1 Effect of current density on water concentration........................... 69

Figure 5.2 Effect of pressure gradient on water concentration........................ 70

Figure 5.3a Tendency towards flooding in the membrane............................ 72

Figure $5.3 \mathrm{~b}$ Tendency towards drying of the membrane............................. 72

Figure 5.4 Effect of membrane hydration on voltage losses......................... 74

Figure 5.5 Effect of membrane hydration on temperature ............................74 
Figure 5.6a Effects of ohmic heating vs convection on the temperature profiles for a $\Delta \mathrm{T}=0.005^{\circ} \mathrm{C}$ across the membrane

Figure 5.6b Effects of ohmic heating vs convection on the temperature profiles for a $\Delta \mathrm{T}={ }^{\circ} \mathrm{C}$ across the membrane............................. 76

Figure 5.7a Water concentration during start-up................................. 78

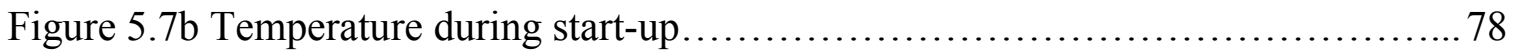

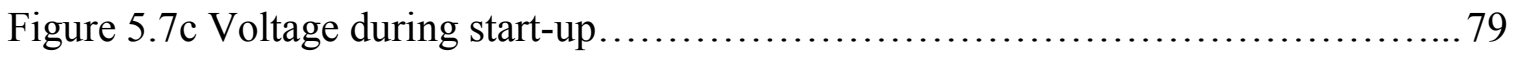

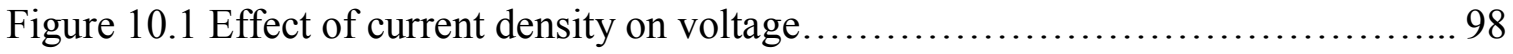

Figure 10.2 Effect of current density on temperature............................... 99

Figure 10.3 Effect of pressure gradient on voltage................................ 99

Figure 10.4 Effect of pressure gradient on temperature..............................100

Figure 10.5 Effects of ohmic heating vs convection on the water concentration. profiles for a $\Delta \mathrm{T}=0.005{ }^{\circ} \mathrm{C}$ across the membrane..................... 100

Figure 10.6 Effects of ohmic heating vs convection on the voltage profiles for a $\Delta \mathrm{T}=0.005{ }^{\circ} \mathrm{C}$ across the membrane......................... 101

Figure 10.7 Effects of ohmic heating vs convection on the water concentration profiles for a $\Delta \mathrm{T}=0.1{ }^{\circ} \mathrm{C}$ across the membrane.................. 101

Figure 10.8 Effects of ohmic heating vs convection on the voltage profiles for a $\Delta \mathrm{T}={ }^{\circ} \mathrm{C}$ across the membrane ....................................... 102

Figure 10.9 Results for boundary condition used to generate

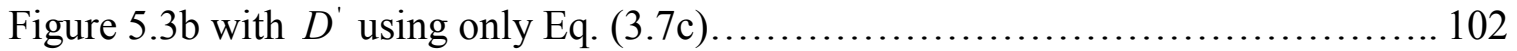




\section{Chapter 1. Introduction}

As the demand for environmentally friendly and cost effective alternatives to traditional power sources continues to grow, it is becoming evident that future energy generation may be somewhat different from that of the present. Many of today's industries, including automotive manufacturers, are investing considerable resources in finding and implementing new technologies to replace traditional power production methods in order to stay competitive in future markets. One of these newly emerging technologies is the fuel cell. Although it has been around for many years, it is only recently that technological advances have made them competitive with traditional power production methods. This chapter discusses the advantages of fuel cells in general and of solid polymer electrolyte membrane fuel cells (PEMFC) in particular, the principles of PEMFC operation and performance and addresses my thesis objectives.

\subsection{Fuel Cells}

A fuel cell is an electrochemical device, which can continuously convert the chemical energy of a fuel and an oxidant to electrical energy (U.S. Fuel Cell Counsel, 1999). The primary fuel consumed and the methods employed to utilize the chemical energy from the fuel can vary greatly depending on the application. The most common types of fuel cells, characterized by the electrolyte (with the exception of the last one in the list below), are the following:

$\begin{array}{ll}\circ & \text { Alkaline Fuel Cell (AFC) } \\ \circ & \text { Proton Exchange Membrane or Polymer Electrolyte Membrane Fuel Cell } \\ & \text { (PEMFC) } \\ \circ & \text { Phosphoric Acid Fuel Cell (PAFC) } \\ \circ & \text { Molten Carbonate Fuel Cell (MCFC) } \\ \circ & \text { Solid Oxide Fuel Cell (SOFC) } \\ \circ & \text { Direct Methanol Fuel Cell (DMFC) }\end{array}$


In general, fuel cells offer many advantages over conventional energy conversion devices. They have higher energy efficiencies at both design and off-design (von Spakovsky, Nelson, and Ellis, 2000). A comparison of fuel cell systems versus other energy conversion systems is shown in Figure 1.1.

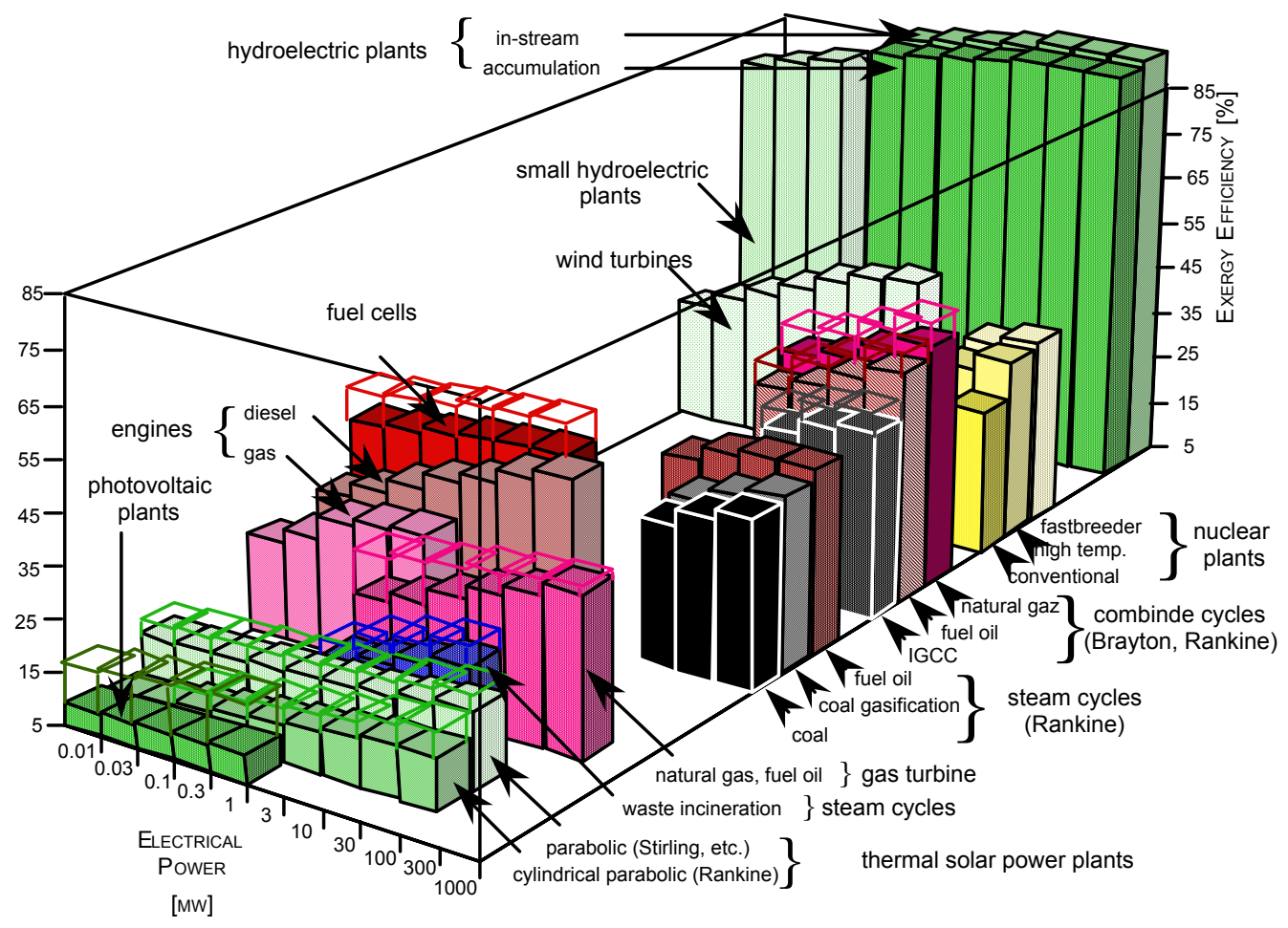

Figure 1.1 Average exergy efficiencies of the principal types of energy conversion systems (von Spakovsky and Olsommer, 1999).

Figure 1.1 demonstrates that the exergy or Second Law efficiency of fuel cell systems compares favorably to all other energy conversion systems using hydrocarbons for fuel. In fact, fuel cell systems have the highest overall average efficiency of all systems except hydroelectric plants. The clear boxes above each efficiency column indicate the theoretical improvements that are predicted for each system. With these predicted improvements in fuel cell system efficiency, fuel cell systems would gain an even larger efficiency advantage over other systems. Figure 1.1 also indicates fuel cell systems can 
be used to generate power over a large range of power requirements. This scalability will be addressed shortly.

These higher efficiencies allow for a better use of natural resources such as hydrocarbons. Being more efficient at off-design allows a fuel cell system to deliver peak power while still being efficient at lower power requirements. This offers a distinct advantage over internal combustion (IC) engines, whose efficiencies drop off drastically the further they operate from their peak (i.e. design) power point. In fact, the vast majority of time, a vehicle, whose primary power source is an IC engine, operates far below peak power. This is also true of most other energy conversion systems, depending of course, on the application.

Fuel cell systems also are easily scaled, allowing them to be used for small applications such as the power source for a personal computer as well as large applications like a stationary power plant. Large or small, all these applications harness the fuel cells inherent efficiency advantages to make better use of a fuel's chemical energy.

As the world becomes more industrialized, a second key advantage of fuel cells, lower emissions, becomes essential for controlling global pollution. With fuel cells, the conversion of chemical energy to electrical energy is accomplished electrochemically only water is created. Although some emissions do occur during the fuel reforming process, temperatures are not high enough for $\mathrm{NO}_{\mathrm{x}}$, sulfur components are removed prior to reforming so that $\mathrm{SO}_{\mathrm{x}}$ formation does not occur, and much less $\mathrm{CO}_{2}$ is released due to the higher average efficiencies of fuel cell systems. In addition, $\mathrm{CO}$ concentrations are below $10 \mathrm{ppm}$ by necessity and unreacted hydrocarbons are recirculated in the system. Furthermore since there are fewer moving parts (none in the stack itself) in a fuel cell system, such systems operate much more quietly, resulting in less noise pollution.

While fuel cell systems offer an excellent alternative for powering vehicles, at this stage in their development they might be most economically feasible in stationary residential power applications. For example, residential fuel cell systems allow electricity to be 
created where it is consumed. This allows the home to become less susceptible to power interruptions due to power grid failures and inclement weather. Having electricity produced locally also spares homeowners living in remote locations the expense of connecting to the electric grid. Furthermore, heat that results from the fuel cell's operation can be harnessed and used to supplement home and hot water heating. Because fuel cells systems are scalable, they could be used to supply power to single homes or large apartment, commercial, or industrial complexes. Thus, the marketplace and our ability to design good fuel cell systems will determine how fuel cells will be best used to meet the energy needs of the future.

\subsection{Proton Exchange Membrane Fuel Cells (PEMFCs)}

As mentioned earlier, many different types of fuel cell systems exist, but it is important to match the fuel cell system to the application. In the case of private as opposed to public transportation applications, the PEMFC is best suited to meet the rigorous demands of the consumer market.

The PEMFC offers a relatively high electrical efficiency. Its average stack efficiency is higher than a comparably sized internal combustion engine (55\% optimistically compared to $37.6 \%$ at full load (von Spakovsky, Nelson, and Ellis, 2000)). It also offers sufficient power density to meet the road load demands of a vehicle. The PEMFC operates at a low enough temperature to be housed safely on-board a vehicle. This low operating temperature also allows the PEMFC to have a quick start-up time compared to other fuel cell systems. Table 1.1 compares the different types of fuel cell systems currently under development. In this table, a green square represents a characteristic that makes the fuel cell system an excellent choice for vehicle applications. A yellow square symbolizes a satisfactory solution and red rules out that type of fuel cell for vehicle applications. From the table one can conclude that the PEMFC is the only fuel cell that excels in all the characteristics essential for private vehicle applications. An additional advantage that the PEMFC offers over some of the other fuel cells are that the PEMFC is a less complicated system to implement and has a longer expected lifetime. 
Table 1.1 Types of fuel cell systems (von Spakovsky and Olsommer, 1999).

\begin{tabular}{|c|c|c|c|c|}
\hline & $\begin{array}{c}\text { Electrical 1 }{ }^{\text {st }} \text { Law Eff. } \\
(\%)\end{array}$ & $\begin{array}{c}\text { Power Density } \\
\left(\mathrm{kW} / \mathrm{m}^{2}\right)\end{array}$ & $\begin{array}{c}\text { Operating } \\
\text { Temps }(\mathrm{C})\end{array}$ & Start-up Time \\
\hline \multirow{2}{*}{ SOFC } & $\begin{array}{c}50-65(\mathrm{stk}) \\
45-50(\mathrm{sys}) \\
>74(\mathrm{cmb})\end{array}$ & $1.5-2.6$ & $800-1000$ & $\mathrm{hrs}$ \\
\hline MCFC & $\begin{array}{c}50-60(\mathrm{sys}) \\
55-70(\mathrm{cmb})\end{array}$ & $0.1-1.5$ & $650-800$ & $\mathrm{hrs}$ \\
\hline PAFC & $\begin{array}{c}40-50(\mathrm{stk}) \\
41(\mathrm{sys})\end{array}$ & $0.8-1.9$ & $160-210$ & $\mathrm{hrs}$ \\
\hline PEMFC & $40-55(\mathrm{stk})$ & $3.8-6.5$ & $50-100$ & sec-min \\
\hline AFC & $45-60(\mathrm{stk})$ & $0.7-8.1$ & $60-100$ & min \\
\hline DMFC & $40(\mathrm{stk})$ & $>1.5$ & $50-200$ & sec-min \\
\hline
\end{tabular}

The PEMFC is made up of an ion conducting membrane sandwiched between an anode and cathode, all held together by two bipolar collector plates. The anode and cathode are thin sheets of porous, graphite paper, wet-proofed with Teflon. The anode and cathode have a catalyst layer pressed onto one side of them. The side containing the catalyst is placed in contact with the proton exchange membrane. The catalyst layer is platinum black with typical loadings ranging from as low as $0.05 \mathrm{mg} \mathrm{Pt} / \mathrm{cm}^{2}$ to as high as $0.5 \mathrm{mg}$ $\mathrm{Pt} / \mathrm{cm}^{2}$ (von Spakovsky, Nelson, and Ellis, 2000). The catalyst layer increases the rate of the electrochemical reaction, allowing it to proceed quickly enough to release electrons which are captured to provide the electrical power required by a vehicle. Collectively, the membrane and electrode form a membrane electrode assembly, commonly referred to as a MEA. The MEA structure is on the order of 725 microns thick (each electrode/catalyst layer each being 300 microns and the membrane being 125 microns (von Spakovsky, Nelson, Ellis, 2000)).

Two bipolar graphite collector plates hold each membrane/electrode assembly together, forming a cell. Each cell is connected electrically to the next cell in series. A collection of cells makes up a stack as shown in Figure 1.2. 


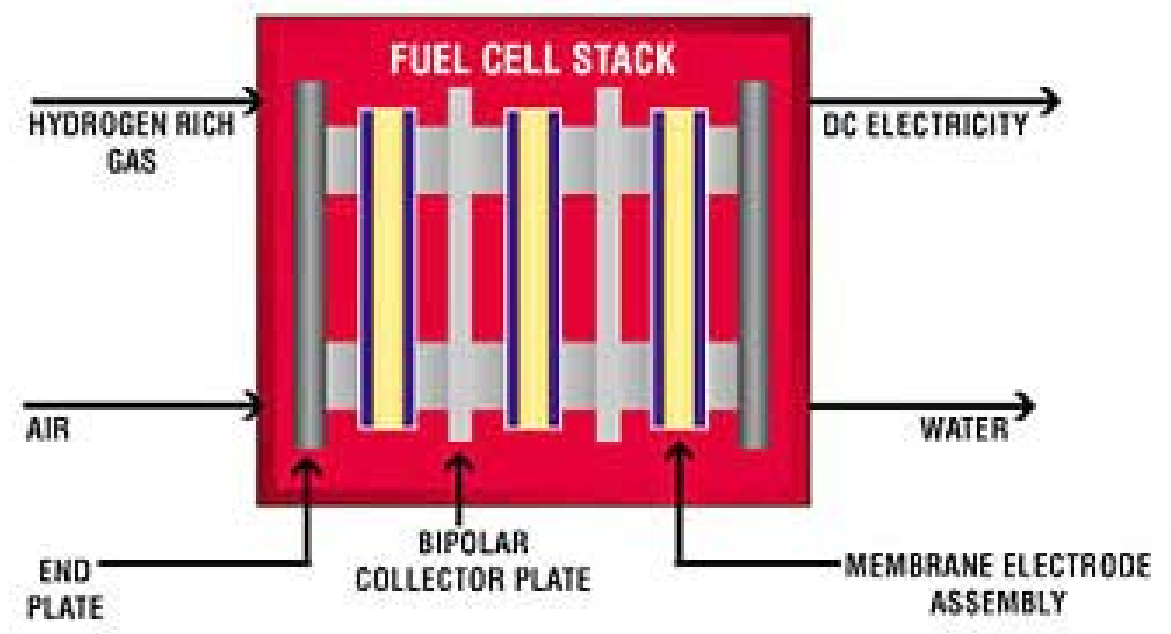

Figure 1.2 PEMFC stack (Energy Partners, 2001).

The number of cells and the surface area of each cell determine the stack's power level. A stack used for a vehicle might contain as many as 400 cells with an active area of 200 $\mathrm{cm}^{2}$ each. At peak power, each cell would operate around $0.6 \mathrm{~V}$ with a current density of $1.25 \mathrm{~A} / \mathrm{cm}^{2}$ delivering $60 \mathrm{~kW}$ of power.

The basic electrochemical principles of PEMFC operation can be summarized as follows. Hydrogen and oxygen gases are supplied to the anode and cathode, respectively. A hydrogen oxidation reaction takes place at the anode; and as a result, hydrogen ions and free electrons are produced. At the cathode, oxygen along with the electrons released at the anode combine with hydrogen protons which diffuse through the membrane. This results in the formation of water (Figure 1.3) and the release of thermal energy. A catalyst layer is present at both the anode and cathode interface with the membrane to encourage these reactions. 


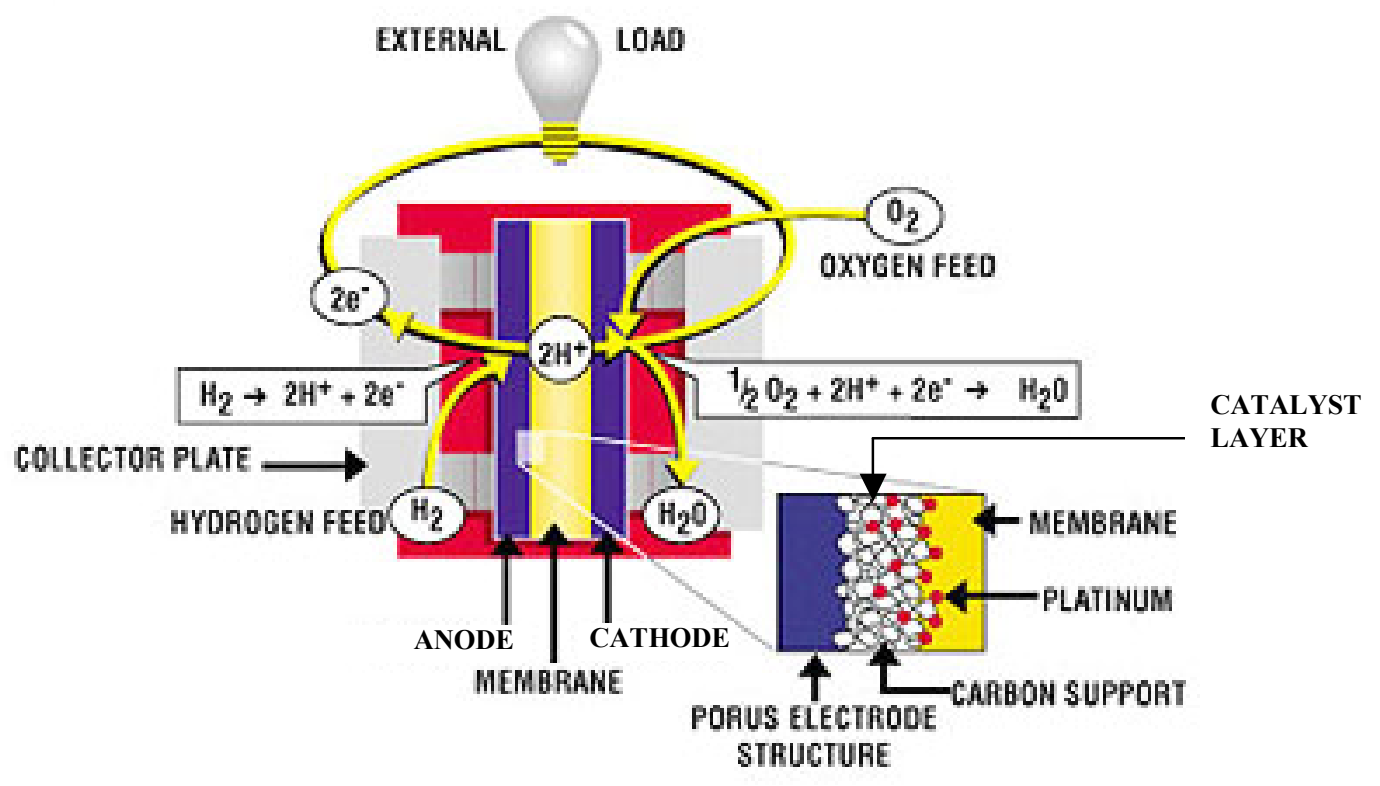

Figure 1.3 Individual cell operation (Energy Partners, 2001).

The functionality of the fuel cell is dependent on the unique properties of the membrane. The membrane allows the transport of protons and water through it but remains mostly impermeable to the hydrogen and oxygen gas. One of the most widely used types of membranes is Nafion ${ }^{\circledR}$ polymeric membranes produced by DuPont. The chemical composition of Nafion ${ }^{\circledR}$ is shown below in Figure 1.4. Nafion ${ }^{\circledR}$ consists of chains of carbon, fluorine and oxygen atoms with sulfonic acid $\left(\mathrm{SO}_{3} \mathrm{H}\right)$ groups attached.

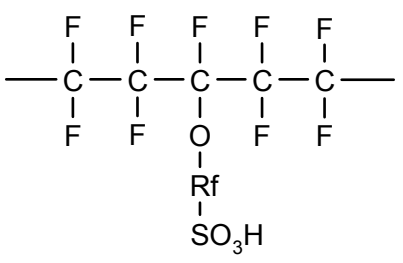

Figure 1.4 Chemical composition of Nafion ${ }^{\circledR}$. 
The ion selectivity of a PEM is the result of its unique structure, mainly the presence of the $\mathrm{SO}_{3} \mathrm{H}$ side groups. When the membrane is fully hydrated, the negatively charged $\mathrm{SO}^{3-}$ groups serve as fixed charge sites that attract positive hydrogen ions (Figure 1.5). It is believed that the protons jump from one negative site to another while moving along the membrane pore (Verbrugge and Hill, 1990).

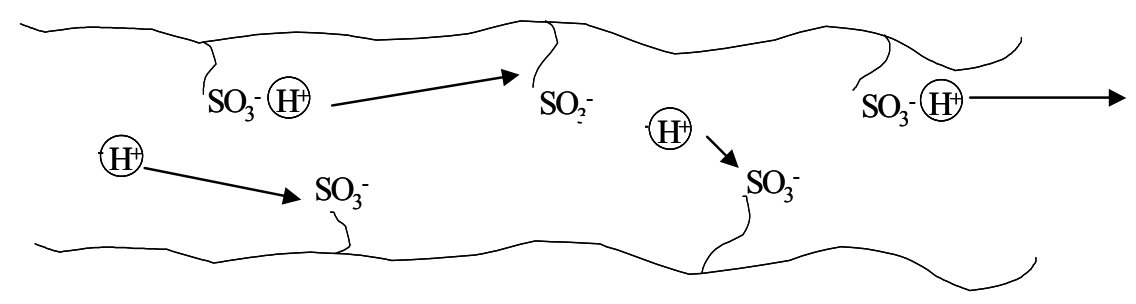

Figure 1.5 Hydrated PEM.

\subsection{Fuel Cell Performance Issues}

Overall fuel cell system performance is dependent on many factors. Limiting the investigation to the fuel cell itself and not the surrounding fuel processing and power conditioning sub-systems, focus is placed on the internal workings of the fuel cell. Efficient fuel cell operation is dependent on the following:

Uniform reactant flow. Uniform reactant flow is essential to ensuring uniform current densities. In order to achieve high efficiency and higher power density, fuel cells must maintain a high current density distributed uniformly across the cell active area. Nonuniform current distribution leads to losses. Without homogeneous distribution of reactants, "dead zones" may occur within the cell.

Water management. Water must be managed within the MEA to insure that the membrane remains hydrated, preventing localized hot spots and damage to the membrane structure. In addition, the membrane must remain hydrated in order to maintain its 
protonic conductivity. Water is transported through the membrane by convection due to a pressure gradient, by diffusion due to a water concentration gradient, and by a drag force imposed on the water molecules by positively charged protons moving through the membrane. All these transport phenomena must be managed so that the membrane remains hydrated on both the anode and cathode sides.

In the anode, water is in the gaseous phase only. The incoming reactant stream is humidified with water allowing some water to be brought into the MEA with this stream. On the cathode side, where water is produced, both liquid and gaseous water are present. Like the reactant stream entering the anode, the cathode reactant stream can also be humidified with water to provide hydration for the MEA. Water produced at the cathode is another means of membrane hydration. However, if an excess of water is present, the water must be removed from the cathode pores to prevent flooding. In most applications, the concentration of water is higher on the cathode side than the anode side and flooding if it occurs, occurs on the cathode side. Water is removed from the cathode side toward the cathode gas channel by capillary driving forces. Thanks to this pressure, a liquid phase pressure gradient (which is actually opposite to the gaseous one) forms, allowing the evacuation of liquid towards the gas channel (Olsommer, 2000). If water is not adequately removed from the cathode pores, flooding occurs and reactant flow through the cathode is partially or totally blocked. With the reactants blocked, the reaction at the cathode is starved of oxygen and fuel cell performance is drastically affected. In addition, at high current densities, the catalyst layers becomes current limiting due to the high concentration of reactants. The presence of water in the catalyst layer pores magnifies this effect by further lowering the intrinsic porosity of the catalyst layer (Olsommer, 2000).

Catalyst layer transport properties and utilization rate. Because of the high costs of catalyst materials, it is important to effectively use the entire catalyst layer. For a uniformly distributed catalyst layer, the most effective use occurs when reactants are transported at similar rates (Springer, Wilson and Gottesfeld, 1993). The catalyst layer is usually composed of agglomerates of Carbon, Platinum and an ionomer (e.g., Nafion ${ }^{\circledR}$ ) 
mixture (Olsommer, 2000). Within the catalyst layer, reactant species are transported through micro-pores separating the agglomerates. The catalyst layer can become current limiting at high currents if reactants cannot adequately diffuse through the catalyst layer's micro-pores. As stated previously, this problem is further magnified if water is present in the pores (due to flooding). A second factor in determining the most effective use of the catalyst layer is finding the effective distance of the electrochemical reaction and developing the catalyst layer to match this thickness (Olsommer, 2000).

Heat management. Many material properties that govern the performance of the fuel cell are temperature dependent. If local temperature spikes occur within the cell, it is likely they will have an adverse effect of performance. Within the cell, heat is released by partial-phase changes, electrical overpotentials and electrochemical reactions (Olsommer, 2000). Some of this heat must be removed to prevent damage to the membrane. Localized hot spots can cause permanent damage to the membrane. The membrane material and fuels used dictate the temperature range the cell must operate. For Nafion ${ }^{\circledR}$ using gaseous fuels this range is $80-100^{\circ} \mathrm{C}$ (Olsommer, 2000).

\subsection{Thesis Objectives}

Having an understanding of the elements that affect fuel cell performance and how design changes affect these elements is important to designing better fuel cells and fuel cell stacks. Currently, the costs of redesigning fuel cells and measuring fuel cell performance make many experimental techniques to arrive at redesigns cost prohibitive. What is needed is a simulation model that can be used to test fuel cell designs. Currently, many models exist that focus on one aspect or region of the fuel cell. But, to create a tool that is useful to designers, the simulation model must take into account heat and mass transfer as well as electrical and electrochemical effects occurring within the fuel cell. The model must also incorporate important design components of the fuel cell from collector plate through the membrane and then out again to the opposite collector plate. The reactant flow fields, electrodes, catalyst layers, and membrane must all be modeled together so that the effects of design changes will be reflected through out the model and 
fuel cell performance can be predicted. A comprehensive model could be used to identify designs will result in the most uniform current density distributions. Such a model could help identify the material properties that are important to fuel cell performance and help drive new component and stack design.

At Virginia Tech, such a model exists. It is composed of nine separate 3D or psuedo-3D component models for the anode and cathode collector plates, the gas channels, the backing layers (electrode/gas diffusers), the catalyst layers (electrode/catalysts), and membrane. Although the entire model is composed of all nine models coupled, solutions are being sought for each individual component model independently. The focus of this thesis is the solution to the one-dimensional membrane model which comprises the psuedo-3D model of the membrane.

The objective of this thesis was to model the transient behavior of a PEMFC membrane and its properties. Accomplishing this goal required that I

- Understand the governing and closure relations developed by Olsommer (2000) that describe the phenomena occurring inside the membrane and at its boundaries

- Make any necessary changes to improve, correct, or clarify these relations

- Investigate options for numerically approximating the thermal energy and water species conservation equations within the membrane

- Develop and test the finite difference algorithm for solving two transient, coupled partial differential equations with variable coefficients

- $\quad$ Approximate the thermal energy and water species conservation equations within the membrane using finite difference techniques

- Develop code to solve for the transient behavior of species concentration, temperature, and material properties within the membrane 


\section{Chapter 2. Fuel Cell Model}

\subsection{Introduction}

The first step toward developing a comprehensive PEMFC model was gaining an understanding of existing models in the literature. A brief overview of existing models is given in Section 2.2. Section 2.3 describes Virginia Tech's fuel cell model and briefly summarizes the essential characteristics of each component model. All the information contained in this chapter can be found in much greater detail in Olsommer (2000).

\subsection{Literature Survey}

Current fuel cell modeling efforts have focused on developing models that can be used to analyze the effects of specific design and material parameters. Many of the effects mentioned previously are addressed individually by existing models. The most relevant and original contributions to the mathematical modeling of PEMFCs are summarized below.

\section{- At General Motors:}

$>$ Verbrugge and Hill (1990) and then Bernardi and Verbrugge (1992) developed a comprehensive steady-state, isothermal, one-dimensional model of the physical and electrochemical processes in a PEMFC and applied it to investigating factors that limit cell performance, such as the porosity and volume fraction of the electrode available for gas transport. They claim that due to capillary forces, the liquid and gas pressure evolve separately within the backing layer. This important assumption implies that the gas and liquid phases are not in equilibrium within the cathode backing layer. Their model is valid for fully hydrated membranes only, and they do not take into account the drag force on water molecules due to proton flux. In addition, their model is unable to predict the flooding due to liquid water in the cathode backing layer and the polarization curve diverges from experimental data for high current densities. 
- At the Los Alamos National Laboratory:

> Springer, Zawodzinski and Gottesfeld (1991a) presented an isothermal, onedimensional, steady state model of a PEMFC with emphasis on water transport phenomena through a Nafion ${ }^{\circledR}$ membrane and related effects, such as membrane conductivity. They argue that the convective transport for water is limited to the drag force on water molecules due to proton flux. An improved model with an in-depth treatment of the gas transport and ionic conductivity limitations in the catalyst layer (pseudo-homogeneous model) and gas transport limitations in the backing layer was latter used for diagnostics of PEMFCs (Springer and Gottesfeld, 1991b, Springer et al., 1993). Unlike the previously mentioned models, this model appeared to predict mass transport limitations at high current densities. However, these models use artificially fitted parameters like the cathode backing layer effective porosity in order to predict physical phenomena like water flooding. In a more recent paper, Springer, Zawodzinski, Wilson and Gottesfeld (1996) provide combined experimental and theoretical results for unsteady state effects in a one-dimensional isothermal PEMFC stack. By using a frequency diagram, they are able to quantify the specific influences of several sources of losses such as activity in the cathode and conductivity of the catalyst layer and the membrane, all three arising from imperfect humidification.

> Based on the previous model, Springer et al. (1991a,b, 1993), Weisbrod, Grot and Vanderborgh $(1995,1996)$ developed a through-the-electrode model of a PEMFC and then combined it with a down-the-channel model to predict fuel cell performance as a function of water balance in the channels and transport across the membrane. Their model predicts the influence of both the catalyst layer thickness and its Pt catalyst loading. They show that the PEMFC passes through an optimum with respect to the latter.

- At Texas A\&M University and at INPG in Grenoble:

$>$ In an attempt to elucidate the mass transport phenomenon in the cathode, Rho, Velev, Srinivasan and Kho (1994) conducted an experimental analysis with various mixtures of $\mathrm{O}_{2} / \mathrm{He}, \mathrm{O}_{2} / \mathrm{Ar}$ and $\mathrm{O}_{2} / \mathrm{N}_{2}$, and then compared the experimental results with a theoretical model of a half-cell. The latter (Rho, Kho and Srinivasan, 1994) is a steady-state, one-dimensional model. Their model does not take into account the 
formation of water droplets resulting in a liquid film in the cathode backing layer. Thus, it is unable to predict transport limitations at high current densities. Mosdale and Srinivasan (1995) present a comparison of different modeling studies of PEMFCs and several approaches to dealing with the water and thermal management problems. According to the work of the former (Mosdale, 1992), the transport limitation in the catalyst layer is determinant at high current densities.

- At the University of Kansas:

> Nguyen and White (1993) developed a one-dimensional, steady-state water and heat management model for PEMFCs. This model does not study the details of the membrane and the catalyst layers, since it groups these elements in the electrodes. This approximate model calculates local current density along the gas channel as a function of resulting local conditions. They applied the model to study various humidification schemes and their effect on fuel cell performance. This model is enhanced (Yi and Nguyen, 1998) with the addition of a linear model for the membrane. It consists of a straightforward linear discretization of the transport equation between the anode and the cathode boundaries of the membrane. This simplification represents a rough idealization of the real phenomena and should only be valid for very thin membranes. In a more recent paper, Yi and Nguyen (1999) present a two-dimensional, steady-state model for multi-species transport in the electrodes. They study the effect of an inter-digitated gas-distributor on PEMFC performance. However, their model is unable to predict the effect of liquid water within the system.

Thirumalai and White (1997) incorporated the previous model into a fuel cell stack model that can be used to predict the effect of operating parameters, flow field design and gas manifold geometry on the performance of the fuel cell stack.

- At the Netherlands Energy Research Foundation:

> Van Bussel, Koene and Mallant (1998) address dynamic behavior with a twodimensional model (one-dimensional within the membrane). The membrane model is based on the work of Springer et al. (1991a) but uses more recent experimental data from Hinatsu, Mizhuta and Takenaka (1994). The model shows that the current 
density can vary strongly along the gas channels, particularly when operating with dry gases.

- At the Research Center in Jülich, the Technical Univertity in München and the Russian Academy of Sciences in Moscow:

$>$ Divisek, Mosig, Steffen and Stimming (1995) proposed a three-dimensional model for the fuel cell stack limited to electric charge, energy and mass transfer. Unlike the previously cited models above, they argue that water transport through the membrane is essentially carried out by convection. In a more recent paper, Eikerlink, Kharkats, Kornyshev and Volfkovich (1998) claim that there is experimental evidence in favor of a convective model. Based on experimental data, Divisek, Eikerling; Mazin, Schmitz, Stimming and Volfkovich (1998) developed a new one-dimensional physical model, accounting for the relation between hydration and capillary pressure. The results seem to reveal that their convective based model is closer to experimental data than diffusion based models.

- At the Electrochemical Laboratory and the Material and Interface Physicochemical Laboratory at St Martin d'Heres, and at the Royal Institute of Technology (KTH) in Stockolm:

> Bultel, Ozil, Durand and Simonsson (1995), Broka and Ekdunge (1997) and Bultel, Ozil and Durand (1998) present a one-dimensional, steady state microscopic model of the catalyst layer. They show the influence of geometry through an agglomerate model (a Carbon, Pt and Nafion mixture separated by pores). Broka and Ekdunge (1997) claim, notably, that the influence of the thickness of the Nafion film surrounding the Carbon-Pt agglomerates is a crucial parameter at medium and high current densities (diffusion through the Nafion from the pores to the Pt catalyst surfaces).

- At the University of Miami:

> Unlike previous articles, Gurau, Kakac and Liu (1998) developed a two-dimensional, non-isothermal model. A special handling of the fundamental equations allows them to consider the gas-channel, diffuser-catalyst layer domains as a single entity, avoiding arbitrary conditions at interfaces. Their model shows that a non-uniform, reactant distribution has an important impact on the current density distribution. Nevertheless, 
their model is based on an infinitively thin catalyst layer, unable to predict the overvoltage due to transport limitations in the catalyst layer.

- At the Lawrence Berkeley Laboratory:

$>$ Fuller and Newman (1993) present a steady-state, two-dimensional model for the membrane-electrode assembly. Unlike all other models, concentrated solution theory is used. They argue that water is produced in gaseous phase at the catalyst surfaces. Their model is valid as long as there is no condensation of water within the catalyst layer. Thus, it can not predict flooding in the backing layer. In a more recent paper, West and Fuller (1996) use the same model to study the influence of rib spacing on cell potential. The results show a slight effect on overall cell potential but a strong influence on water management.

Among all of the above mentioned phenomena, water management in the membrane allows one to classify some of these contributions. Four groups can be distinguished, in that they are uniformly recognized and served as a basis for the other models:

1. the "Los Alamos" model (Springer et al., 1991-1996) arguing that the convective process for water is restricted to the drag of water molecules by protons;

2. the "General Motors" model (Verbrugge, Bernardi and Hill, 1990-1992) neglecting the interaction of the opposite proton and water fluxes (drag term);

3. the "Jülich" model (Divisek et al., 1995, Eikerling, Kornyshev et al., 1998) arguing that the water diffusion (osmotic) term can be disregarded in comparison to the convective term limited to the Darcy term;

4. the "Berkeley" model (Fuller and Newman, 1992) basing itself on concentrated solution theory and assuming that the water is produced in gaseous phase at the cathode. In addition, two other models can be distinguished: the "Miami" model (Gurau et al., 1998) and the "Kansas" model (Yi and Nguyen, 1998). Both are primarily based on the "Los Alamos" model with an additional convective term. Table 2.1 summarizes these distinctions. 
Table 2.1 Transport phenomena in membranes: mechanisms and models

$$
\text { ( } \left.\mathrm{w}=\text { water, } \mathrm{H}^{+}=\text {hydrogen proton }\right)
$$

\begin{tabular}{|c|c|c|c|c|}
\hline \multirow{2}{*}{$\begin{array}{l}\text { Models } \\
\text { Forces Modeled }\end{array}$} & \multicolumn{2}{|c|}{ Diffusive (electro-osmotic) } & \multicolumn{2}{|c|}{ Convective } \\
\hline & Osmotic & electro & drag & pressure \\
\hline \multicolumn{5}{|c|}{ Dilute solution theory (Nernst-Plank-Einstein relation) } \\
\hline Verbrugge, et al., (GM) (1990-92) & $\begin{array}{l}\mathrm{w} \\
\mathrm{H}^{+}\end{array}$ & $\mathrm{H}^{+}$ & & $\begin{array}{l}\mathrm{W} \\
\mathrm{H}^{+}\end{array}$ \\
\hline $\begin{array}{l}\text { Springer, et al., (Los Al.) (1991-93) } \\
\text { Weisbrod, et al., (Los Al.) (1995-96) } \\
\text { van Bussel, et al., (Netherland) (1995-98) }\end{array}$ & $\mathrm{w}$ & & $\mathrm{w}$ & \\
\hline Gurau, et al., (98) & $\begin{array}{l}\mathrm{w} \\
\mathrm{H}^{+}\end{array}$ & $\mathrm{H}^{+}$ & $\mathrm{w}$ & $\begin{array}{l}\mathrm{W} \\
\mathrm{H}^{+}\end{array}$ \\
\hline Divisek, Eikerling, et al., (Juelich), (1995-98) & & $\mathrm{H}^{+}$ & $\mathrm{w}$ & $\begin{array}{l}\mathrm{W} \\
\mathrm{H}^{+}\end{array}$ \\
\hline Nguyen, et al., (Kansas) (1993-99) & $\mathrm{w}$ & & $\mathrm{w}$ & $\mathrm{w}$ \\
\hline \multicolumn{5}{|c|}{ Concentrated solution theory (Stefan-Maxwell relation) } \\
\hline Fuller, Newman, et al., (Berkeley) (1992-95) & $\mathrm{W}$ & $\mathrm{w}$ & & $\mathrm{W}$ \\
\hline
\end{tabular}

It should be noted that the important models of Stockholm and St-Martin d'Heres (Bultel, Ozil, Durand, Simonsson, Broka and Ekdunge, 1995-1997) are absent in the preceding classification, because they focus on the catalyst layer only. For the same reason, the models of Texas A\&M and Grenoble (Rho, Kho and Srinivasan, 1994, and Mosdale, 1992) are not included in Table 2.1.

At this time, there does not exist a general consensus on the physical behavior within the PEMFC. Most of the experimental data and mathematical models are available under specific and sometimes unrealistic, idealized conditions. Almost all of them assume a uniform supply of reactants and isothermal conditions, both being convenient simplifications. Furthermore, these models address specific aspects of fuel cell behavior independent of other effects. None of them address the overall problem with a comprehensive model able to tackle simultaneously all the phenomena mentioned above. A comprehensive model should incorporate in a single integrated model threedimensional effects as well as steady-state and dynamic effects for multiple physical processes, including reactant flows, heat and mass transfer, electrochemistry, and 
electrical and ionic conduction. Such a simulation model be a powerful design tool for the fuel cell stack.

\subsection{Mathematical Model}

\subsubsection{Model Overview}

The PEM fuel cell model developed in Olsommer (2000) incorporates models of nine separate components. These are

- two (anode and cathode) collector plates that act as electron conductors

- two (anode and cathode) gas channels that supply the fuel cell with reactants

- two (anode and cathode) porous electrode/gas diffusers that transport reactants/products to and from the catalyst layers and conduct electrons from the catalyst layer to the collector plates

- two (anode and cathode) catalyst layers where the electrochemical reactions take place

- $\quad$ one polymer membrane that allows the transport of water and protons and separates the reactants $\mathrm{H}_{2}$ and $\mathrm{O}_{2}$

\subsubsection{Component Model Summaries}

What follows is a summary of the essential characteristics of each component model.

The membrane model is presented in greater detail in Chapter 3.

\begin{tabular}{|l|l|}
\hline Domain & Collector Plates (anode and cathode) \\
\hline Structure & $\begin{array}{l}\text { Non-porous, solid electron conducting plate containing a } \\
\text { complex channel network in contact with anode }\end{array}$ \\
\hline Transported Species & $\begin{array}{l}\text { anode: electrons } \\
\text { cathode: electrons }\end{array}$ \\
\hline Sources/Sinks & $\begin{array}{l}\text { anode entropy generation: ohmic overpotential } \\
\text { cathode entropy generation: ohmic overpotential }\end{array}$ \\
\hline Function & $\begin{array}{l}\text { Electron conductor } \\
\text { Thermal energy conductor for system cooling } \\
\text { Distributes reactants and collects products to and from } \\
\text { the membrane-electrode assembly (MEA) }\end{array}$ \\
\hline
\end{tabular}




\begin{tabular}{|l|ll|}
\hline $\begin{array}{l}\text { Impact on } \\
\text { Performance }\end{array}$ & $\bullet$ & $\begin{array}{l}\text { It is important to ensure homogeneous heat transfer } \\
\text { within the plate, requiring a three-dimensional model of } \\
\text { electron and energy transport }\end{array}$ \\
\hline Unknowns & $\begin{array}{l}\bullet \\
\bullet\end{array}$ & $\begin{array}{l}\text { Temperature } \\
\text { Current flow }\end{array}$ \\
\hline System of Governing & $\bullet$ & Electrical potential \\
Equations to Solve & $\bullet$ & $\begin{array}{l}\text { Conservation of current equation } \\
\text { Electrical potential equation (Ohm's law) }\end{array}$ \\
\hline Assumptions & $\bullet$ & Conservation of energy equation \\
& $\bullet \begin{array}{l}\text { The cooling system is formed by a liquid film with } \\
\text { infinite capacity (constant temperature) flowing on the } \\
\text { external collector surface } \\
\text { The impedance of the plate is restricted to electrical } \\
\text { resistance so that there are no transient effects }\end{array}$ \\
\hline
\end{tabular}

\begin{tabular}{|c|c|}
\hline Domain & Gas Channels (anode and cathode) \\
\hline Structure & $\begin{array}{l}\text { Plain, series of gas channels running through the collector } \\
\text { plates and feeding into the electrodes }\end{array}$ \\
\hline Transported Species & $\begin{array}{ll}\text { anode: } & \text { gases (hydrogen, water) } \\
\text { cathode: } & \text { gases (air, water), liquid (water) }\end{array}$ \\
\hline Sources/Sinks & $\begin{array}{l}\text { anode: none } \\
\text { cathode: none }\end{array}$ \\
\hline Function & $\begin{array}{l}\text { - Reactants are transported to the electrodes and products } \\
\text { are transported out of the MEA }\end{array}$ \\
\hline $\begin{array}{l}\text { Impact on } \\
\text { Performance }\end{array}$ & $\begin{array}{l}\text { To avoid loses due to parasitic currents, it is vital to } \\
\text { ensure homogeneous distributions of reactants } \\
\text { Water produced at the cathode must be able to be } \\
\text { removed through the gas channels to prevent flooding }\end{array}$ \\
\hline Unknowns & $\begin{array}{ll}- & \text { Densities } \\
\text { - } & \text { Flow velocity vectors } \\
\text { - } & \text { Pressures } \\
\text { - } & \text { Species concentrations } \\
\text { - } & \text { Temperature }\end{array}$ \\
\hline $\begin{array}{l}\text { System of Governing } \\
\text { Equations to Solve }\end{array}$ & $\begin{array}{ll}\text { - } & \text { continuity equation } \\
\text { - } & \text { momentum equations } \\
\text { - } & \text { conservation of energy equation } \\
\text { - } & \text { species equations } \\
\text { - } & \text { state equation } \\
\text { - } & \text { mixture model (Dalton) }\end{array}$ \\
\hline
\end{tabular}




\begin{tabular}{|c|c|}
\hline Assumptions & $\begin{array}{l}\text { - Single phase flow } \\
\text { - } \quad \text { Liquid water velocity set to a realistic value because } \\
\text { there is no equation for liquid water velocity } \\
\text { - } \quad \text { Water not subject to phase change in the gas channels } \\
\text { - } \quad \text { Irreversible work due to viscous forces and the work of } \\
\text { compression neglected in the energy equation } \\
\text { - Flow not subject to any electrochemical or chemical } \\
\text { - } \quad \text { Noaction charged species in flow }\end{array}$ \\
\hline
\end{tabular}

\begin{tabular}{|c|c|}
\hline Domain & $\begin{array}{l}\text { Backing Layers/Electrodes/Gas Diffuser (anode and } \\
\text { cathode) }\end{array}$ \\
\hline Structure & Porous, usually carbon black \\
\hline Transported Species & $\begin{array}{ll}\text { anode: } & \text { gases (hydrogen, water), electrons } \\
\text { cathode: } & \text { gases (air, water), liquid (water), electrons }\end{array}$ \\
\hline Sources/Sinks & $\begin{array}{l}\text { anode entropy generation: ohmic overpotential } \\
\text { cathode entropy generation: evaporation, ohmic } \\
\text { overpotential }\end{array}$ \\
\hline Function & $\begin{array}{l}\text { Through the pores of the backing layer reactants are } \\
\text { transported towards the catalyst layers and products are } \\
\text { evacuated into the gas channels } \\
\text { Matrix (solid) phase carries electrons from the catalyst } \\
\text { layers to the collector plates or vise versa }\end{array}$ \\
\hline $\begin{array}{l}\text { Impact on } \\
\text { Performance }\end{array}$ & $\begin{array}{l}\text { - To avoid loses due to parasitic currents, it is vital to } \\
\text { ensure homogeneous distributions of reactants } \\
\text { Water produced at the cathode must be transported to } \\
\text { the gas channels to be removed and to prevent flooding }\end{array}$ \\
\hline Unknowns & $\begin{array}{ll}\text { - } & \text { Densities } \\
\text { - } & \text { Mass velocity vectors } \\
\text { - } & \text { Pressure } \\
\text { - } & \text { Temperature } \\
\text { - } & \text { Electrical current } \\
\text { - } & \text { Electrical potential }\end{array}$ \\
\hline
\end{tabular}




\begin{tabular}{|c|c|}
\hline $\begin{array}{l}\text { System of Governing } \\
\text { Equation to Solve }\end{array}$ & $\begin{array}{l}\text { - } \text { mass conservation equations } \\
\text { - } \text { momentum (Darcy) equations } \\
\text { - } \quad \text { state equation } \\
\text { - } \quad \text { conservation of current } \\
\text { - } \quad \text { electrical potential equation in the matrix (Ohm's Law) } \\
\text { The following additional relations are used in order to close } \\
\text { the system } \\
\text { - capillary pressure (Leverett) equation } \\
\text { - } \quad \text { water vapor pressure (Kelvin) equation } \\
\text { mixture model (Dalton) }\end{array}$ \\
\hline Assumptions & $\begin{array}{l}\text { - Anode backing layer includes only two phases: solid } \\
\text { and gas } \\
\text { - The liquid phase at the cathode contains only water. } \\
\text { - The liquid phase is assumed incompressible } \\
\text { - The temperature is considered uniform in all phases } \\
\text { (thermal local equilibrium) } \\
\text { - The momentum conservation equation can be described } \\
\text { by Darcy's relation } \\
\text { Interfacial liquid-gas shear forces, the irreversible work } \\
\text { of viscous forces as well as the work of compression } \\
\text { can be neglected in the energy equation } \\
\text { An assumption of equilibrium between the water vapor } \\
\text { pressure and the liquid phase pressure as well as the } \\
\text { capillary pressure is also made }\end{array}$ \\
\hline
\end{tabular}

\begin{tabular}{|c|c|}
\hline Domain & Catalyst Layers (anode and cathode) \\
\hline Structure & $\begin{array}{l}\text { Porous, mixture made from the superposition of the polymer } \\
\text { membrane, the backing layer and some additional catalyst } \\
\text { particles. }\end{array}$ \\
\hline Transported Species & $\begin{array}{ll}\text { anode: } & \begin{array}{l}\text { gases (hydrogen, water), electrons, ions } \\
\text { (hydrogen protons) }\end{array} \\
\text { cathode: } & \begin{array}{l}\text { gases (air, water), liquid (water), electrons, ions } \\
\text { (hydrogen protons) }\end{array} \\
\end{array}$ \\
\hline Sources/Sinks & $\begin{array}{l}\text { anode entropy, heat, species generation: overpotentials } \\
\text { (ohmic, activation, and concentration), reversible } \\
\text { heat, electrons and hydrogen protons } \\
\text { species consumption: hydrogen } \\
\text { cathode entropy, heat, species generation: overpotentials } \\
\text { (ohmic, activation, and concentration), reversible } \\
\text { heat, water } \\
\text { species consumption: electrons, protons, oxygen }\end{array}$ \\
\hline
\end{tabular}




\begin{tabular}{|c|c|}
\hline Function & $\begin{array}{l}\text { Protons are transported by migration and convection } \\
\text { through the polymer agglomerates } \\
\text { Other reactants and the product (water at the cathode) } \\
\text { are transported within the pores of the catalyst layer, as } \\
\text { in the backing layer }\end{array}$ \\
\hline $\begin{array}{l}\text { Impact on } \\
\text { Performance }\end{array}$ & $\begin{array}{l}\text { - Catalyst material is very expensive, therefore, effective } \\
\text { utilization of material is very important to cost } \\
\text { management } \\
\text { - Catalyst layer can become current limiting at high } \\
\text { current densities due to its lower intrinsic porosity } \\
\text { Catalyst layer can become further current limited by a } \\
\text { drop in porosity due to flooding at the cathode }\end{array}$ \\
\hline Unknowns & $\begin{array}{ll}\text { - } & \text { Densities } \\
\text { - } & \text { Species concentrations within the polymer phase } \\
\text { - } & \text { Mass velocity vectors } \\
\text { - } & \text { Pressure } \\
\text { - } & \text { Temperature } \\
\text { - } & \text { Electrical and ionic current } \\
\text { - } & \text { Electrical and ionic potential }\end{array}$ \\
\hline
\end{tabular}




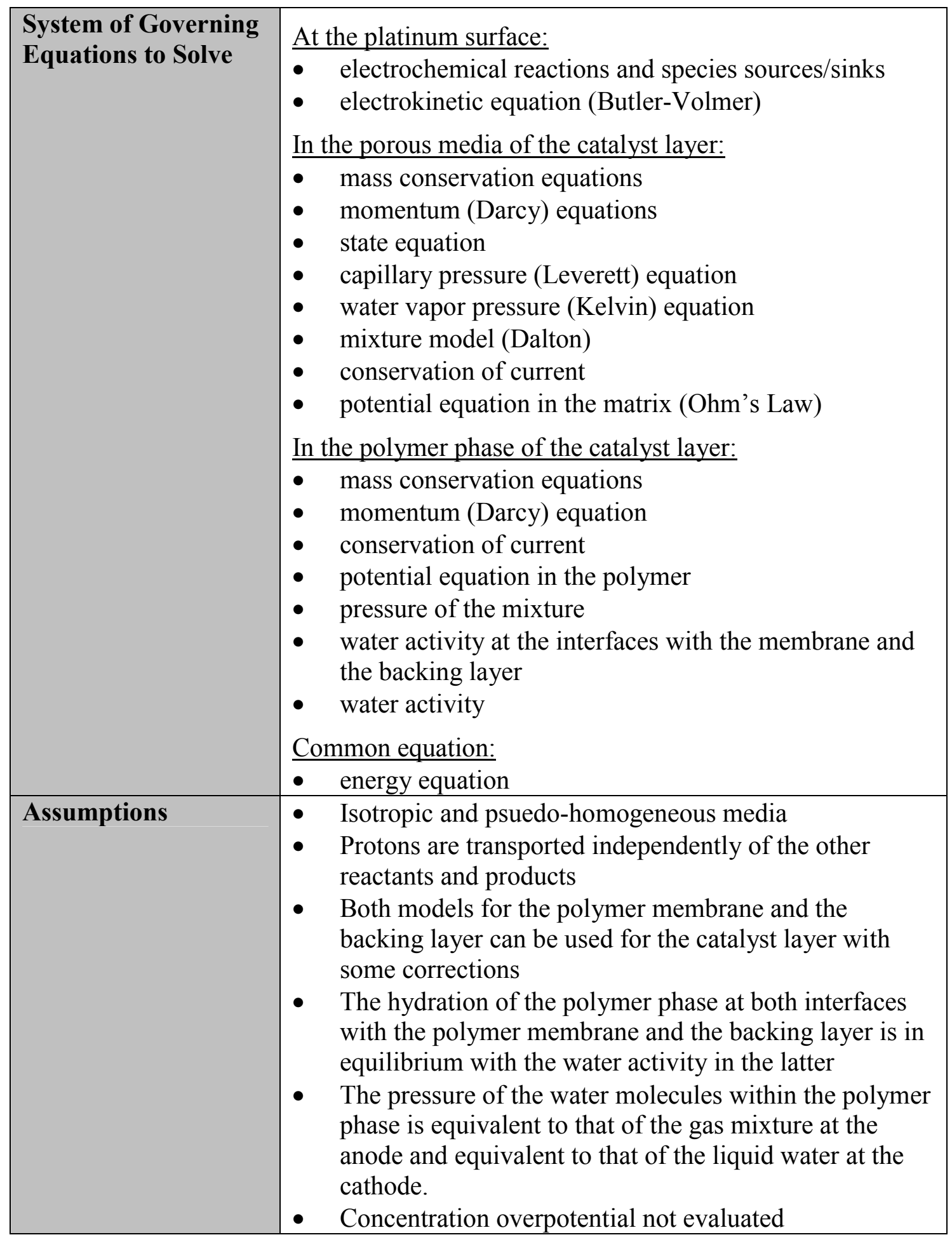

\begin{tabular}{|l|l|}
\hline Domain & Membrane \\
\hline Structure & $\begin{array}{l}\text { Porous, interwoven chains of carbon, fluorine and oxygen } \\
\text { atoms with sulfonic acid }\left(\mathrm{SO}_{3} \mathrm{H}\right) \text { groups attached }\end{array}$ \\
\hline
\end{tabular}




\begin{tabular}{|c|c|}
\hline Transported Species & $\begin{array}{l}\text { ions (protons) } \\
\text { water }\end{array}$ \\
\hline Sources/Sinks & entropy generation: ohmic overpotential \\
\hline Function & $\begin{array}{l}\text { - Transport the ions (protons) from anode to cathode } \\
\text { - } \quad \text { Prevents the transport of other reactants }\end{array}$ \\
\hline $\begin{array}{l}\text { Impact on } \\
\text { Performance }\end{array}$ & $\begin{array}{l}\text { - In order to ensure good proton conductivity the } \\
\text { membrane must remain hydrated with water } \\
\text { - If the membrane does not remain impermeable to } \\
\text { reactants, additional unwanted reactions may occur } \\
\text { - The membrane must remain hydrated to prevent } \\
\text { permanent damage to its structure }\end{array}$ \\
\hline Unknowns & $\begin{array}{ll}\text { - } & \text { Temperature } \\
\text { - } & \text { Water concentration } \\
\text { - } & \text { Proton potential }\end{array}$ \\
\hline $\begin{array}{l}\text { System of Governing } \\
\text { Equations to Solve }\end{array}$ & $\begin{array}{ll}\text { - } & \text { mass conservation equations } \\
\text { - } & \text { momentum (Darcy) equation } \\
\text { - } & \text { conservation of energy equation } \\
\text { - } & \text { conservation of current } \\
\text { - } & \text { potential equation in the polymer } \\
\text { - } & \text { linear relation for the pressure of the mixture } \\
\text { - } & \text { relation for the water activity at both the anode and } \\
\text { - } & \text { relathode interface }\end{array}$ \\
\hline Assumptions & 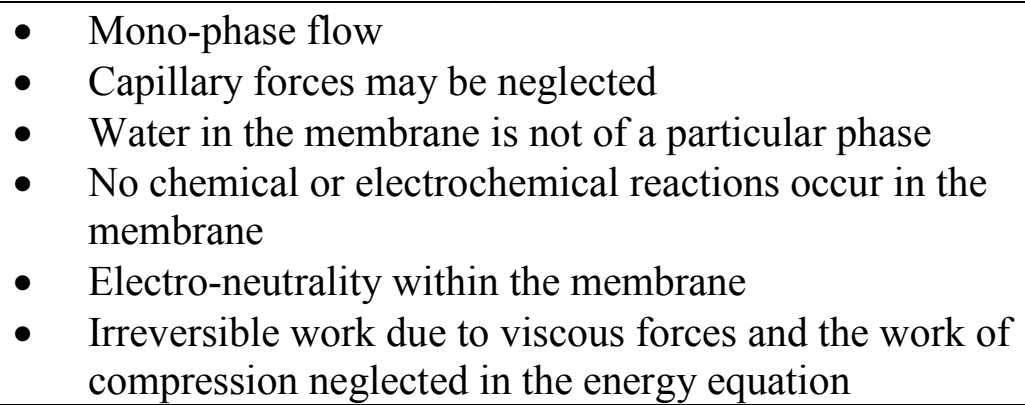 \\
\hline
\end{tabular}




\section{Chapter 3. Membrane Model}

\subsection{Phenomena}

The purpose of a proton exchange membrane is to transfer protons from the anode to cathode of the fuel cell. The membrane must also block the transfer of hydrogen, oxygen (or other reactants), and electrons between anode and cathode. Present within the membrane are water and hydrogen protons. Water and proton transfer are, therefore, two important phenomena to investigate. In addition to species transfer, the primary phenomena investigated inside the membrane are energy transfer and potential conservation.

For water transport (Figure 3.1), the principle driving forces modeled are a convective force, an osmotic force (i.e. diffusion), and an electric force. The first of these results is from a pressure gradient, the second from a concentration gradient, and the third from the migration of protons from anode to cathode and their effect (drag) on the dipole water molecules.

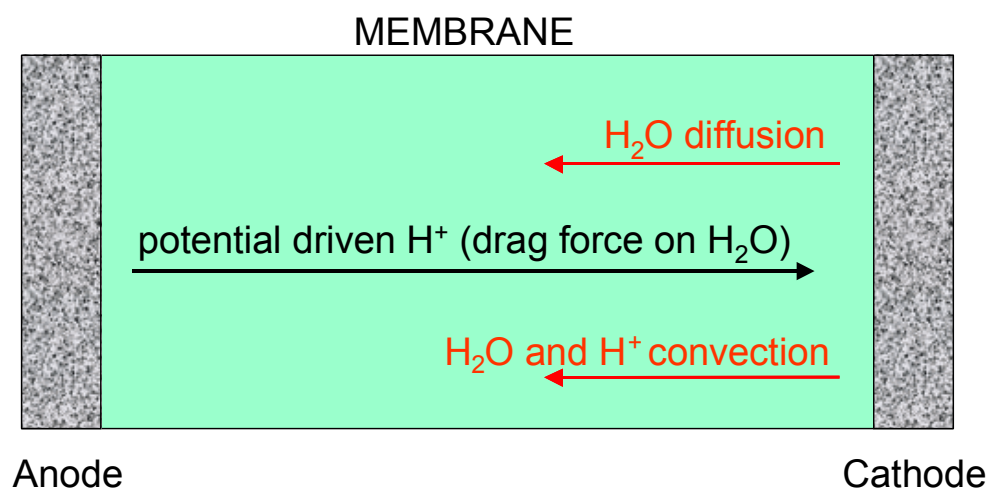

Figure 3.1 Membrane Transport Phenomena.

The assumption of electro-neutrality governs hydrogen proton conservation in our model and indicates that a proton occupies every fixed $\mathrm{SO}_{3}{ }^{-}$charge site. The picture at the bottom of Figure 3.2 illustrates the electro-neutrality assumption. It is assumed that these charge sites are distributed homogeneously throughout the membrane. This results in a 
constant proton concentration in the membrane. A flux of protons, thus, results from a potential gradient and not a concentration gradient. Proton transport is described as a protonic current and consists of this proton driven flux and a convective flux due to the pressure driven flow of water in the membrane. Again, Figure 3.1 illustrates the transport phenomena for the protons taking place within the membrane

The energy transfer within the membrane is modeled based on Kjelstrup, Okada, and Ottoy's (1999) work neglecting several coupled effects. They provide the mathematical model as well as the phenomenological coefficients necessary for the model.

\subsection{Structure and Resulting Assumptions}

The membrane structure can best be described as a plate full of spaghetti where each piece of spaghetti can move on the plate. The picture at the top of Figure 3.2 is an illustration of this membrane structure.

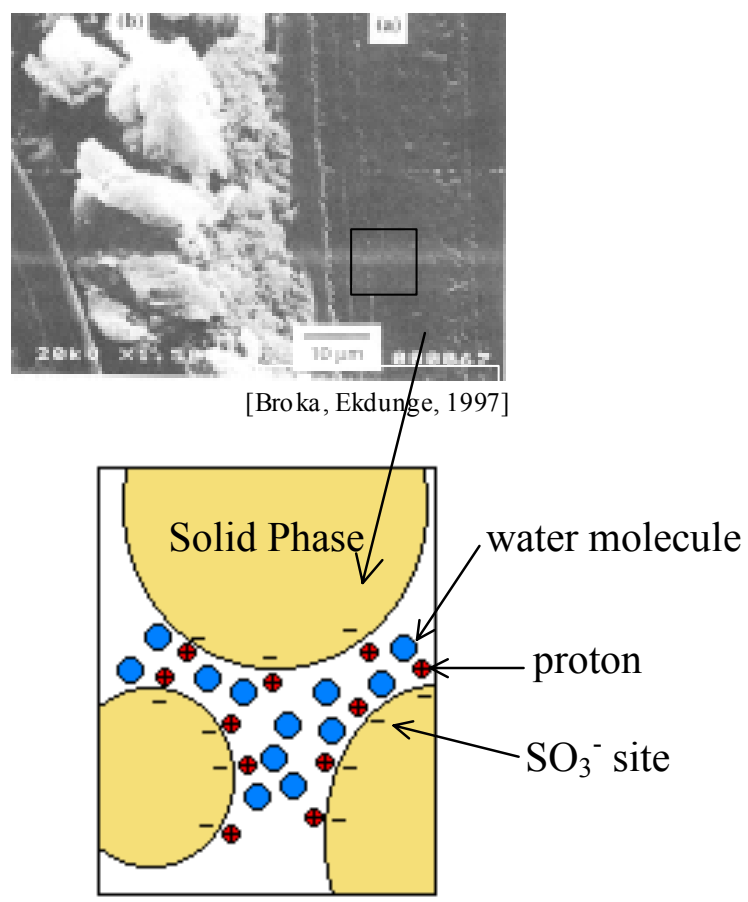

Figure 3.2 Membrane Structure. 
This structure requires one to make assumptions in order to be able to model the phenomena occurring within the membrane. One important assumption is mono-phase rather than muti-phase flow. This assumption is based on the size of the pores, which are approximately $1 \mathrm{~nm}$. Based on this assumption, capillary forces may be neglected. Because of the low velocities of the mixture in the membrane the effects of viscous forces and the work of compression are also neglected in the energy equation.

Another assumption made is that the water in the membrane is not of a particular phase (liquid or gas) but rather simply treated as water molecules. Without knowing the phase of the water in the membrane, a state equation relating water pressure to water concentration and temperature cannot be applied. Since this relation is lacking, the

pressure gradient across the membrane is approximated as linear. Finally, the assumption that no chemical or electrochemical reactions occur in the membrane is made. This is a good assumption with respect to chemical reactions because there is little if any oxidant in the membrane. This also works for the electrochemical reactions since they can not occur at the temperatures in question in the absence of a catalyst.

\subsection{Governing and Constitutive Equations}

The following is a list of the governing and constitutive equations used to model the phenomena in the membrane as well as a brief description of the terms involved in each equation:

- mass conservation equations

- momentum (Darcy) equation

- conservation of energy equation

- conservation of current

- potential equation in the polymer

- linear relation for the pressure of the mixture

- relation for the water activity at both the anode and cathode interface

- relation for water activity within the membrane 


\subsubsection{Mass or Species Conservation Equations}

For both water and protons the mass conservation equation can be represented as

$$
\frac{\partial c_{i}}{\partial t}=-\frac{\partial}{\partial x} N_{i} \quad i=\mathrm{H}_{2} \mathrm{O}, \mathrm{H}^{+}
$$

Because the species are in solution, $c_{i}$ is the molar concentration and $N_{i}$ is the molar flux due to electro-osmotic driving forces and convection. In a diluted solution, $N_{i}$ is given by the Nernst-Planck equation along with the Nernst-Einstein relationship, i.e.

$$
N_{i}=J_{i}+c_{i} u^{m}
$$

where $u^{m}$ is the mixture velocity and $J_{i}$ is the diffusive flux. For water, the diffusive flux is made up of osmotic and drag terms resulting in the following relation:

$$
J_{\mathrm{H}_{2} \mathrm{O}}=-D_{c_{\mathrm{H}_{2} \mathrm{O}}, \mathrm{T}} \frac{\partial c_{\mathrm{H}_{2} \mathrm{O}}^{m}}{\partial x}+n_{\text {drag }} \frac{i_{x}}{F}
$$

where $n_{\text {drag }}=2.5 \frac{\lambda_{\mathrm{H}_{2} \mathrm{O} / \mathrm{SO}}}{22}$

where $\lambda_{\mathrm{H}_{2} \mathrm{O} / \mathrm{SO}_{3}}=\frac{c_{\mathrm{H}_{2} \mathrm{O}}^{m}}{\frac{\rho_{d r y}^{m}}{M^{m}}-b c_{\mathrm{H}_{2} \mathrm{O}}^{m}}$

and $b=0.0126 . n_{\text {drag }}$ is the measured drag coefficient ${ }^{1}$ (Springer et al.; 1991), $i_{x}$ the protonic current in the $x$ direction, $F$ Faraday's constant, $\lambda_{\mathrm{H}_{2} \mathrm{O} / \mathrm{SO}_{3}}$ is the water content in $\left(\mathrm{mol}_{\mathrm{H}_{2} \mathrm{O}} \mathrm{mol}_{\mathrm{SO}_{3}^{-}}^{-1}\right) \cdot \rho_{d r y}^{m}$ is the dry membrane density $\left(\mathrm{kg}_{\mathrm{m}_{\mathrm{dy}}} \mathrm{m}_{\mathrm{dry}}^{-3}\right), M^{m}$ the membrane molecular mass $\left(\mathrm{kg}_{\mathrm{m}_{\mathrm{dy}}} \mathrm{mol}_{\mathrm{sO}_{3}^{-}}^{-1}\right)$ and $b$ the membrane extension coefficient in the $x$ direction determined experimentally (Springer et al., 1991).

\footnotetext{
${ }^{1}$ Also named the water transference coefficient. The drag coefficient is assumed to be a linear function of water content. 2.5 represents the number of water molecules dragged per $\mathrm{H}^{+}$ion moved by electric field for a fully hydrated membrane. The 22 in the denominator is derived from the maximum water content measured inside the membrane when immersed in boiling water.
} 
In Eq. (3.3), $D_{c_{H_{2},}, T}\left(\mathrm{~m}^{2}-\mathrm{s}^{-1}\right)$ is the diffusion coefficient including a correction for the temperature and for the water content (Springer et al.; 1991). It is expressed in a fixed coordinate system with the dry membrane by (Springer et al.; 1991) such that

$$
D_{c_{H_{2},}, T}=D^{\prime}\left\{\exp \left[2416\left(\frac{1}{303}-\frac{1}{T}\right)\right] \lambda_{H_{2} O / S O_{3}} \frac{1}{a} \frac{1}{17.81-78.9 a+108 a^{2}}\right\}
$$

Where $a$ is the activity of water (see Eqs. (3.26)-(3.27) below) and $D^{\prime}\left(\mathrm{m}^{2} \mathrm{~s}^{-1}\right)$ is the diffusion coefficient measured at constant temperature and in coordinates moving with the swelling of the membrane (Springer, et al., 1991). Equation (3.7a) does not appear in the work of Springer et al. but has been added to ensure that water contents below 1.23 do not result in negative diffusion coefficients ${ }^{2} . D^{\prime}$ is, thus, written as

$$
\begin{array}{ll}
D^{\prime}=2.642276 e(-13) \lambda_{\mathrm{H}_{2} \mathrm{O} / \mathrm{SO}_{3}} & \text { for } \lambda_{\mathrm{H}_{2} \mathrm{O} / \mathrm{SO}} \leq 1.23 \\
D^{\prime}=7.75 e(-11) \lambda_{\mathrm{H}_{2} \mathrm{O} / \mathrm{SO}_{3}}-9.5 e(-11) & \text { for } 1.23<\lambda_{\mathrm{H}_{2} \mathrm{O} / \mathrm{SO}_{3}} \leq 6 \\
D^{\prime}=2.5625 e(-11) \lambda_{\mathrm{H}_{2} \mathrm{O} / \mathrm{SO} \mathrm{O}_{3}}+2.1625 e(-10) & \text { for } 6<\lambda_{\mathrm{H}_{2} \mathrm{O} / \mathrm{SO} \mathrm{O}_{3}} \leq 14 \\
D^{\prime}\left(\mathrm{m}^{2} \mathrm{~s}^{-1}\right) \text { is measured at 30 C. } &
\end{array}
$$

The total molar flux for water can, thus, be written

$$
N_{\mathrm{H}_{2} \mathrm{O}}=J_{\mathrm{H}_{2} \mathrm{O}}+\left(c_{\mathrm{H}_{2} \mathrm{O}}^{m} u^{m}\right)
$$

Where the mixture velocity $u^{m}$ is given by the momentum equation (Eq (3.13)) below.

Substituted into Eq. (3.1), the mass conservation of water is expressed as

$$
\frac{\partial c_{H_{2} \mathrm{O}}^{m}}{\partial t}=-\frac{\partial}{\partial x} J_{H_{2} \mathrm{O}}-\frac{\partial}{\partial x}\left(c_{H_{2} \mathrm{O}}^{m} u^{m}\right)
$$

\footnotetext{
2 The linear approximation of experimental data for $D^{\prime}$ presented in Springer et al. (1991) accurately approximated experimental results for $D^{\prime}$ at higher water contents, but for water contents below 1.23, where no data points were taken, approximated $D^{\prime}$ values became negative. Eq. (3.7a) is a linear approximation so that a water content of zero results in a $D^{\prime}$ of zero and a water content of 1.23 results in the same value for $D^{\prime}$ as it would using Eq. (3.7b) from Springer.
} 
Now, due to the assumption of electro-neutrality and the homogeneous distribution of charge sites, the mass conservation of protons simplifies since

$$
\frac{\partial c_{H^{+}}}{\partial x}=0, \frac{\partial c_{H^{+}}}{\partial t}=0
$$

Thus, as soon as a current exists, the membrane is charged; and the concentration of protons remains constant. The charge of the protons equals that of the fixed charges ${ }^{3}$. The diffusive molar flux for the protons $\left(J_{H^{+}}\right)$can, therefore, be written as

$J_{H^{+}}=-\frac{F}{R T} D_{H^{+}} c_{H^{+}} \frac{\partial \Phi}{\partial x}$

where $\Phi_{m}$ is the membrane proton potential and $D_{H^{+}}$the proton diffusivity ${ }^{4}$. Combining this diffusive flux with the convective flux results in the total molar flux for the hydrogen protons, i.e.

$$
N_{H^{+}}=J_{H^{+}}+\left(c_{H^{+}} u^{m}\right)
$$

\subsubsection{Momentum Equation}

For the mixture (water and protons), the assumption is made that the momentum equation takes the form of the generalized Darcy relation, namely

$$
u^{m}=-\frac{K k_{r}^{g}}{\mu}\left[\frac{\partial p}{\partial x}-\rho g \cos \theta\right]
$$

and $u^{m}$ is the mixture velocity, $K$ the absolute permeability of the porous medium, $k_{r}^{g}$ the relative permeability ${ }^{5}, g$ the gravity, and $\theta$ the angle the $\mathrm{x}$-axis (the direction of flow)

\footnotetext{
${ }^{3}$ Bernardi and Verbrugge (1991) give a value of $c_{H^{+}}=1.2 \mathrm{e}-3\left(\mathrm{~mol} \mathrm{~cm}^{-3}\right)$ for Nafion 117.

${ }^{4}$ Bernardi and Verbrugge (1992) give a value of $D_{H^{+}}=4.5 \mathrm{e}-5\left(\mathrm{~cm}^{2} \mathrm{~s}^{-1}\right)$ Nafion 117.

${ }^{5}$ given by $k_{r}^{g}=(1-s)^{\mathrm{n}} . s=0$, therefore, $k_{r}^{g}=1$, meaning the relative permeability does not affect mixture velocity in the membrane.
} 
makes to the direction of gravity. The mixture density, $\rho$, and the dynamic viscosity of the mixture, $\mu$, are written as

$$
\begin{aligned}
& \rho=M_{H^{+}} c_{H^{+}}+M_{\mathrm{H}_{2} \mathrm{O}} c_{H_{2} \mathrm{O}}^{m} \\
& \mu=\frac{M_{H^{+}} c_{H^{+}}}{\rho} \mu_{H^{+}}+\frac{M_{H_{2} O} c_{H_{2} O}^{m}}{\rho} \mu_{H_{2} \mathrm{O}}
\end{aligned}
$$

where the $M_{i}$ are the molecular weights of the species $i$.

\subsubsection{Conservation of Energy Equation}

Energy is transported by conduction and convection within the three phases of the membrane (polymer, liquid/gas). The effects of ohmic losses within the membrane are taken into account by an additional source term in the energy balance equation so that energy conservation is given by

$\overline{\rho c_{p}} \frac{\partial T}{\partial t}=\lambda_{m} \frac{\partial^{2} T}{\partial x^{2}}-\overline{M c_{p} N} \frac{\partial T}{\partial x}+R_{m}$

where $\overline{\rho c_{p}}=\rho_{m}^{d r y} c_{p_{m}}+\rho_{H_{2} O}^{m} c_{p_{H_{2} O}}^{m}+\rho_{H^{+}} c_{p_{H^{+}}}$

$\rho_{H^{+}}=M_{H^{+}} c_{H^{+}}$

$\rho_{\mathrm{H}_{2} \mathrm{O}}^{m}=M_{\mathrm{H}_{2} \mathrm{O}} c_{\mathrm{H}_{2} \mathrm{O}}^{m}$

$\overline{M c_{p} N}=M_{\mathrm{H}_{2} \mathrm{O}} c_{p_{\mathrm{H}_{2} \mathrm{O}}}^{m} N_{\mathrm{H}_{2} \mathrm{O}}+M_{\mathrm{H}^{+}} c_{p_{H^{+}}} N_{H^{+}}$

The transient energy effect associated with mass storage within the hydrated membrane is neglected due to the fact that the dry membrane mass does not change and is several orders of magnitude larger than that of the water which hydrates the membrane.

Substituting the expressions for $N_{H_{2 O}}$ and $N_{H+}$ from Eqs. (3.8) and (3.12), an expanded expression for $\overline{M c_{p} N}$ can be obtained, namely 


$$
\begin{aligned}
\overline{M c_{p} N} & =M_{H_{2} O} c_{p_{H_{2}} \mathrm{O}}\left(c_{H_{2} O}^{m} u^{m}-D_{c_{H_{2} O}, T} \frac{\partial c_{H_{2} O}^{m}}{\partial x}+2.5 \frac{\lambda_{H_{2} O / S O_{3}}}{22} \frac{i_{m_{x}}}{F}\right) \\
& +M_{H^{+}} c_{p_{H^{+}}}\left(c_{H^{+}} u^{m}-\frac{F}{R T} D_{H^{+}} c_{H^{+}} \frac{\partial \Phi_{m}}{\partial x}\right)
\end{aligned}
$$

Returning once more to the energy conservation equation, Eq. (3.16), $\lambda_{m}$ is the thermal conductivity coefficient of the membrane and is assumed constant. The source term, $R_{m}$, is given by

$$
R_{m}=\frac{i^{2}}{\sigma_{m}}
$$

where $\sigma_{m}$ is the conductivity of the membrane ${ }^{6}$ and is written as a function of the temperature and the water content as (Springer et al., 1991)

$$
\sigma_{m}=\sigma_{m 303} \exp \left[1268\left(\frac{1}{303}-\frac{1}{T}\right)\right]
$$

with $\sigma_{m 303}$ the conductivity of the membrane at $303 \mathrm{~K}$ given by (Springer et al., 1991)

$$
\sigma_{m 303}=100 *\left(0.005139 \lambda_{\mathrm{H}_{2} \mathrm{O} / \mathrm{SO}_{3}}-0.00326\right) \quad \text { for } \lambda_{\mathrm{H}_{2} \mathrm{O} / \mathrm{SO}_{3}}>1
$$

\subsubsection{Conservation of Current}

The assumption of a fixed and uniform number of charge sites in the membrane along with the electro-neutrality assumption leads to the following relation for the protonic current:

$$
\frac{\partial i}{\partial x}=0
$$

${ }^{6}$ The conductivity is defined by $\sigma_{m}=\frac{F^{2}}{R T} D_{H^{+}}{ } H^{+}$. In this thesis work, use has been made of the measurements of Springer et al. (1991). Since these authors make use of a high frequency impedance technique in measuring $\sigma_{\mathrm{m}}$, they avoid the convective contributions in their measurements which implies that their values can be used for $\sigma_{\mathrm{m}}$ here. 


\subsubsection{Ohm's Law}

The equation for the proton potential is derived from Ohm's Law. Both terms represent the proton flux divided by the membrane conductivity. The electro-neutrality assumption allows the total molar proton flux given by Eq. (3.12) to be related directly to current density and results in the first term. The second term containing $u^{m}$ represents the convective flux of protons. Combined they result in the following equation:

$$
\frac{\partial \Phi_{m}}{\partial x}=-\frac{i}{\sigma_{m}}+\frac{F}{\sigma_{m}} c_{H^{+}} u^{m}
$$

\subsubsection{Mixture Pressure Relation}

As a rough approximation, the mixture pressure gradient is assumed to behave linearly between the anode and cathode interfaces so that ${ }^{7}$

$$
p=p_{c a x+}^{g}+\frac{\left\lfloor s p_{H_{2} O_{c c x-}}^{l}+(1-s) p_{c c x-}^{g}\right\rfloor-p_{c a x+}^{g}}{x_{m x+}-x_{m x-}}\left(x-x_{m x-}\right)
$$

At the interface with the anode catalyst layer, the mixture pressure is assumed equal to that of the gas pressure $\left(\left\{p^{g}\right\}_{c a x+}\right)$ under the assumption that no liquid is present. At the cathode catalyst interface, it is assumed that the mixture pressure can be approximated by a linear relation (see bracketed terms in Eq. (3.26)) between the gas pressure $\left(\left\{p^{g}\right\}_{c c x-}\right)$ and the liquid pressure $\left(\left\{p_{H_{2} O}^{l}\right\}_{c c x-}\right.$ ), weighted by the saturation ratio $s$ (the volume ratio of liquid water to gaseous water in the pores of the catalyst layer). For the results generated in Chapter 5 saturation ratio was set to zero, therefore there was no effect of liquid pressure on the pressure gradient. The boundary coordinate at each interface is given by $x_{m x+}$ and $x_{m x-}$.

\footnotetext{
${ }^{7}$ Note that this simple linear relationship is due to the statement above that the water pressure is not defined.
} 


\subsubsection{Interface Water Activity Relation}

At the membrane interfaces, the water vapor activity is given by

$$
a=\frac{R T}{p_{\text {sat }}(T)} c_{H_{2} O}^{g}+2 s \quad a \in[0, . ., 3]
$$

where $c_{\mathrm{H}_{2} \mathrm{O}}^{g}$ is the water vapor concentration and $\mathrm{s}$ is the saturation ratio. In Eq. (3.27) the last term accounts for a "wet" mixture ${ }^{8}$. This expression differs with respect to the one given in Springer et al. in that it defines activity as a function of water concentration and not pressure and attempts to relate saturation ratio to activity. Here an assumption is made that $s$ is zero for activities less than 1, meaning that no liquid water is present in the membrane pores until the activity exceeds 1 . The highest value that the first term $\left(\frac{R T}{p_{\text {sat }}(T)} c_{\mathrm{H}_{2} \mathrm{O}}^{g}\right)$ in Eq. (3.27) can reach is 1 ; and, therefore, a maximum saturation ratio of 1 results in an activity of 3 which is consistent with the maximum value set in Springer et al. (1991).

\subsubsection{Membrane Water Activity Relation}

The relation for the water activity within the membrane is given by the reciprocal of the sorption curve. As with the water vapor activity at the interfaces, use is made of the results from Springer et al. (1991) for water vapor activity in Nafion 117 at $30 \mathrm{C}$. The activity is, thus, given by

$$
\begin{array}{rlr}
a & =1 / 2160\left(c_{1}+c_{2} \lambda_{\mathrm{H}_{2} \mathrm{O} / \mathrm{SO}_{3}}+216\left(c_{3}-c_{4} \lambda_{\mathrm{H}_{2} \mathrm{O} / \mathrm{SO}_{3}}\right.\right. & \\
& \left.\left.+c_{5} \lambda_{\mathrm{H}_{2} \mathrm{O} / \mathrm{SO}_{3}}{ }^{2}\right)^{(1 / 2)}\right)^{(1 / 3)}-134183 / 2160 / & \\
& \left(c_{1}+c_{2} \lambda_{\mathrm{H}_{2} \mathrm{O} / \mathrm{SO}_{3}}+216\left(c_{3}-c_{4} \lambda_{\mathrm{H}_{2} \mathrm{O} / \mathrm{SO}_{3}}\right.\right. & \\
& \left.\left.+c_{5} \lambda_{\mathrm{H}_{2} \mathrm{O} / \mathrm{SO}_{3}}{ }^{2}\right)^{(1 / 2)}\right)^{(1 / 3)}+797 / 2160 &
\end{array}
$$

\footnotetext{
${ }^{8}$ The sorption of water at the cathode and anode interface is given by Springer et al. (1991) as a function of the water vapor activity. Accounting for the wet mixture, they allow this activity to increase above 1 , up to 3. Although it is incorrect to define a vapor pressure greater than the saturation pressure, this procedure is convenient because it gives a simple algebraic relation for the water content at these two interfaces.
} 


$$
\begin{array}{ll}
c_{1}=-41956 \mathrm{e} 4 & \\
c_{2}=139968 \mathrm{e} 3 & \\
c_{3}=382482 \mathrm{e} 6 & \\
c_{4}=251739 \mathrm{e} 3 & \text { for } 14 \leq\left(\lambda_{\mathrm{H}_{2} / \mathrm{SO} 3}\right) \leq 16.8 \\
c_{5}=419904 \mathrm{e} 6 & \text { for } 16.8 \leq\left(\lambda_{\mathrm{H}_{2} / \mathrm{SO}_{3}}\right) \\
a=0.7143\left(\lambda_{\mathrm{H}_{2} / \mathrm{SO}_{3}}\right)-9.0021 & \\
a=3 &
\end{array}
$$

\subsection{Boundary and Initial Conditions}

This section presents the initial and boundary conditions for the mathematical membrane model presented in Section 3.3. To indicate from where a property is taken, the following notation is used:

- The first letter symbolizes the domain:

- c: catalyst layer

- m: polymer membrane

- The second letter refers to the anode or the cathode ${ }^{9}$ :

- a: anode

- c: cathode

- The third letter indicates the normal to the interface:

- $\mathrm{x}$ : perpendicular to the $y-z$ plane

- The fourth letter specifies the side of the interface:

- +: catalyst layer-membrane interface anode side

- -: catalyst layer-membrane interface cathode side

\footnotetext{
${ }^{9}$ Note that the polymer membrane does not make use of the second letter, as it is the electrolyte.
} 
In the membrane, the model is one-dimensional. The model presented in Section 3.3 requires solving for two constitutive variables, i.e. the concentration of water $\left(c_{H_{2} O}^{m}\right)$, and the temperature $(T)$. Based on the solutions found and a voltage value at the anode catalyst boundary (cax + ), a voltage drop across the membrane is determined. However, in order to solve for the transient temperature, concentration, and voltage profiles, initial and boundary conditions are needed. They are described in the following sections.

\subsubsection{Water concentration $\left(c_{H_{2} \mathrm{O}}^{m}(t, x)\right)$}

The species equation for water requires two boundary conditions and one initial condition. The boundary conditions state that the water activity at the interface is in equilibrium with the water activity in the catalyst layers (at cax+ and ccx-), so that the equation for water activity takes the form:

$$
\begin{aligned}
& \{a\}_{t, x=x_{m x-}, y, z}=\left\{\frac{R T}{p_{s a t}(T)} c_{H_{2} O}^{g}+2 s\right\}_{t, x=x_{c a x+}, y, z} \\
& \{a\}_{t, x=x_{m x+}, y, z}=\left\{\frac{R T}{p_{s a t}(T)} c_{H_{2} O}^{g}+2 s\right\}_{t, x=x_{c c x-}, y, z}
\end{aligned}
$$

where

$$
p_{\text {sat }}(T)=p_{0} \exp \left(\frac{\left(\frac{1}{T_{0}}-\frac{1}{T}\right) L_{v} M_{H_{2} O}}{R}\right)
$$

Given the water activity, the water concentration at the boundaries can be easily found using Eqs (3.31) and (3.32) below. Eq. (3.31) formulates water concentration as a function of the water uptake and is used only with the boundary condition and initial conditions. Thus,

$$
\left\{c_{H_{2} O}^{m}=\lambda_{\frac{H_{2} O}{S O_{3}}} \frac{\rho_{d r y}^{m}}{M^{m}} \frac{1}{1+b \lambda_{\frac{H_{2} O}{S O_{3}}}}\right\}_{\begin{array}{l}
t, x=x_{m x-}, y, z \\
t, x=x_{m x+}, y, z \\
t=0, x, y, z
\end{array}}
$$


where the water uptake, $\left(\lambda_{\mathrm{H}_{2} \mathrm{O} / \mathrm{SO}_{3}}(t, x, y, z)\right)$ is a function of the activity, i.e.

$$
\left\{\lambda_{\mathrm{H}_{2} \mathrm{O} / \mathrm{SO}_{3}}=0.043+17.81(a)-39.85(a)^{2}+36(a)^{3}\right\}_{\substack{t, x=x_{m x-}, y, z \\ t, x=x_{m x+}, y, z \\ t=0, x, y, z}} \text { for } a<1
$$

$$
\left\{\lambda_{\mathrm{H}_{2} \mathrm{O} / \mathrm{SO}_{3}}=14+1.4(a-1)\right\}_{\begin{array}{r}
t, x=x_{m x-}, y, z \\
t, x=x_{m x+}, y, z \\
t=0, x, y, z
\end{array}} \quad \text { for } 1 \leq a \leq 3
$$

$$
\begin{aligned}
& \left\{\lambda_{\mathrm{H}_{2} \mathrm{O} / \mathrm{SO}_{3}}=16.8\right\}_{t, x=x_{m x-}, y, z} \text { for } 3 \leq a \\
& t, x=x_{m x+}, y, z \\
& t=0, x, y, z
\end{aligned}
$$

The initial condition for the concentration assumes a linear concentration profile across the membrane:

$$
\left\{c_{H_{2} O}^{m}\right\}_{t=0, x, y, z}=\left\{c_{H_{2} O}^{m}\right\}_{t=0, x=x_{m x}, y, z}+\frac{\left\{c_{H_{2} O}^{m}\right\}_{t=0, x=x_{m x}, y, z}-\left\{c_{H_{2} O}^{m}\right\}_{t=0, x=x_{m x-}, y, z}}{x_{m x+}-x_{m x-}}\left(x-x_{m x-}\right)
$$

\subsubsection{Temperature $(T(t, x))$}

At both extremities of the membrane, the interfacial heat flux is continuous. Thus,

$$
\begin{aligned}
& \left\{\lambda_{m} \frac{\partial T}{\partial x}\right\}_{t, x=x_{m x-}, y, z}=\left\{\lambda^{e f f} \frac{\partial T}{\partial x}\right\}_{t, x=x_{c a x+}, y, z} \\
& \left\{\lambda_{m} \frac{\partial T}{\partial x}\right\}_{t, x=x_{m x+}, y, z}=\left\{\lambda^{e f f} \frac{\partial T}{\partial x}\right\}_{t, x=x_{c c x-}, y, z}
\end{aligned}
$$

The initial condition for the temperature assumes a linear temperature profile across the membrane, i.e.

$$
\{T\}_{t=0, x, y, z}=\{T\}_{t=0, x=x_{m x-}, y, z}+\frac{\{T\}_{t=0, x=x_{m x+}, y, z}-\{T\}_{t=0, x=x_{m x-}, y, z}}{x_{m x+}-x_{m x-}}\left(x-x_{m x-}\right)
$$




\section{Chapter 4. Model Solutions}

\subsection{Finite Difference Approach}

The governing equations solved in the membrane are in the form of transient second order, parabolic, partial differential equations with variable coefficients. Because of the complexity of these equations, they cannot be solved analytically. However, they can be solved numerically using a finite difference method. The finite difference method used approximates each derivative and coefficient in each of the partial differential equations. The following is a description of the finite difference scheme used to solve the system of coupled equations presented in Chapter 3.

\subsubsection{Difference Operators}

In finite difference schemes, the derivatives that occur within the equation being solved are approximated using finite difference operators. In order to derive these operators, one must first partition the $x$ (spatial direction) and the $t$ (time dimension) plane into uniform cells $\Delta x$ by $\Delta t$ with cell spacing $\Delta x=1 / \mathrm{J}$ and $\Delta \mathrm{t}=1 / \mathrm{N}$. An example is shown in Figure 4.1.

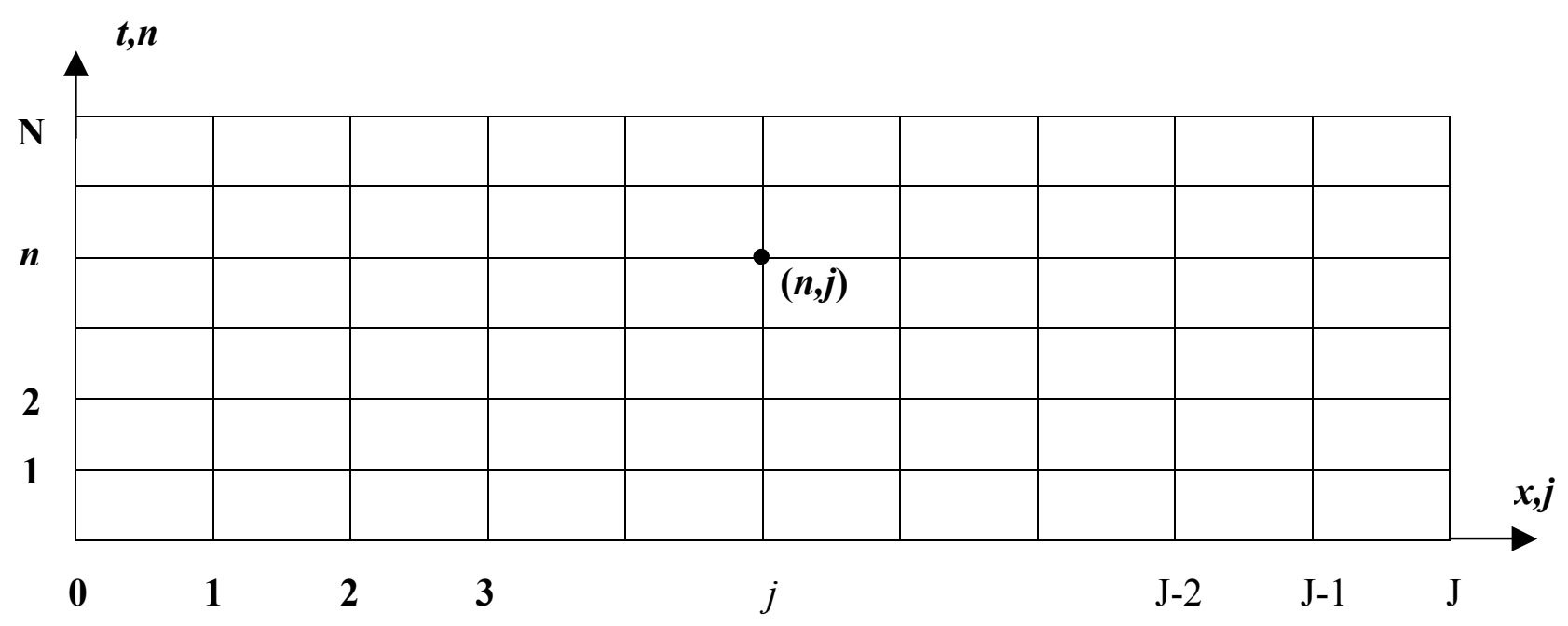

Figure 4.1 Grid Spacing. 
After grid spacing has been established in the general terms depicted in Figure 4.1, derivatives are approximated using the system of line intersections (nodes) shown. Taylor's formula or series expansion is used to express the value of some dependent variable $u$ at node $n, j+1\left(u_{j+1}^{n}\right)$ in terms of its adjacent node $n, j\left(u_{j}^{n}\right)$ and its spatial derivatives, where $t_{\mathrm{n}}=n \Delta t$ and $x_{\mathrm{j}}=j \Delta x$. Thus,

$$
\begin{aligned}
u_{j+1}^{n} & =u_{j}^{n}+\left(\frac{\partial u}{\partial x}\right)_{j}^{n} \Delta x+\frac{1}{2 !}\left(\frac{\partial^{2} u}{\partial x^{2}}\right)_{j}^{n} \Delta x^{2}+\cdots+\frac{1}{k !}\left(\frac{\partial^{k} u}{\partial x^{k}}\right)_{j}^{n} \Delta x^{k} \\
& +\frac{1}{(k+1) !}\left(\frac{\partial^{k+1} u}{\partial x^{k+1}}\right)_{j+\delta}^{n} \Delta x^{k+1}
\end{aligned}
$$

The last term or remainder involves the evaluation of $\left(\partial^{k+1} u / \partial x^{k+1}\right)$ at $x=(j+\delta) \Delta x$ and $t$ $=n \Delta t$. If only terms up to $\left(\partial^{2} u / \partial x^{2}\right)$ are retained and one solves for $(\partial u / \partial x)$, the result is $\left(\frac{\partial u}{\partial x}\right)=\frac{u_{j+1}^{n}-u_{j}^{n}}{\Delta x}-\frac{1}{2}\left(\frac{\partial^{2} u}{\partial x^{2}}\right)_{j+\delta}^{n} \Delta x, \quad$ for $0<\delta<1$

The first term on the right hand side of Eq. (4.2) is called the first forward finite difference approximation (Adjerid, 2000). The second term is referred to as the local discretization (or local truncation) error.

Backward difference operators are determined in much the same way, expanding $u_{j-1}^{n}$ about $x_{\mathrm{j}}, t_{\mathrm{n}}$ using a Taylor series, i.e.

$$
\begin{aligned}
u_{j-1}^{n}= & u_{j}^{n}-\left(\frac{\partial u}{\partial x}\right)_{j}^{n} \Delta x+\frac{1}{2 !}\left(\frac{\partial^{2} u}{\partial x^{2}}\right)_{j}^{n} \Delta x^{2}+\cdots+\frac{(-1)^{k}}{k !}\left(\frac{\partial^{k} u}{\partial x^{k}}\right)_{j}^{n} \Delta x^{k} \\
& +\frac{(-1)^{k+1}}{(k+1) !}\left(\frac{\partial^{k+1} u}{\partial x^{k+1}}\right)_{j-\delta}^{n} \Delta x^{k+1}
\end{aligned}
$$

Following the same procedure used to arrive at the first forward difference operator, the results is 


$$
\left(\frac{\partial u}{\partial x}\right)=\frac{u_{j}^{n}-u_{j-1}^{n}}{\Delta x}+\frac{1}{2}\left(\frac{\partial^{2} u}{\partial x^{2}}\right)_{j-\delta}^{n} \Delta x, \quad \text { for } 0<\delta<1
$$

where the first term on the right hand side of Eq. (4.4) is now called the first backward finite difference approximation and the second term is still referred to as the local truncation error (Adjerid, 2000). An alternative to the directional forward and backward operators is the centered difference operator. For the first centered difference operator, all the terms in Eqs (4.1) and (4.3) up to the $\left(\partial^{3} u / \partial x^{3}\right)_{j}^{n}$ are subtracted from one another resulting in

$$
\left(\frac{\partial u}{\partial x}\right)=\frac{u_{j+1}^{n}-u_{j-1}^{n}}{2 \Delta x}-\frac{1}{6}\left(\frac{\partial^{3} u}{\partial x^{3}}\right)_{j+\delta}^{n} \Delta x^{2}, \quad \text { for }-1<\delta<1
$$

where the first term on the right hand side of Eq. (4.5) is referred to as the first centered finite difference approximation and the second term is referred to as the local truncation error (Adjerid, 2000).

Eqs. (4.2), (4.4), and (4.5) give three first difference operators to choose from. The local truncation error of the first centered difference operator is $O\left(\Delta x^{2}\right)$ compared to $O(\Delta x)$ for the forward and backward difference operators. For this reason the centered difference operator is the choice of the finite difference scheme used to numerically solve equations such as those developed for the membrane.

Just as easily, higher order spatial derivatives can be found. By adding all the terms up to $\left(\partial^{4} u / \partial x^{4}\right)_{j}^{n}$ in Eqs. (4.1) and (4.3), the second centered finite difference approximation can be determined (Adjerid, 2000). It is expressed as

$$
\left(\frac{\partial^{2} u}{\partial x^{2}}\right)=\frac{u_{j-1}^{n}-2 u_{j}^{n}+u_{j+1}^{n}}{\Delta x^{2}}-\frac{1}{12}\left(\frac{\partial^{4} u}{\partial x^{4}}\right)_{j+\delta}^{n} \Delta x^{2}, \quad \text { for }-1<\delta<1
$$

As with the first centered difference operator, its truncation error is of the order $O\left(\Delta x^{2}\right)$. 
Using a Taylor expansion, it is also possible to approximate time derivatives. In Eqs. (4.1) and (4.2) first order spatial derivatives were approximated. Just as easily, the first forward difference operator approximating $(\partial u / \partial t)$ could have been found if the Taylor

expansion had been used to find $u_{j}^{n+1}$ in terms of $u_{j}^{n}$ time derivatives instead of spatial derivatives. The resulting first forward difference approximation for $(\partial u / \partial t)$ is

$$
\left(\frac{\partial u}{\partial t}\right)=\frac{u_{j}^{n+1}-u_{j}^{n}}{\Delta t}-\frac{1}{2}\left(\frac{\partial^{2} u}{\partial t^{2}}\right)_{j}^{n+\delta} \Delta t, \quad \text { for } 0<\delta<1
$$

Using these finite difference operators, all the first and second order derivatives within the species and thermal energy conservation equations (Eqs. (3.9) and (3.16)) for the membrane are approximated.

\subsubsection{Implicit versus Explicit Schemes}

The determining factor for whether a finite difference scheme is implicit or explicit is the time step at which spatial derivatives are approximated. In fully implicit schemes, spatial derivatives are approximated at the time step being solved for $(t=(n+1) \Delta t)$. In fully explicit schemes, spatial derivatives are approximated at the pervious time step $(t=n \Delta t)$. To illustrate the difference between fully implicit and explicit schemes, Eq. (4.9)

$$
\frac{\partial u}{\partial t}=\alpha \frac{\partial^{2} u}{\partial x^{2}}
$$

will be approximated with both an implicit and explicit scheme. It is important to note that in this equation, $\alpha$ is constant and can, therefore, be factored out of each $u$ term.

An explicit backward temporal and second centered spatial scheme is shown in Eq. (4.10), i.e. 


$$
\begin{aligned}
\frac{u_{j}^{n+1}-u_{j}^{n}}{\Delta t}= & \alpha \frac{u_{j-1}^{n}-2 u_{j}^{n}+u_{j+1}^{n}}{\Delta x^{2}} \rightarrow \\
& u_{j}^{n+1}=u_{j}^{n}+\alpha \Delta t \frac{u_{j-1}^{n}-2 u_{j}^{n}+u_{j+1}^{n}}{\Delta x^{2}}
\end{aligned}
$$

This scheme is termed explicit because the expression for $u_{j}^{n+1}$ is explicit, containing only known values from the previous time step $n$. For an explicit scheme all spatial derivatives are approximated at time equals $n \Delta t$.

An implicit backward temporal and second centered spatial scheme (often referred to as the Backward Euler method (Adjerid, 2000)) is shown in Eq. (4.11), i.e.

$$
\begin{aligned}
& \frac{u_{j}^{n+1}-u_{j}^{n}}{\Delta t}=\alpha \frac{u_{j-1}^{n+1}-2 u_{j}^{n+1}+u_{j+1}^{n+1}}{\Delta x^{2}} \rightarrow \\
& \quad-\frac{\alpha \Delta t}{\Delta x^{2}} u_{j-1}^{n+1}+\left(1+2 \frac{\alpha \Delta t}{\Delta x^{2}}\right) u_{j}^{n+1}-\frac{\alpha \Delta t}{\Delta x^{2}} u_{j+1}^{n+1}=u_{j}^{n}
\end{aligned}
$$

This scheme is termed implicit because $u_{j}^{n+1}$ must be solved for simultaneously with all other $u^{n+1}$ values using a matrix formulation. For an implicit scheme, all spatial derivatives are approximated at time equals $(n+1) \Delta t$. Figure 4.2 demonstrates the formulation and solution technique used to solve for $u_{0 \rightarrow J}^{n+1}$. The result of this scheme is a tridiagonal (j-1 by $j-1)$ matrix labeled $\overline{\bar{A}}$, a solution vector $\bar{B}$ and load vector $\bar{C}$. It is important to note, the solution method illustrated in Figure 4.2 is for Dirichlet boundary conditions. The terms multiplied by $s$ and then added to $u_{1}^{n}$ and $u_{J-1}^{n}$, respectively, in load vector $\bar{C}$ represent the contributions of boundary conditions for the time step $(n+1)$ being solved for. The treatment of boundary conditions will be covered in much greater detail in Section 4.4. 


$$
\begin{gathered}
\frac{\left(u_{j}^{n+1}-u_{j}^{n}\right)}{\Delta t}-\alpha \frac{\left(u_{j-1}^{n+1}-2 u_{j}^{n+1}+u_{j+1}^{n+1}\right)}{\Delta x^{2}}=0 \\
-s u_{j-1}^{n+1}+(1+2 s) u_{j}^{n+1}-s u_{j+1}^{n+1}=u_{j}^{n} \\
{\left[\begin{array}{lllllll}
1+2 s & -s & 0 & 0 & 0 & \cdots & 0 \\
-s & 1+2 s & -s & 0 & 0 & \cdots & 0 \\
0 & -s & 1+2 s & -s & 0 & \cdots & 0 \\
0 & 0 & \ddots & \ddots & \ddots & \cdots & 0 \\
0 & 0 & 0 & -s & 1+2 s & -s & 0 \\
\vdots & 0 & 0 & 0 & -s & 1+2 s & -s \\
0 & 0 & 0 & \cdots & 0 & -s & 1+2 s
\end{array}\right]\left\{\begin{array}{l}
u_{1}^{n+1} \\
u_{2}^{n+1} \\
u_{3}^{n+1} \\
u_{4}^{n+1} \\
\vdots \\
u_{J-2}^{n+1} \\
u_{J-1}^{n+1}
\end{array}\right\}=\left[\begin{array}{c}
\Delta t \\
u_{1}^{n}+s u_{0}^{n+1} \\
u_{2}^{n} \\
u_{3}^{n} \\
u_{4}^{n} \\
\vdots \\
u_{J-2}^{n} \\
u_{J-1}^{n}+s u_{J}^{n+1}
\end{array}\right]} \\
\bar{B}
\end{gathered}
$$

Figure 4.2 Implicit formulation and solution technique.

Implicit and explicit schemes represent the two extremes used for one-level finite difference schemes. One-level schemes use only nodal solutions from time step $t_{n}$ to obtain a solution at time step $t_{n+1}$. Multi-level schemes were not considered in this thesis work. They are more difficult to start but can offer increased accuracy. To represent all the possible one-level schemes, a variable $\theta$ is introduced. $\theta$ is referred to as a weighting factor. It ranges between zero and unity and represents the time step where spatial time derivatives are located. Using the theta method, spatial derivatives are approximated at $t$ $=(n+\theta) \Delta t$. Eq. (4.12) demonstrates how this weighted method can be used to approximate Eq. (4.1) (Adjerid, 2000):

$$
\frac{u_{j}^{n+1}-u_{j}^{n}}{\Delta t}=\theta \alpha \frac{u_{j-1}^{n+1}-2 u_{j}^{n+1}+u_{j+1}^{n+1}}{\Delta x^{2}}+(1-\theta) \alpha \frac{u_{j-1}^{n}-2 u_{j}^{n}+u_{j+1}^{n}}{\Delta x^{2}} \quad \text { for } 0 \leq \theta \leq 1
$$

- if $\theta=0$, Eq. (4.12) is an explicit scheme

- if $\theta=1$, Eq. (4.12) is a fully implicitly scheme

- if $\theta=1 / 2$, Eq. (4.12) is an implicit scheme called the Crank-Nicolson method. 
The scheme depicted in Eq. (4.12) can be rewritten in the following more common form, grouping nodes at similar time steps and using $s=\alpha \Delta t / \Delta x^{2}$ :

$$
\begin{aligned}
& -\theta s u_{j-1}^{n+1}+(1+2 \theta s) u_{j-1}^{n+1}-\theta s u_{j+1}^{n+1}= \\
& (1-\theta) s u_{j-1}^{n}+(1-2(1-\theta) s) u_{j-1}^{n}+(1-\theta) s u_{j+1}^{n}
\end{aligned}
$$

The finite difference scheme used to solve for temperature and water concentration in the membrane is a weighted or theta scheme. This allows it to be changed from fully implicit to fully explicit or any fraction of either depending on the value of theta. When generating results for this thesis theta was set to one resulting in a fully implicit scheme.

\subsubsection{Variable Coefficients}

This section will detail the methods used to approximate the variable coefficients which appear in the transient, second order, partial differential equations developed in Chapter 3. These coefficients were approximated using methods described in Mitchell \& Griffiths (1981).

The first step was to start with a general equation of the form which describes the thermal energy conservation equation (Eq. (3.16)) and the water concentration conservation equation (Eq. (3.9)) in the membrane. Such a general equation is expressed as

$$
\frac{\partial u}{\partial t}=\frac{\partial}{\partial x}\left(a(x, t) \frac{\partial u}{\partial x}\right)+b(x, t) \frac{\partial u}{\partial x}+s(x, t)
$$

This equation is made up of a second order term multiplied by a variable coefficient $a(x, t)$, a first order term multiplied by a variable coefficient $b(x, t)$, and a source term, $s(x, t)$.

The next step in approximating Eq. (4.14) using finite difference methods is the application of a weighting scheme to the spatial terms and a forward difference scheme to the transient term. Once that has been done, the spatial terms containing variable coefficients (on the right hand side of Eq. (4.15) inside the square brackets) can be 
properly approximated and substitutions made. Consider Eq. (4.15) to be located at time $t=(n+\theta) \Delta t$, and $x=j \Delta$. Thus

$$
\begin{array}{r}
\left(\frac{u_{j}^{n+1}-u_{j}^{n}}{\Delta t}\right)=\theta\left[\frac{\partial}{\partial x}\left(a(x, t) \frac{\partial u}{\partial x}\right)+b(x, t) \frac{\partial u}{\partial x}+s(x, t)\right]_{j}^{n+1}+ \\
(1-\theta)\left[\frac{\partial}{\partial x}\left(a(x, t) \frac{\partial u}{\partial x}\right)+b(x, t) \frac{\partial u}{\partial x}+s(x, t)\right]_{j}^{n}
\end{array}
$$

To approximate the first order term and its variable coefficient, a first centered finite difference approximation like the one shown in Eq. (4.5) is used, namely

$$
b(x, t)\left(\frac{\partial u}{\partial x}\right)=b_{j} \frac{u_{j+1}-u_{j-1}}{2 \Delta x}+O\left(\Delta x^{2}\right)
$$

Notice that the value of $b(x, t)$ is taken at node $u_{j}$ and the time step at which $u_{j+1}, u_{j-1}$, and $b_{j}$ are taken is not specified. In the final finite difference scheme, $u_{j+1}, u_{j-1}$, and $b_{j}$ will be taken at both $t=(n+1) \Delta \mathrm{t}$ and $t=n \Delta t$ and weighted by theta.

To approximate the second order term and its variable coefficient $(a(x, t))$, a more complicated approach is needed. First, the time derivative and second order term are written in the following form:

$$
\frac{\partial u}{\partial t}=-\frac{\partial w}{\partial x}
$$

where $w=-a(x, t) \frac{\partial u}{\partial x}$

Eq. (4.18) is now rewritten in the form given below and integrated with respect to $x$ over the intervals $[(j-1) \Delta x, j \Delta x]$ and $[j \Delta x,(j+1) \Delta x]$, assuming $w=w_{j-1 / 2}$ over the first interval and $w=w_{\mathrm{j}+1 / 2}$ over the second interval. The result is 


$$
\begin{aligned}
& \frac{w}{a(x, t)}=-\frac{\partial u}{\partial x} \rightarrow \\
& w_{j+1 / 2} \int_{j \Delta x}^{(j+1) \Delta x} \frac{d x}{a(x, t)}=u_{j}-u_{j+1} \\
& w_{j-1 / 2} \int_{(j-1) \Delta x}^{j \Delta x} \frac{d x}{a(x, t)}=u_{j-1}-u_{j}
\end{aligned}
$$

Eq. (4.17) is then approximated using a first forward approximation for $\partial u / \partial t$ and a centered finite difference approximation (the derivation of which is detailed on page 23 in Mitchell and Griffiths (1981)) for $\frac{\partial w}{\partial x}$. This yields

$$
\begin{aligned}
\frac{u_{j}^{n+1}-u_{j}^{n}}{\Delta t}+O(\Delta t) & =\frac{w_{j-1 / 2}-w_{j+1 / 2}}{\Delta x}+O\left(\Delta x^{2}\right) \\
& =A_{j+1}\left(u_{j+1}-u_{j}\right)-A_{j}\left(u_{j}-u_{j-1}\right)+O\left(\Delta x^{2}\right)
\end{aligned}
$$

where

$$
\begin{aligned}
& A_{j}=\frac{1}{\Delta x}\left[\int_{(j-1) \Delta x}^{j \Delta x} \frac{d x}{a(x)}\right]^{-1} \\
& A_{j+1}=\frac{1}{\Delta x}\left[\int_{j \Delta x}^{(j+1) \Delta x} \frac{d x}{a(x)}\right]^{-1}
\end{aligned}
$$

The advantage of the approximation described in Eqs. (4.17) through (4.21b) is that it does not destroy the self-adjoint nature of the operator $\frac{\partial}{\partial x}\left(a(x, t) \frac{\partial u}{\partial x}\right)$ (Mitchell and Griffiths, 1980). Having used Eqs. (4.20) and (4.21) to relate the approximation of the second order spatial term to the transient term, only the source term in Eq. (4.14) is left to approximate. The source term $s$ will be approximated by evaluating it at $t=(n+\theta) \Delta t$, $x=j \Delta x$.

Now substituting the approximations Eqs. (4.16) and (4.20) as well as that for the source term into Eq. (4.15), the resulting finite difference approximation for Eq. (4.14) is obtained and expressed by 


$$
\begin{aligned}
\left(\frac{u_{j}^{n+1}-u_{j}^{n}}{\Delta t}\right)= & \theta\left[A_{j+1}\left(u_{j+1}-u_{j}\right)-A_{j}\left(u_{j}-u_{j-1}\right)+b_{j} \frac{1}{2 \Delta x}\left(u_{j+1}-u_{j-1}\right)+s\right]_{j}^{n+1}+ \\
& (1-\theta)\left[A_{j+1}\left(u_{j+1}-u_{j}\right)-A_{j}\left(u_{j}-u_{j-1}\right)+b_{j} \frac{1}{2 \Delta x}\left(u_{j+1}-u_{j-1}\right)+s\right]_{j}^{n}
\end{aligned}
$$

Eq. (4.23) below results from grouping $n+1$ and $n$ terms on separate sides of the equation and then grouping by node. Thus

$$
\begin{aligned}
& {\left[1+\theta \Delta t\left(A_{j+1}^{n+1}+A_{j}^{n+1}\right)\right] u_{j}^{n+1}-\theta \Delta t\left[\left(A_{j+1}^{n+1}+\frac{1}{2 \Delta x} b_{j}^{n+1}\right) u_{j+1}^{n+1}+\left(A_{j}^{n+1}-\frac{1}{2 \Delta x} b_{j}^{n+1}\right) u_{j-1}^{n+1}\right]-\Delta t s_{j}^{n+1}=} \\
& {\left[1-(1-\theta) \Delta t\left(A_{j+1}^{n}+A_{j}^{n}\right)\right] u_{j}^{n}+(1-\theta) \Delta t\left[\left(A_{j+1}^{n}+\frac{1}{2 \Delta x} b_{j}^{n}\right) u_{j+1}^{n}+\left(A_{j}^{n}-\frac{1}{2 \Delta x} b_{j}^{n}\right) u_{j-1}^{n}\right]} \\
& +\Delta t(1-\theta) s_{j}^{n}
\end{aligned}
$$

This equation or scheme results in a tri-diagonal matrix like the one described in Figure 4.2. One significant difference is that the coefficients populating the $\overline{\bar{A}}$ matrix are not necessarily symmetric about the diagonal. This is because each coefficient in the matrix is the product of a different set of variables. Furthermore, the examples in Section 4.1.2 where Figure 4.2 was developed were for constant coefficients, not variable ones. Thus, for variable coefficients, the off-diagonal term to the left of the diagonal is $\left(A_{j+1}^{n+1}+\frac{1}{2 \Delta x} b_{j}^{n+1}\right)$ and to the right it is $\left(A_{j}^{n+1}-\frac{1}{2 \Delta x} b_{j}^{n+1}\right)$. These terms will in most cases not equal one another. It can also be said that the diagonal terms $\left(1-\theta \Delta t\left(A_{j+1}^{n}+A_{j}^{n}\right)\right)$ will not remain constant, again the result of the algorithm being used to account for the variable coefficients in the original differential equation. All the terms on the right hand side of the equation are multiplied by known node values and, therefore, known. They are summed and used to solve for node values at the next time step $(n+1)$. Along with the boundary conditions for time step $(n+1)$, they make up the load vector $\bar{C}$. 


\subsubsection{Boundary Conditions}

Boundary conditions provide a link to what is happening along the boundary of the $\mathrm{x}$ domain which is being solved. In the case of the membrane model, boundary conditions represent what is happening at the interface between the anode catalyst layer and the anode side of the membrane and the cathode catalyst layer and the cathode side of the membrane. Two types of boundary conditions are possible: Dirichlet and Neumann. Dirichlet boundary conditions are specified values at a particular time step (i.e. $T_{0}^{n+1}=25^{\circ} \mathrm{C}$ ). In the membrane, these would be a specified temperature (for the thermal energy conservation equation) or water concentration (for the water species conservation equation) at the anode or cathode interface. Neumann boundary conditions are specified gradients at the boundaries (i.e. $\left.(\partial T / \partial x)_{0}^{n+1}=.005^{\circ} \mathrm{C} / \mathrm{m}\right)$. In the membrane these could be related to water or heat fluxes at the boundaries.

The MATLAB code written to solve the system of equations, which have been developed here for the membrane, accounts for any combination of Dirichlet and Neumann boundary conditions for either equation. This results in a combination of sixteen possible boundary condition configurations.

In either case, Dirichlet or Neumann, boundary conditions contribute to the solution by contributing to the load vector. Because the membrane is one-dimensional and, therefore, has only two boundaries boundary conditions are added to the top and bottom position of the load vector. The contribution of Dirichlet boundary conditions is illustrated in Figure 4.3 where the vector labeled Load represents the contribution of all the internal node values at the time step $n$ and vector BJCs represents the contribution of the boundary conditions at times $n \Delta t$ and $(n+1) \Delta t$ weighted by theta. 


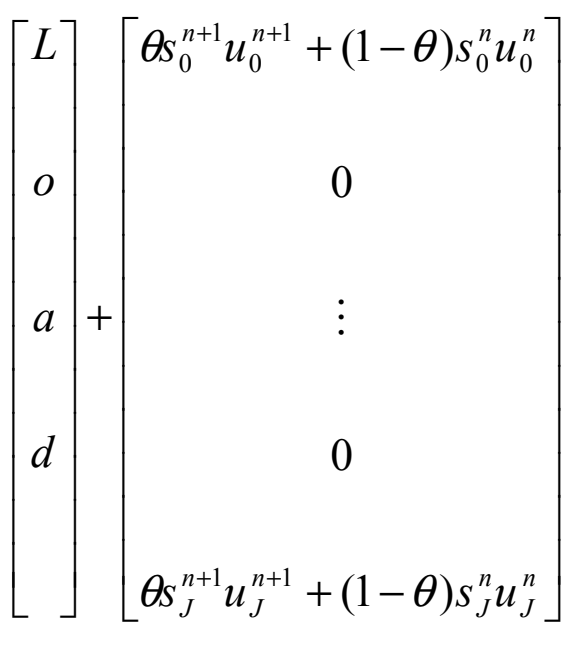

Load

BJCs

Figure 4.3 Dirichlet Boundary Conditions.

The effect of Dirichlet boundary conditions can also be illustrated by rewriting a weighted finite difference scheme (like the one shown in Eq. (4.14)) at the node closest to one of the boundaries. This is done below for Eq. (4.24) with $j=1$.

$-\theta s u_{0}^{n+1}+(1+2 \theta s) u_{1}^{n+1}-\theta s u_{2}^{n+1}=(1-\theta) s u_{0}^{n}+(1+2(1-\theta) s) u_{1}^{n}+(1-\theta) s u_{2}^{n}$

Now, placing the term containing the boundary condition, $\theta s u_{0}^{n+1}$, on the right hand side of the Eq. (4.24) along with the other known values from the previous time step results in Eq. (4.25).

$(1+2 \theta s) u_{1}^{n+1}-\theta s u_{2}^{n+1}=(1-\theta) s u_{0}^{n}+(1-2(1-\theta) s) u_{1}^{n}+(1-\theta) s u_{2}^{n}+\theta s u_{0}^{n+1}$

The first and last term on the right hand side of Eq. (4.25) represent the contribution of the Dirichlet boundary conditions.

In the case of Neumann boundary conditions, the process is much the same. The difference lies in approximating the boundary condition and then modifying the 
algorithm. The Neumann boundary condition is approximated using a centered difference formula. The approximation for the boundary condition at $j=\mathrm{J}$ is given by

$\left(\frac{\partial u}{\partial x}\right)_{J}^{n+1}=\frac{u_{J+1}^{n+1}-u_{J-1}^{n+1}}{2 \Delta x}+O\left(\Delta x^{2}\right)$

Solving for $u_{J+1}^{n+1}$ the result is

$u_{J+1}^{n+1}=u_{J-1}^{n+1}+2 \Delta x g_{J}^{n+1}$

where $g_{J}^{n+1}$ is the Neumann boundary condition $(\partial u / \partial x)_{J}^{n+1}$. This approximation required the creation of an imaginary grid line at $j=\mathrm{J}+1$. As shown in Figure 4.1, the $x$ plane was originally partitioned along the $x$-axis by grid lines labeled 0 to J. Substituting Eq. (4.27) written at time steps $n$ and $n+1$, into Eq. (4.14) written at $j=\mathrm{J}$ yields

$$
\begin{aligned}
-2 s \theta u_{J-1}^{n+1}+(1+2 s \theta) u_{J}^{n+1}= & 2 s(1-\theta) u_{J-1}^{n}+(1-2 s(1-\theta)) u_{J}^{n}+ \\
& 2 s(1-\theta) \Delta x g_{J}^{n}+2 s \theta \Delta x g_{J}^{n+1}
\end{aligned}
$$

where the last two terms on the right hand side of the equation represent the contribution of the Neumann boundary conditions at time steps $n$ and $n+1$.

\subsection{MATLAB Code}

The MATLAB code (code referring to the collection of MATLAB functions) presented in this section houses all of the algorithms needed to numerically approximate the governing equations of the membrane. It is composed of 13 separate functions and totals in excess of 1600 lines of code. MATLAB was chosen based on its ability to solve problems requiring matrix inversion.

An outline of the MATLAB code is given in Figure 4.4. The code takes prescribed 


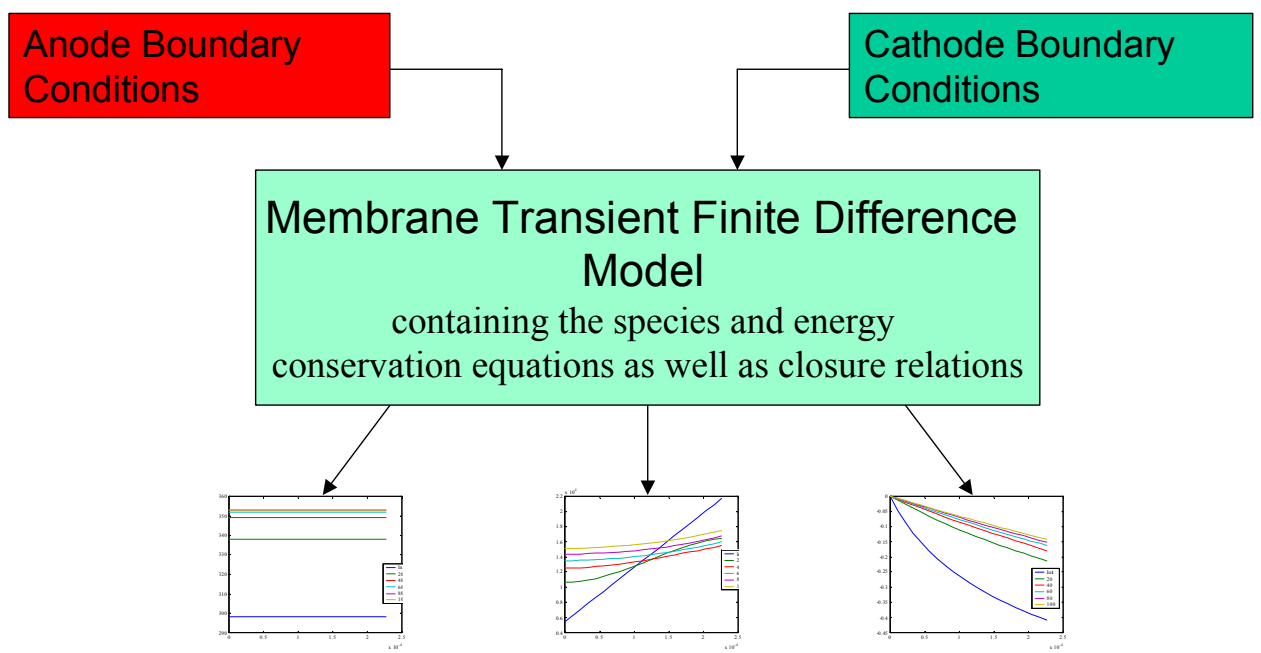

Temperature, Water Concentration, and Voltage Profiles

Figure 4.4 Outline of the MATLAB code developed to build and solve the membrane model.

boundary conditions at the anode and cathode for each time step starting at time equals zero and produces temperature, water concentration, and voltage profiles for each of these time steps. Section 4.2.1 provides a brief summary of each function used to determine these profiles, while Section 4.2.2 details the flow of information between functions.

\subsubsection{Function Descriptions}

In this section tables will be used to summarize each function used by the code.

\begin{tabular}{|l|l|}
\hline Name & \multicolumn{1}{|c|}{ START.m } \\
\hline Variables Passed To & None \\
\hline Variables Passed From & $\begin{array}{l}\text { anode and cathode boundary } \\
\text { conditions (temperatures, saturation } \\
\text { ratios, gas concentrations, pressures, } \\
\text { heat and water fluxes) numerical } \\
\text { solution parameters and geometry }(\theta, \\
\text { total time, membrane thickness, } \\
\text { number of nodes })\end{array}$ \\
\hline
\end{tabular}




\begin{tabular}{|l|l|}
\hline Description & START.m lets the user specify the \\
boundary conditions for each time \\
step and sets all the parameters used \\
to numerically approximate the \\
equations. START.m then calls \\
MAIN.m and passes MAIN.m all the \\
information it needs to solve the \\
problem at each time step. In the \\
future, linked models of the catalyst \\
layers will provide transient boundary \\
conditions replacing START.m.
\end{tabular}

\begin{tabular}{|c|c|}
\hline Name & MAIN.m \\
\hline Variables Passed To & $\begin{array}{l}\text { anode and cathode boundary } \\
\text { conditions, numerical solution } \\
\text { parameters and geometry }\end{array}$ \\
\hline Variables Passed From & $\begin{array}{l}\text { transient temperature, water } \\
\text { concentration, and voltage profiles / } \\
\text { average membrane resistance, etc. }\end{array}$ \\
\hline Description & $\begin{array}{l}\text { MAIN.m first determines the initial } \\
\text { water concentration, voltage drop and } \\
\text { temperature profiles across the } \\
\text { membrane by calling } \\
\text { INITBOUNDCONC, INITVOLT and } \\
\text { INITBOUNDTEMP, respectively. It } \\
\text { then loops through time steps } \\
\text { calculating temperature and water } \\
\text { concentration profiles for each time } \\
\text { step by applying the finite difference } \\
\text { algorithm in Eq. ( } 4.23 \text { ) to Eqs. ( } 3.9) \\
\text { and (3.16). In order to calculate the } \\
\left.\text { coefficients } A_{j} \text { and } b_{j} \text { in Eq. ( } 4.23\right) \text {, } \\
\text { functions AjT, AjC, bjT and bjC are } \\
\text { called. The source term, } s_{j} \text {, is } \\
\text { calculated using functions sT and sC. } \\
\text { Concentration and temperature are } \\
\text { solved for iteratively with } \\
\text { temperature solved first. Profiles for } \\
\text { temperature and concentration are not } \\
\text { set for a time step until temperature } \\
\text { has converged. After temperature } \\
\text { and concentration profiles are set, } \\
\text { voltage drop across the membrane is } \\
\text { found as a function of temperature } \\
\text { and concentration calling the } \\
\text { functions VOLTGRAD.m and }\end{array}$ \\
\hline
\end{tabular}




\begin{tabular}{|l|l|}
\hline & $\begin{array}{l}\text { VOLTAGE.m. Lastly average } \\
\text { resistance across the membrane is } \\
\text { calculated and results are plotted. }\end{array}$ \\
\hline
\end{tabular}

\begin{tabular}{|l|l|}
\hline Name & INITBOUNDTEMP.m \\
\hline Variables Passed To & $\begin{array}{l}\text { anode and cathode boundary } \\
\text { conditions (temperatures) }\end{array}$ \\
\hline Variables Passed From & $\begin{array}{l}\text { Initial temperature profile and } \\
\text { transient temperature boundary } \\
\text { conditions }\end{array}$ \\
\hline $\begin{array}{l}\text { INITBOUNDTEMP.m takes the } \\
\text { boundary conditions passed from } \\
\text { MAIN.m and creates an initial } \\
\text { temperature profile at time }=0 . \text { This } \\
\text { initial profile connects the anode and } \\
\text { cathode temperatures with a straight } \\
\text { line (see Eq. (3.35)). When MAIN.m } \\
\text { starts to loop through the time steps, } \\
\text { INITBOUNDTEMP.m is called at the } \\
\text { beginning of the loop to set the } \\
\text { temperature boundary conditions for } \\
\text { that time step. }\end{array}$ \\
\hline
\end{tabular}

\begin{tabular}{|l|l|}
\hline Name & INITBOUNDTEMP.m \\
\hline Variables Passed To & $\begin{array}{l}\text { anode and cathode boundary } \\
\text { conditions (gas concentrations, } \\
\text { saturation ratios, temperatures) }\end{array}$ \\
\hline Description & $\begin{array}{l}\text { Initial water concentration profile and } \\
\text { transient water concentration } \\
\text { boundary conditions }\end{array}$ \\
\hline $\begin{array}{l}\text { INITBOUNDCONC.m takes the } \\
\text { boundary conditions passed from } \\
\text { MAIN.m and creates an initial } \\
\text { concentration profile at time }=0 . \\
\text { This initial profile connects the anode } \\
\text { and cathode concentrations with a } \\
\text { straight line (see Eq. (3.33)). When } \\
\text { MAIN.m starts to loop through the } \\
\text { time steps, INITBOUNDCONC.m is } \\
\text { called at the beginning of the loop to } \\
\text { set the concentration boundary } \\
\text { conditions for that time step. }\end{array}$ \\
\hline
\end{tabular}




\begin{tabular}{|l|l|}
\hline Name & INITBOUNDVOLT.m \\
\hline Variables Passed To & $\begin{array}{l}\text { initial temperature and water } \\
\text { concentrations, current density, } \\
\text { pressure boundary conditions }\end{array}$ \\
\hline Variables Passed From & Initial voltage profile \\
\hline Description & $\begin{array}{l}\text { INITBOUNDVOLT.m calls } \\
\text { VOLTGRAD.m where voltage } \\
\text { gradients at all nodes at time }=0 \text { are } \\
\text { calculated. The array of voltage } \\
\text { gradients is then sent to } \\
\text { VOLTAGE.m where a voltage profile } \\
\text { at time }=0 \text { is determined. }\end{array}$ \\
\hline
\end{tabular}

\begin{tabular}{|l|l|}
\hline Name & AjT.m \\
\hline Variables Passed To & $\begin{array}{l}\text { temperature and water concentration, } \\
\text { node number, time step }\end{array}$ \\
\hline Variables Passed From & $\lambda_{m} / \overline{\rho c_{p}}$ \\
\hline Description & $\begin{array}{l}\text { AjT.m calculates at different nodes. } \\
\text { It is sent the node value and time step } \\
\text { and proceeds to calculate } \overline{\rho c_{p}} \text { using } \\
\text { Eq. }(3.17) \text { at that node and time step. } \\
\lambda_{m} / \overline{\rho c} \text { corresponds to the variable } \\
\text { coefficient } a(x, t) \text { in Eq. (4.14). } \\
\text { AjT.m is called by MAIN.m. }\end{array}$ \\
\hline
\end{tabular}

\begin{tabular}{|l|l|}
\hline Name & AjC.m \\
\hline Variables Passed To & $\begin{array}{l}\text { temperature and water concentration, } \\
\text { node number, time step }\end{array}$ \\
\hline Variables Passed From & $D_{c_{H 2 O}, T}$ \\
\hline
\end{tabular}




\begin{tabular}{|l|l|}
\hline Description & $\begin{array}{l}\text { AjC.m calculates } D_{c_{H 2 O}, T} \text { at different } \\
\text { nodes. It is sent the node value and } \\
\text { time step and proceeds to calculate } \\
\text { water content and activity at that node } \\
\text { and time step. } D_{c_{H 2 O}, T} \text { is then } \\
\text { calculated using Eq. (3.6). } D_{c_{H 2 O}, T} \\
\text { corresponds to the variable } \\
\text { coefficient } a(x, t) \text { in Eq. }(4.14) . \text { It is } \\
\text { important to note that water drag has } \\
\text { been removed from coefficient } a(x, t) \\
\text { and is treated in the source term. } \\
\text { This is because water drag is not an } \\
\text { explicit function of } c_{H 2 O} . \text { AjC.m is } \\
\text { called by MAIN.m. }\end{array}$ \\
\hline
\end{tabular}

\begin{tabular}{|l|l|}
\hline Vame & bjT.m \\
\hline Variables Passed To & $\begin{array}{l}\text { temperature and water concentration, } \\
\text { boundary conditions, node number, } \\
\text { time step }\end{array}$ \\
\hline Description & $\overline{M c_{p} N} / \overline{\rho c_{p}}$ \\
\hline $\begin{array}{l}\text { bjT.m calculates } \overline{M c_{p} N} / \overline{\rho c_{p}} \text { at } \\
\text { different nodes. It is sent the node } \\
\text { value and time step and proceeds to } \\
\text { calculate the molar flux } N . \text { In order } \\
\text { to calculate molar flux, bjT.m must } \\
\text { calculate all variables associated with } \\
\text { species flux in the membrane } \\
\text { including } D_{c_{H 2 O}, T}, u^{m}, \text { water drag, } \\
\text { potential gradients, and pressure } \\
\text { gradients. Variables are calculated } \\
\text { and then substituted according to Eqs. } \\
(3.17) \text { and (3.20a). } \\
M c_{p} N / \overline{\rho c} \text { corresponds to the } \\
\text { variable coefficient } b(x, t) \text { in Eq. } \\
(4.14) . \text { bjT.m is called by MAIN.m. }\end{array}$ \\
\hline
\end{tabular}

\begin{tabular}{|l|l|}
\hline Name & bjC.m \\
\hline Variables Passed To & $\begin{array}{l}\text { water concentration, pressure and } \\
\text { saturation ratio boundary conditions, } \\
\text { node number, time step }\end{array}$ \\
\hline Variables Passed From & $u^{m}$ \\
\hline Description & bjC.m calculates the mixture velocity, \\
\hline
\end{tabular}




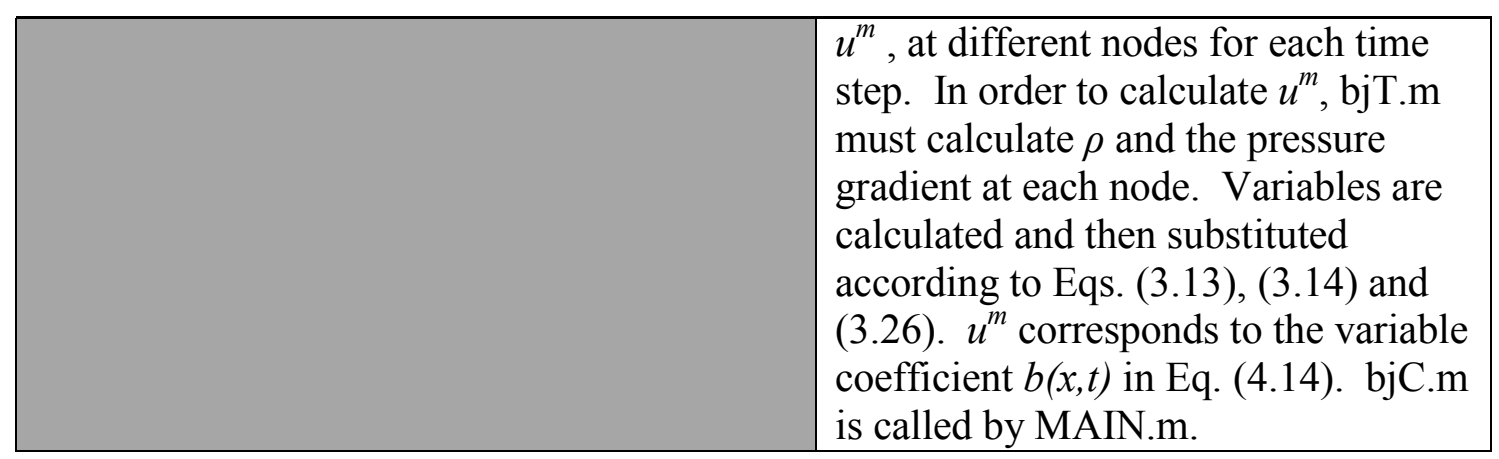

\begin{tabular}{|c|c|}
\hline Name & sT.m \\
\hline Variables Passed To & $\begin{array}{l}\text { water concentration and temperature, } \\
\text { current density, node number, time } \\
\text { step }\end{array}$ \\
\hline Variables Passed From & $\frac{i_{m x}^{2}}{\sigma_{m} \overline{\rho c_{p}}}$ \\
\hline Description & $\begin{array}{l}\text { sT.m calculates the ohmic loss term, } \\
\frac{i_{m x}{ }^{2}}{\sigma_{m} \overline{\rho c_{p}}} \text {, at different nodes. In order } \\
\text { to calculate the ohmic loss term, sT.m } \\
\text { must calculate } \overline{\rho c_{p}} \text { and the } \\
\text { membrane conductivity, } \sigma_{m} \text {, at each } \\
\text { node. Variables are calculated } \\
\text { according to Eqs. }(3.17),(3.21) \text {, and } \\
\text { (3.22) and then substituted } \\
\text { accordingly. } \frac{i_{m x}{ }^{2}}{\sigma_{m}} \overline{\rho c_{p}} \text { corresponds to } \\
\text { the variable coefficient } s(x, t) \text { in Eq. } \\
\text { (4.14). sT.m is called by MAIN.m. }\end{array}$ \\
\hline
\end{tabular}

\begin{tabular}{|l|l|}
\hline Name & sC.m \\
\hline Variables Passed To & $\begin{array}{l}\text { water concentration, current density, } \\
\text { node number, time step }\end{array}$ \\
\hline Variables Passed From & $\frac{\partial}{\partial x}\left(\frac{2.5 \lambda_{\mathrm{H}_{2} \mathrm{O} / \mathrm{SO}_{3}} i_{m x}}{22 \mathrm{~F}}\right)$ \\
\hline
\end{tabular}




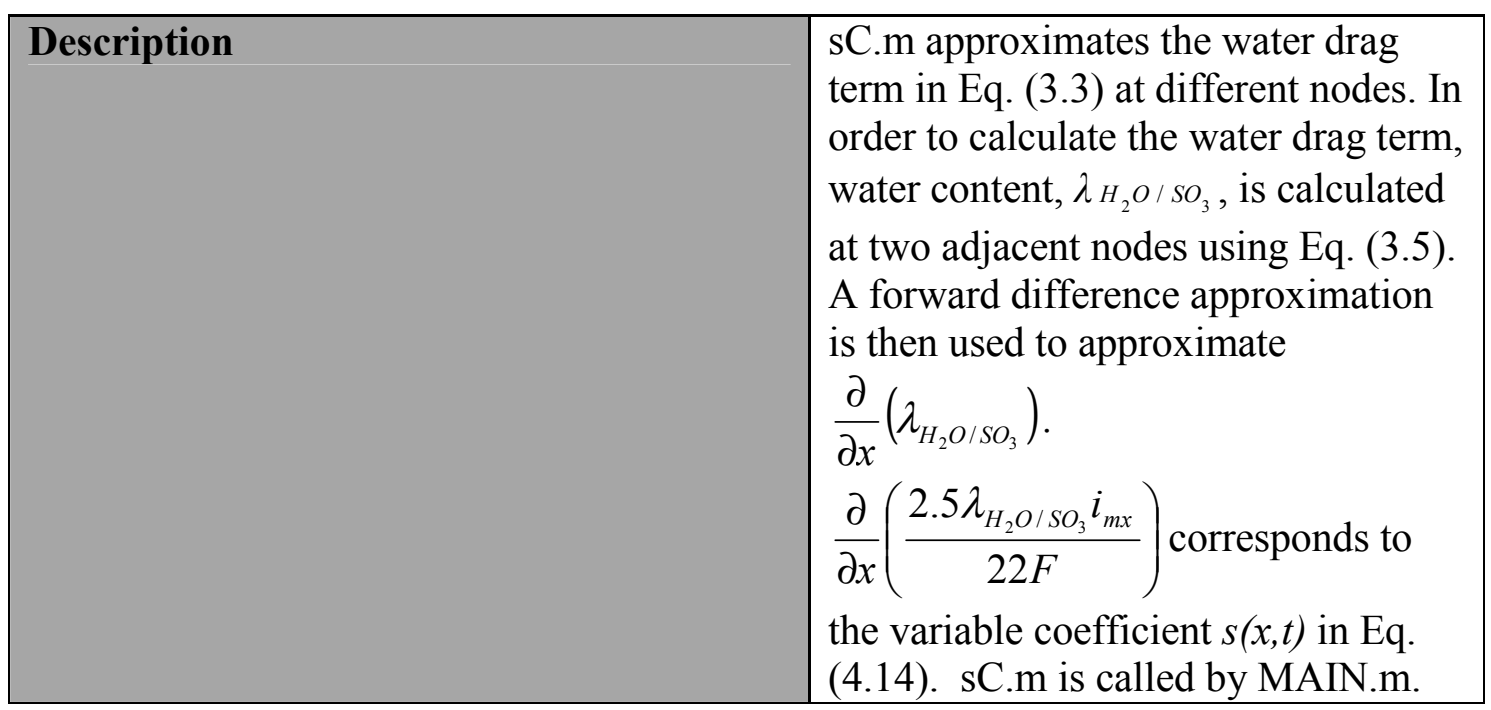

\begin{tabular}{|l|l|}
\hline Name & VOLTGRAD.m \\
\hline Variables Passed To & $\begin{array}{l}\text { water concentration and temperature, } \\
\text { current density, anode and cathode } \\
\text { pressures and saturation ratios, node } \\
\text { number, time step }\end{array}$ \\
\hline Variables Passed From & voltage gradient at each node, $\frac{\partial \Phi_{m}}{\partial x}$ \\
\hline Description & $\begin{array}{l}\text { VOLTGARD.m calculates the } \\
\text { voltage gradient at a node. After final } \\
\text { water concentration and temperature } \\
\text { profiles have been determined for a } \\
\text { time step, VOLTGRAD.m is called } \\
\text { by MAIN.m. Membrane conductivity } \\
\text { and mixture velocity are calculated } \\
\text { then substituted according to Eq. } \\
\text { (3.25). Voltage gradients are then } \\
\text { sent back to MAIN.m. }\end{array}$ \\
\hline
\end{tabular}

\begin{tabular}{|l|l|}
\hline Name & VOLTAGE.m \\
\hline Variables Passed To & voltage gradients, deltax \\
\hline Variables Passed From & voltage profile across the membrane \\
\hline
\end{tabular}




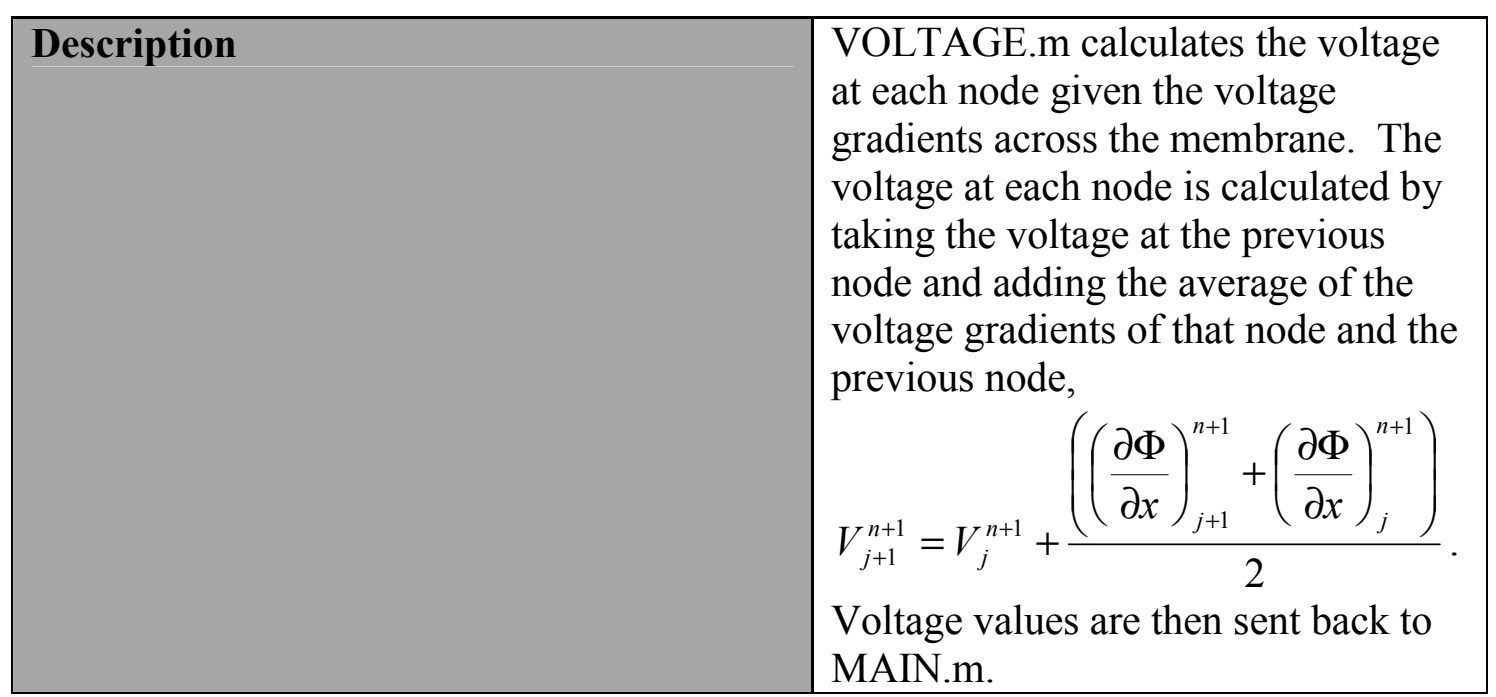

\subsubsection{Program Flow}

This section details the flow of information between the functions described in the previous section. Figure 4.5 visually describes this flow

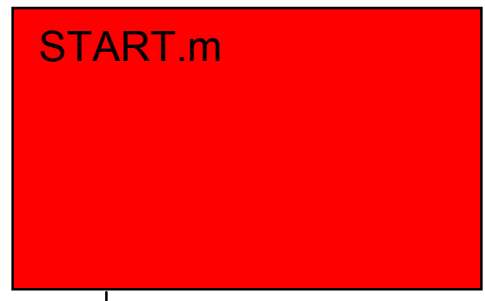

boundary conditions, numerical solution parameters (\#nodes, $\theta$ ), and geometry

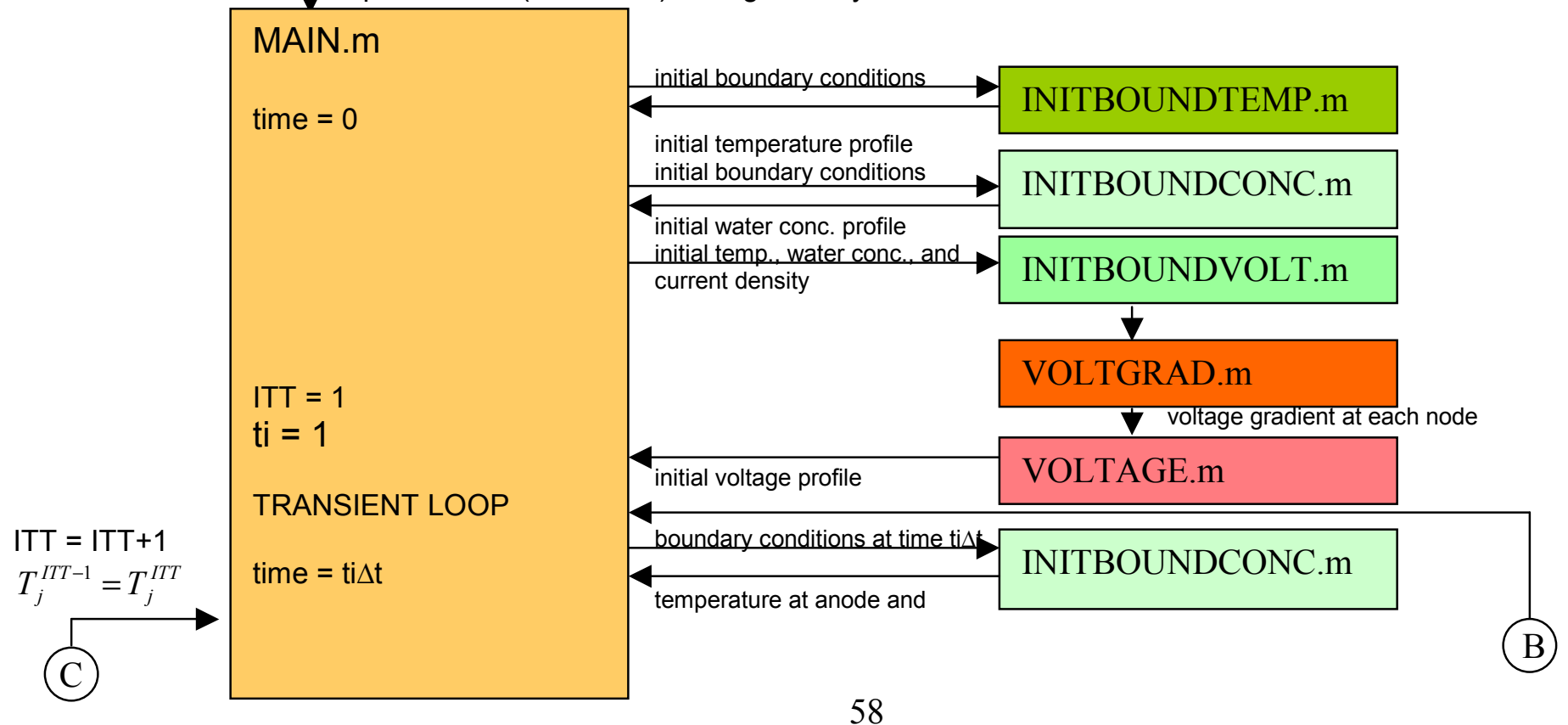




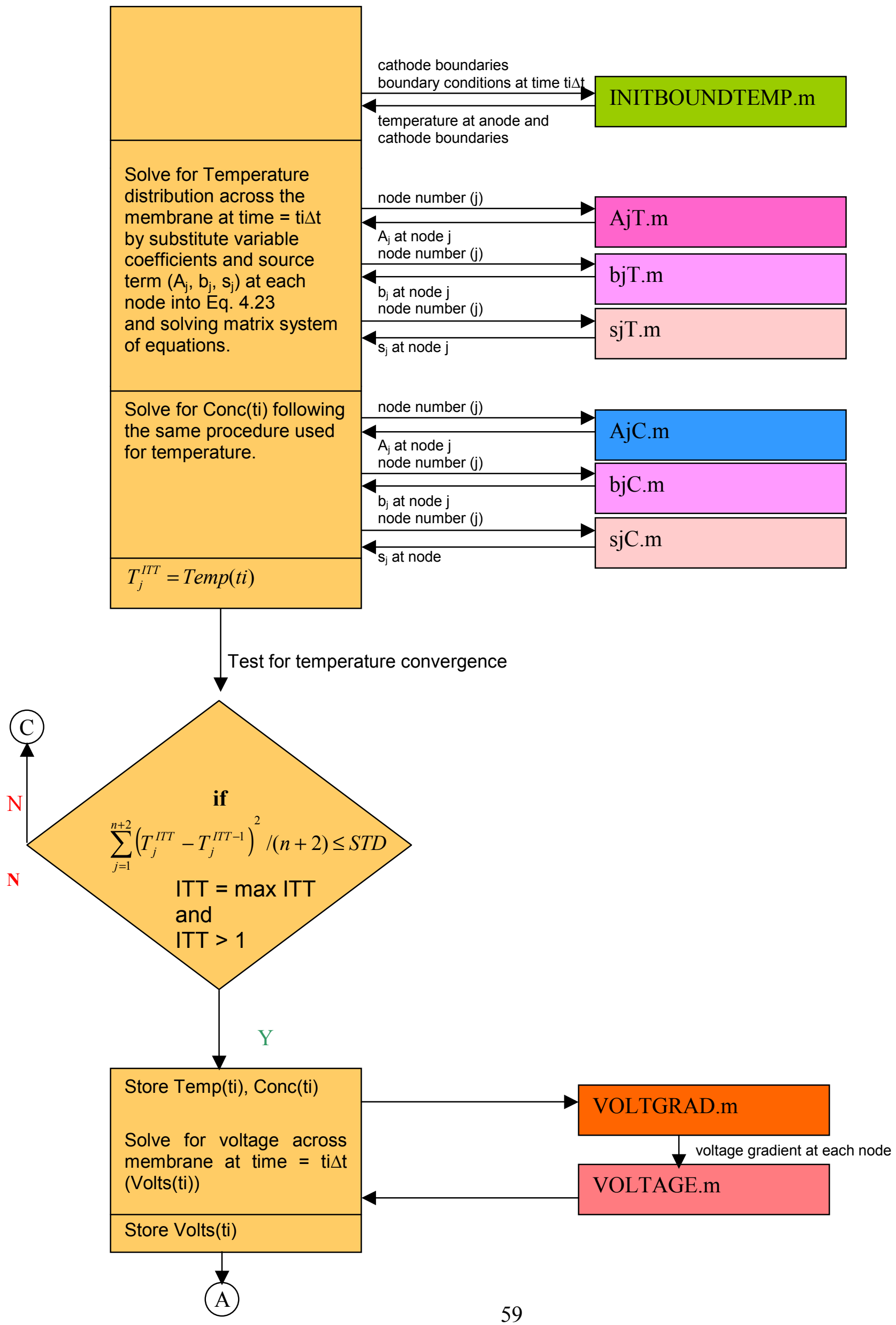




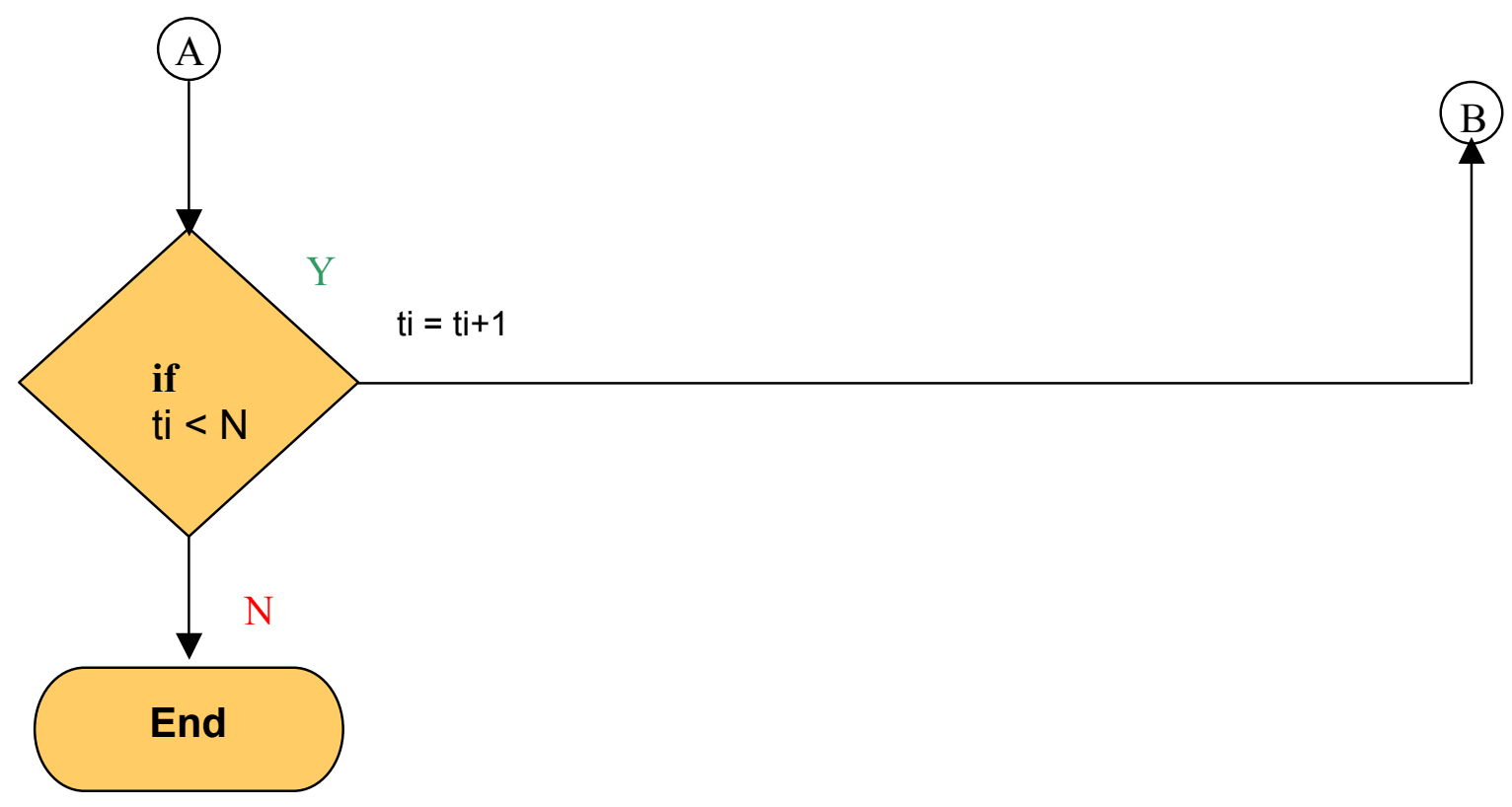

Figure 4.5 Program flowchart.

It can be seen that START.m passes boundary conditions, geometry, and numerical solution parameters to MAIN.m to start the solution process. MAIN.m takes this information and calls INITBOUNDTEMP.m, INITBOUNDCONC.m, and INITBOUNDVOLT.m (which calls VOLTGRAD.m and VOLTAGE.m) to establish initial conditions for temperature, water concentration, and voltage. MAIN.m then begins to solve for temperature, water concentration, and voltage across the membrane for each time step $n$.

Temperature is solved for before concentration. As stated earlier, the finite difference scheme described in Eq. (4.23) is used to approximate the thermal energy conservation equation for the membrane (Eq. (3.16)). First, the variables $A_{j}, b_{j}$, and $s_{j}$ must be determined at each node for the time step, $n+1$, being solved for and for the previous time step, $n$. Functions AjT.m, bjT.m, and sT.m are sent node values and return $A_{j}, b_{j}$, and $s_{j}$ at that node. $A_{j}, b_{j}$, and $s_{j}$ are also functions of temperature, water concentration, and voltage gradient. The temperature, water concentration, and voltage gradient used to evaluate $A_{j}, b_{j}$, and $s_{j}$ at time step $n+1$ is the temperature, water concentration, and voltage gradient from the previous iteration within the same time step. This insures that 
each coefficient is calculated using updated variables. After $A_{j}, b_{j}$, and $s_{j}$ have been determined at each node for $t=(n+1) \Delta t$ and $t=n \Delta t$, a matrix is created using $A_{j}^{n+1}$ and $b_{j}^{n+1}$ values and a load vector is formed using boundary conditions and $A_{j}^{n}, b_{j}^{n}, s_{j}^{n}$ and $s_{j}^{n+1}$ values. Temperatures at each node at $t=(n+1) \Delta t$ are then found by solving this matrix system of equations.

The same process is followed to obtain water concentration values at each node for $t=$ $(n+1) \Delta t$. Calling functions AjC.m, bjC.m, and sC.m, the equation for water species conservation, Eq. (3.9), is approximated and solved.

The temperature solution is then tested for convergence. Two loops exist, one for each time step and one that tests for temperature convergence within the time step loop. There are three conditions on the temperature convergence loop. They are

- $\quad \frac{\sum_{j=1}^{n+2}\left(T_{j}^{I T T}-T_{j}^{I T T-1}\right)^{2}}{n+2} \leq S T D$ (STD is a number set by the user based on a desired maximum deviation from the previous time step.)

- $\quad$ number of iterations $=$ maximum number of iterations (maximum number set by the user)

- $\quad$ number of iterations $=1$

The loop is written so that if either of the first two conditions is true and the third condition is false, the loop stops and the program solves for voltage drop across the membrane and then moves on to the next time step. The first time through the convergence loop, the array of values for $T_{j}^{I T T-1}$ is taken from the previous time step. Each time through the loop, if $\sum_{j=1}^{n+2}\left(T_{j}^{I T T}-T_{j}^{I T T-1}\right)^{2} /(n+2) \geq S T D, T_{j}^{I T T-1}$ values are updated to the most recent temperature solution. The third condition insures that the program runs through the loop at least two times. 
Once convergence on temperature has been reached, voltage drop across the membrane is calculated when MAIN.m calls VOLTGRAD.m and VOLTAGE.m. VOLTGRAD.m calculates the voltage gradient at each node and VOLTAGE.m takes these gradients and a voltage at the anode side catalyst layer-membrane interface and calculates the voltage at each node across the membrane. After voltages have been found, the time loop in MAIN.m moves on to the next time step. The process of finding the temperature and water content in the membrane then repeats itself for the next time step until all time steps are complete. Lastly, results are plotted. Some results currently being generated are average membrane resistance, water content in the membrane, water diffusion coefficient in the membrane, and transient temperature, water concentration, and voltage profiles across the membrane.

\subsubsection{Code Validation}

The major difficulties associated with using the finite difference scheme in Eq. (4.23) for the membrane was validating that the scheme was programmed correctly and that variable coefficients of the membrane equations $\left(A_{j}, b_{j}\right.$, and $\left.s_{j}\right)$ were being calculated correctly based on Eqs. (3.9) and (3.16).

In order to validate that the algorithm (Eq. (4.23)) was coded correctly the following method was used:

1. An exact solution was assumed.

2. Variable coefficients $a(x, t)$ and $b(x, t)$ were assumed.

3. The exact solution was differentiated with respect to $x$ and $t$.

4. The source term was calculated so that the exact solution assumed was the actual solution. 
Assumed Exact Solution: $\quad u(x, t)=x^{2} t+x$

Variable Coefficients: $\quad a(x, t)=3 x+20 t \quad b(x, t)=t+2 x$

Derivatives: $\quad \partial u / \partial x=2 x t+1 \quad \frac{\partial}{\partial x}\left(a(x, t) \frac{\partial u}{\partial x}\right)=12 x t+40 t^{2}+3$

$\partial u / \partial t=x^{2}$

Source Term:

$$
\begin{aligned}
& x^{2}=12 x t+40 t^{2}+3+(t+2 x)(2 x t+1)+s \rightarrow \\
& s=x^{2}-\left(4 x^{2} t+2 x t^{2}+12 x t+40 t^{2}+2 x+t+3\right)
\end{aligned}
$$

Using this method, the code was tested, and the effect of different solution parameters and geometry were investigated. Figure 4.6 shows the effect grid refinement had on the approximated solution's accuracy. It illustrates that as more nodal points are used in the $\mathrm{x}$ and t-directions the approximate solution moves closer to the exact solution (shown in red). The blue lines show the approximate solution produced by the code for a grid spacing of 25 nodes in the x-direction and 25 nodes in the t-direction. When the node number was increased to 100 nodes in each direction the approximate solution (shown in green in Figure 4.6) better approximates the exact solution. These results helped validate that the code was in fact functioning properly.

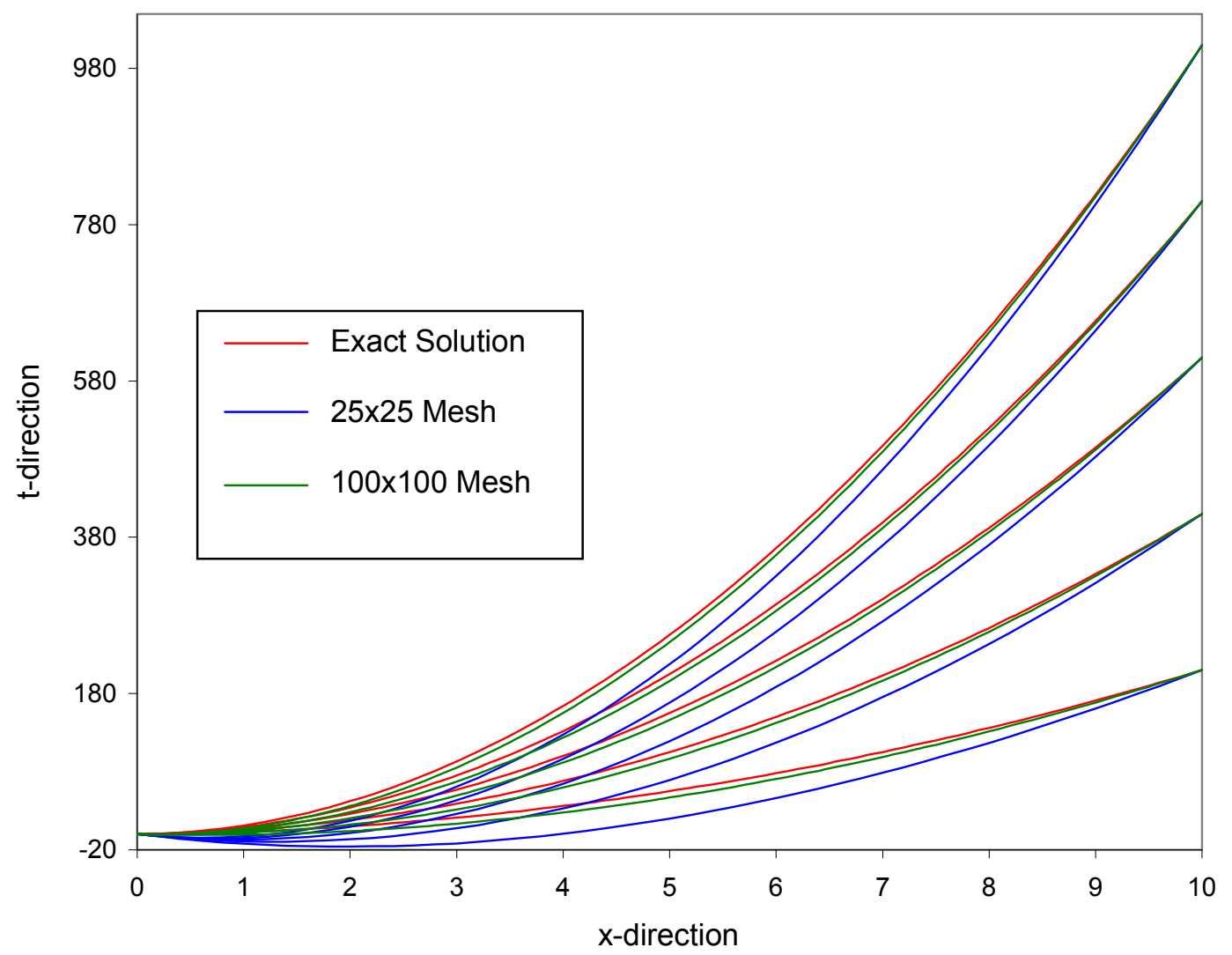

Figure 4.6 Code validation. 
After it was established that the algorithm was programmed into the code correctly, the code was tested to determine whether the variable coefficients in Eqs. (3.9) and (3.16) were being calculated correctly. Excel was used to calculate each coefficient for given boundary conditions, temperatures, and water concentrations. These coefficients were checked against the same coefficients being produced by the code. If differences were found, it indicated that an error inputting the equations had been made. The equations programmed into Excel and the MATLAB code were then compared to the mathematical model for the membrane and corrections were made to whichever one contained the error. This process was repeated until the equations programmed into both the code and Excel matched the equations for the membrane model and the Excel coefficients and code coefficients matched one another.

\subsection{Finite Element Approach}

Currently, efforts are being made to solve the membrane model using a finite difference approach and then collapsing those results down to nodal values on the y-z plane that can be used in a finite element approximation of the rest of the fuel cell model (collector plates, gas channels, gas diffusers/electrodes, and catalyst layers). Blue Ridge Numerics of Charlottesville, Virginia has provided Virginia Tech with a one-dimensional shell element $\mathrm{C}$ routine, specel1d, that interfaces with CFDesign (their CFD code). The routine solves for multiple nodes in the membrane and catalyst layers and then transfers this information to the rest of the fuel cell model.

CFDesign is a computational fluid dynamics program that interfaces with a CAD modeling software (in Virginia Tech's case SDRC's I-DEAS). CFDesign is capable of solving three-dimensional heat and mass transfer problems. To use CFDesign to solve the entire fuel cell model, CFDesign must be modified to handle multi-species flow, electro-chemical effects, and have the governing equations of the fuel cell model programmed into the source code. Blue Ridge Numerics has begun to make these modifications. At Virginia Tech, I-DEAS models are being created to approximate the 
geometry of the collector plate flow channels. In addition, source code from CFDesign is being studied so that it can be modified to solve the governing equations outlined in Olsommer (2000).

The current plan is to take the one-dimensional shell element routine and alter it to include the thermal energy, species, and potential conservation equations for both catalyst layers and the membrane. Virginia Tech will create a separate routine (USERVAR) that calculates variable values at each node and supplies them to the shell element routine (specel1d). Using these variables, the variable coefficients of the conservation equations will be calculated at each node between two interface points in one dimension perpendicular to the $\mathrm{y}-\mathrm{z}$ plane. A finite difference approximation will then be used to solve for species concentrations, temperatures, and voltages in the catalyst layers and membrane. Nodal solutions will exist for all these variables in the x-direction. These nodal solutions are then collapsed down into representative values at the nodes on the $y-z$ plane that interface with the anode and cathode backing layers. Only these nodes that interface with the anode and cathode backing layers will be used for the finite element approximation of the entire fuel cell model. By collapsing the nodal solutions across the catalyst layers and membrane down to only nodes on the anode and cathode backing layer/catalyst layer interface, effects within the catalyst and membrane are included in the larger fuel cell model without introducing the complication of solving for many nodes across a very short distance. 


\section{Chapter 5. Results}

The results presented in this section represent a few of the many possible transient operating conditions the fuel cell membrane model may experience. Current density, anode and cathode pressure, gaseous water concentrations, temperatures, saturation ratios, or water concentration and temperature gradients can be specified at each time step to simulate the transient behavior of the fuel cell. These results will help to demonstrate the membrane model's ability respond to different transient boundary conditions and will illustrate some of the transport phenomena occurring within the membrane.

\subsection{Influence of Transient Boundary Conditions}

Currently, the membrane model is programmed to act as a stand-alone model to which initial and transient boundary conditions are specified and from which transient temperature, water concentration, and voltage profiles across the membrane are produced. To solve the transient problem, the model requires boundary conditions that either specify the temperature and water concentration at the anode and cathode boundaries or the temperature and water concentration gradients at these boundaries. In addition, pressures at the boundaries and current density must be given at each time step.

To establish a concentration and temperature at a boundary, the saturation ratio, gaseous water concentration, and temperature at the catalyst-membrane boundary must be given. The difficulty in generating relevant results using this method to solve the membrane model is that the variables stated above must reflect the transient behavior of the fuel cell as a whole. The problem of providing transient boundary conditions will be experienced by anyone using any of the individual component models of the completed fuel cell model. In the future, this task should become easier because inlet boundary conditions (gas flows and ambient temperatures) are much better understood and more easily measured than internal boundary conditions such as saturation ratios, temperatures, and gaseous concentrations at the catalyst-membrane interface. When the overall fuel cell model is solved in its entirety, linked models will calculate these internal boundary 
conditions based on the transient behavior of the fuel cell and provide them to the membrane model. Currently this responsibility falls to the user of the model.

To avoid the problem of specifying concentrations and temperatures at the boundaries for each time step, the membrane model was adapted to allow for the application of gradients (or fluxes) as boundary conditions. This allows the membrane model to determine a water concentration and a temperature at the catalyst-membrane boundary based on a specified flux, and doesn't require specific values for saturation ratio, gaseous water concentration, and temperature to be given after initial conditions are specified.

The results in the following sections will demonstrate some of the phenomena taking place in the membrane and their effect on water concentration, temperature, and voltage across the membrane. Table 5.1 summarizes the initial and boundary conditions used to generate the results presented in the following sections.

Table 5.1 Initial and boundary conditions used to generate results in Figures 5.1 to 5.7c.

\begin{tabular}{|c|c|c|c|c|c|c|c|c|c|}
\hline Figure & 5.1 & 5.2 & $5.3 a$ & $5.3 b$ & $5.4,5.5$ & $5.4,5.5$ & \multicolumn{2}{|l|}{$5.6 a, b$} & $5.7 a, b, c$ \\
\hline \multicolumn{10}{|c|}{ Initial Conditions (all Initial Boundary Conditions are Fixed) } \\
\hline \multicolumn{10}{|c|}{ Gaseous Water Concentration $\left(\mathrm{mol} / \mathrm{m}^{3}\right)$} \\
\hline anode & 5 & 5 & 5 & 5 & \multicolumn{2}{|l|}{5} & \multicolumn{2}{|l|}{5} & 0.82 \\
\hline cathode & 9.5 & 9.5 & 9.5 & 9.5 & \multicolumn{2}{|l|}{9.5} & \multicolumn{2}{|l|}{9.5} & 1.6 \\
\hline \multicolumn{10}{|c|}{ Temperature $(\mathrm{C})$} \\
\hline anode & 69.85 & 69.85 & 69.85 & 69.85 & \multicolumn{2}{|l|}{69.85} & 69.85 & 69.85 & 25.00 \\
\hline cathode & 69.855 & 69.855 & 69.855 & 69.855 & \multicolumn{2}{|l|}{69.855} & 69.855 & 69.95 & 25.005 \\
\hline \multicolumn{10}{|c|}{ Transient Boundary Conditions (Boundary Conditions are Fixed (Dirichlet) or Flux (Nuemann)) } \\
\hline \multicolumn{10}{|c|}{ Gaseous Water Concentration (Fixed: $\mathrm{mol} / \mathrm{m}^{3}$, Flux: $\mathrm{mol} / \mathrm{m}^{4}$ ) } \\
\hline anode & Fixed: 5 & Fixed: 5 & Flux: 0 & Flux: 0 & \multicolumn{2}{|l|}{ Flux: 0} & \multicolumn{2}{|l|}{ Fixed: 5} & Flux: 0 \\
\hline cathode & Fixed: 9.5 & Fixed: 9.5 & $\begin{array}{l}\text { Flux: } \\
9.2 \mathrm{E} 7\end{array}$ & $\begin{array}{l}\text { Flux: } \\
-9.2 E 7\end{array}$ & $\begin{array}{l}\text { Flux: } \\
9.2 \mathrm{E} 7\end{array}$ & $\begin{array}{l}\text { Fixed: } \\
9.5\end{array}$ & \multicolumn{2}{|c|}{ Fixed: 9.5} & Flux:0-9.2E7 \\
\hline \multicolumn{10}{|c|}{ Temperature (Fixed: ${ }^{\circ} \mathrm{C}$, Flux: ${ }^{\circ} \mathrm{C} / \mathrm{m}$ ) } \\
\hline anode & Fixed: 69.85 & Fixed: 69.85 & $\begin{array}{l}\text { Fixed: } \\
69.85\end{array}$ & $\begin{array}{l}\text { Fixed: } \\
69.85\end{array}$ & \multicolumn{2}{|c|}{ Fixed: 69.85} & \multicolumn{2}{|c|}{ Fixed: 69.85} & $\begin{array}{l}\text { Fixed: } \\
25-80\end{array}$ \\
\hline cathode & Flux: 22 & Flux: 22 & Flux: 22 & Flux: 22 & Flux: 22 & & 69.855 & 69.95 & Flux: 22 \\
\hline \multicolumn{10}{|c|}{ Pressure (atm) } \\
\hline anode & 1.86 & 0.93 & 1.86 & 1.86 & \multicolumn{2}{|l|}{1.86} & 1.86 & & 1.86 \\
\hline cathode & 2.56 & 3.83 & 2.56 & 2.56 & 2.56 & & 2.56 & & 2.56 \\
\hline $\begin{array}{l}\text { Current } \\
\text { Density } \\
\left(\mathrm{A} / \mathrm{cm}^{2}\right)\end{array}$ & 0.1 & 0.6 & 0.6 & 0.6 & 0.6 & & 0.6 & & 0.2 \\
\hline $\begin{array}{l}\text { Data } \\
\text { Plotted }\end{array}$ & $\begin{array}{l}\text { Water Conc. } \\
\text { vs. Thickness }\end{array}$ & $\begin{array}{l}\text { Water Conc. } \\
\text { vs. Thickness }\end{array}$ & $\begin{array}{l}\text { Tempera } \\
\text { ture vs. } \\
\text { Thick. }\end{array}$ & $\begin{array}{l}\text { Water } \\
\text { Conc. vs. } \\
\text { Thick. }\end{array}$ & $\begin{array}{l}\text { Temp } \\
\text { Voltage } \\
\text { Thicknes }\end{array}$ & $\begin{array}{r}\text { and } \\
\text { vs. } \\
\text { s }\end{array}$ & $\begin{array}{l}\text { Temper } \\
\text { Thickne }\end{array}$ & ture vs. & $\begin{array}{l}\text { Water } \\
\text { Conc.,Temp. } \\
\text { and Volt. vs. } \\
\text { Thickness }\end{array}$ \\
\hline
\end{tabular}


The red boxes contain the variables changed to reflect certain phenomena such as effect of pressure and current density on water concentration in the membrane and flooding and drying in the membrane. In the Table 5.1, blue represents water concentration initial and boundary conditions, yellow temperature, brown current density, and green pressure.

\subsection{Water Management Within the Membrane}

Within the membrane, water is transported as a result of a diffusive force, a convective force due to an applied pressure gradient, and an electric drag force imposed on the water molecules by the charged protons moving from anode to cathode. To demonstrate the electric drag force, the concentration at both the anode and cathode interface is held constant and the current density is varied. By varying current density, the relative effect of moving more charged particles through the membrane is demonstrated. These results are discussed with Figure 5.1 below.

To demonstrate the effect of the convective force on water transport in the membrane, different pressure gradients were applied across the membrane. The higher the gradient, the more water molecules are moved in the opposite direction to the gradient. These results are discussed in relation to Figure 5.2.

Also in this section on water management, the effects of water flux into and out of the membrane are demonstrated. Figures 5.3a and 5.3b touch on the issues of "flooding" and excessive drying that may occur if water concentrations in the membrane are not controlled.

Finally, all the results in Section 5.2 correspond to the same initial and boundary conditions on temperature and voltage. Due to the coupling between the water, temperature, and voltage equations, the transient temperature and voltage profiles that result are not the same. The coupling effects of water concentration on temperature and voltage are demonstrated in Figures 5.4 and 5.5. The exact boundary conditions used to generate all the figures in Section 5.2 are summarized in Table 5.1. 


\subsubsection{Effects of Electric Drag}

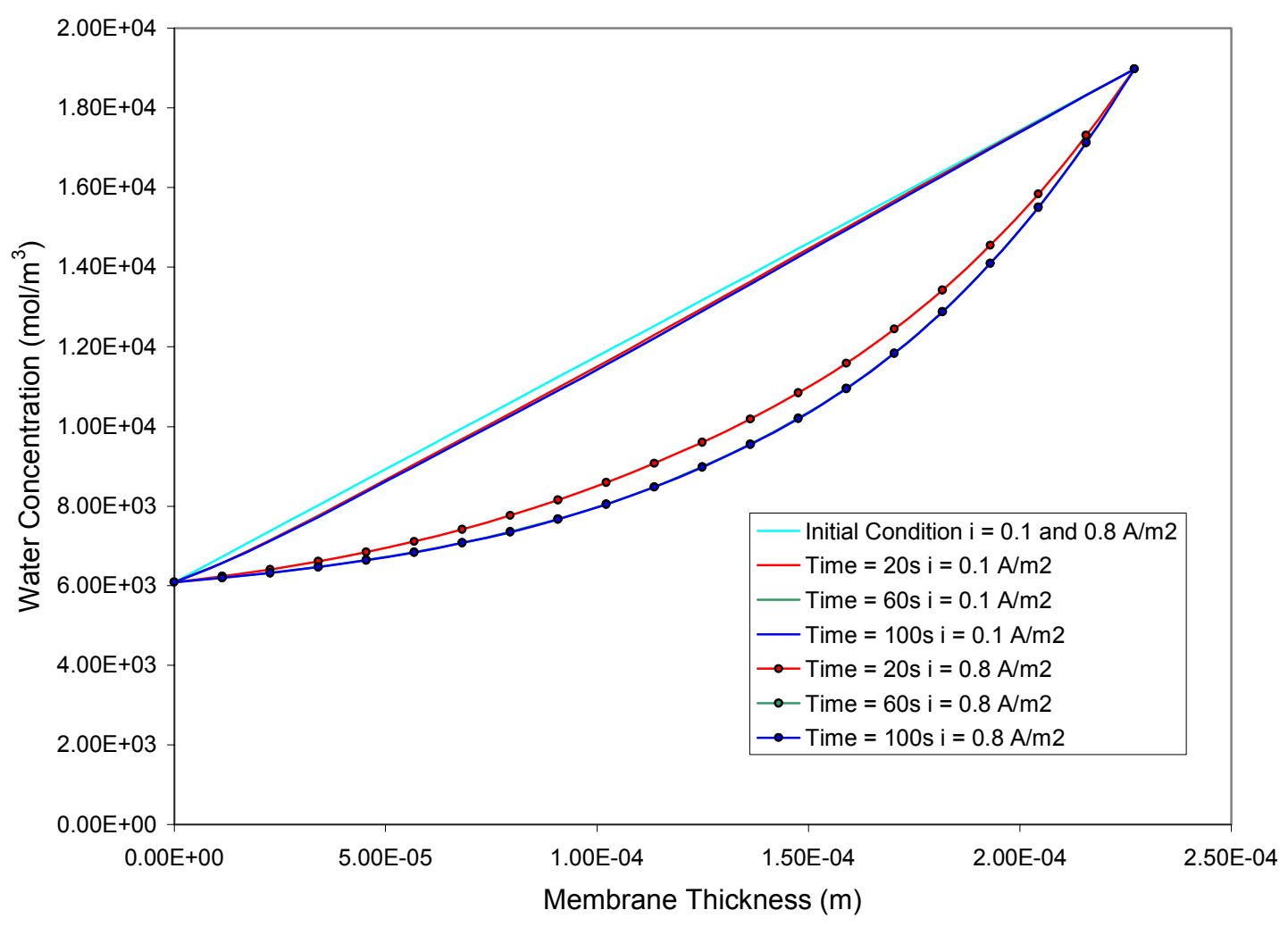

Figure 5.1 Effect of current density on water concentration.

Figure 5.1 demonstrates the effect of the electric drag force. As current density increases, more protons migrate from the anode where they are produced to the cathode where they are consumed. As they migrate, the charged protons drag the dipole water molecules with them from anode to cathode. Figure 5.1 shows how the water concentration in the membrane changes through time with an applied current density. The solid lines show water concentration with an applied current density of $0.1 \mathrm{~A} / \mathrm{cm}^{2}$. The lines with dots show water concentration at the same time steps and the same applied boundary conditions but with an applied current density of $0.8 \mathrm{~A} / \mathrm{cm}^{2}$. Analyzing the results, it can be seen that water concentration on the anode side for a given time step is lower with the higher applied current density. This is because the higher current density drags more 
water molecules towards the cathode side. It is also true that overall water content in the membrane is lower with the higher current density. This is because the increased protonic current is dragging more water molecules out of the membrane.

\subsubsection{Effect of Pressure Gradients}

Figure 5.2 demonstrates the effect of pressure gradient on water concentration in the membrane. A positive pressure gradient can be established between the anode and cathode to force water molecules from cathode to anode.

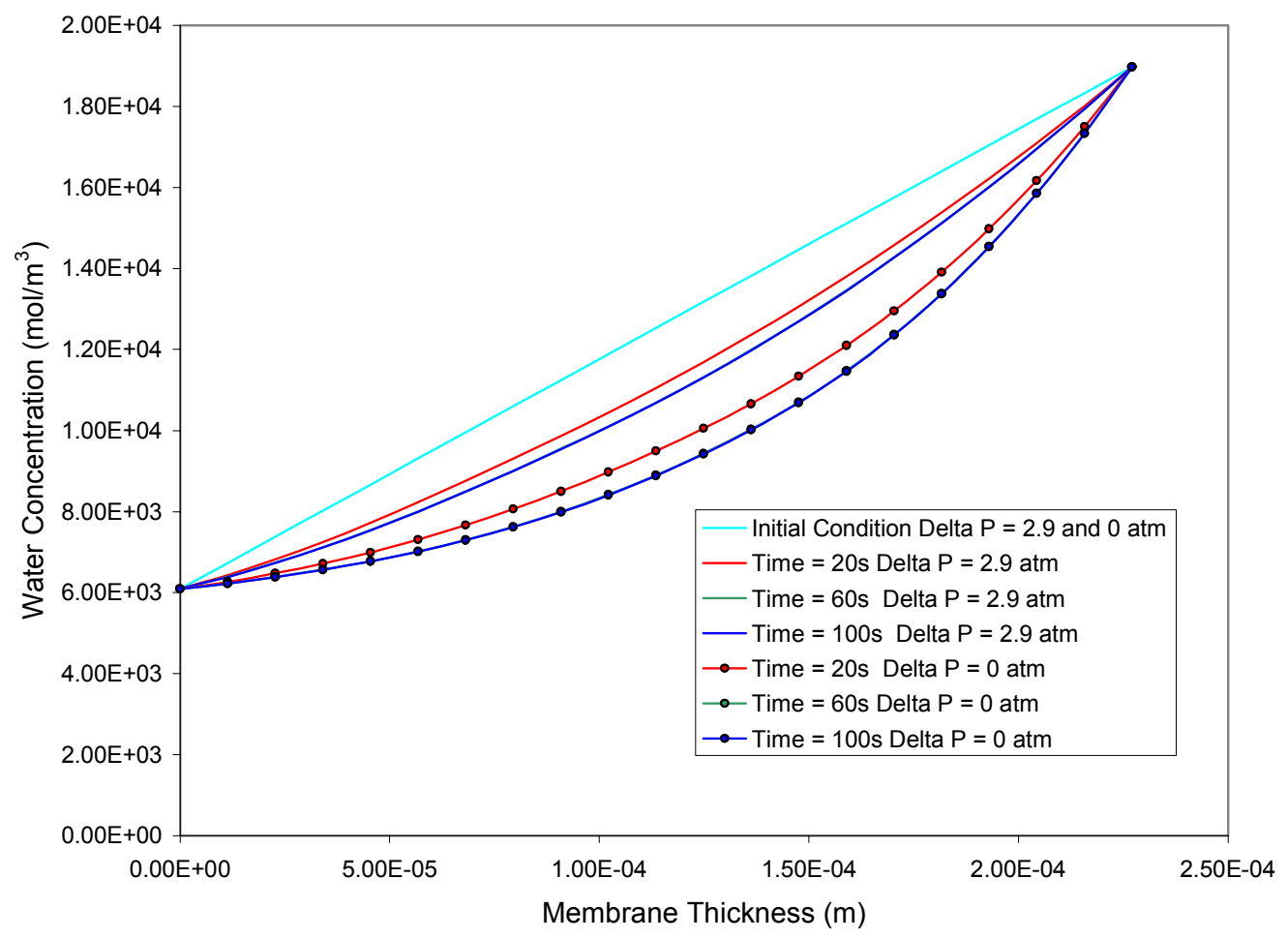

Figure 5.2 Effect of pressure gradient on water concentration.

This boundary condition can be established to help keep the anode side of the membrane hydrated. Anode side drying is more of an issue than cathode side drying because water content is usually higher on the cathode side. This is because water is produced at the cathode and water molecules are driven from the anode to the cathode due to the drag force illustrated in Figure 5.1. 
Figure 5.2 shows how the water concentration in the membrane changes through time with an applied pressure gradient between the anode and cathode. The solid lines show water concentration with an applied pressure gradient of 2.9 atm between the anode and cathode i.e. a pressure of $0.93 \mathrm{~atm}$ was applied as a boundary condition at the anodemembrane interface and a pressure of 3.83 atm was applied at the cathode-membrane interface. These numbers are based on establishing a $2 \mathrm{~atm}$ difference between the anode and cathode inlets (3.5 atm at the cathode compared to $1.5 \mathrm{~atm}$ at the anode) and then estimating the pressure at the anode and cathode side of the membrane for a current density of $0.6 \mathrm{~A} / \mathrm{cm}^{2}$ (Bernardi and Verbrugge, 1992). The lines with dots show water concentration at the same time steps with the same applied boundary conditions but with the pressures at the anode and cathode sides of the membrane set equal, i.e. no applied pressure gradient. Figure 5.2 shows that the water concentration on the anode side is higher when the pressure gradient is applied compared to when no gradient is applied. This figure demonstrates that a positive pressure gradient established between anode and cathode can be used to push water from the cathode side of the membrane to the anode side. Figure 5.2 also demonstrates that the pressure gradient established helps to combat the lose of water brought about by protonic drag on the water molecules, increasing the overall water content in the membrane compared to when no pressure gradient is applied. This figure, thus, shows that applying a positive pressure gradient from anode to cathode is one way membrane water concentration can be managed.

\subsubsection{Effects of Water Flux Entering and Exiting}

Figure 5.3a and 5.3b illustrate the extremes that must be dealt with when managing water concentration in the membrane. In both cases, water fluxes are applied at the boundaries. 


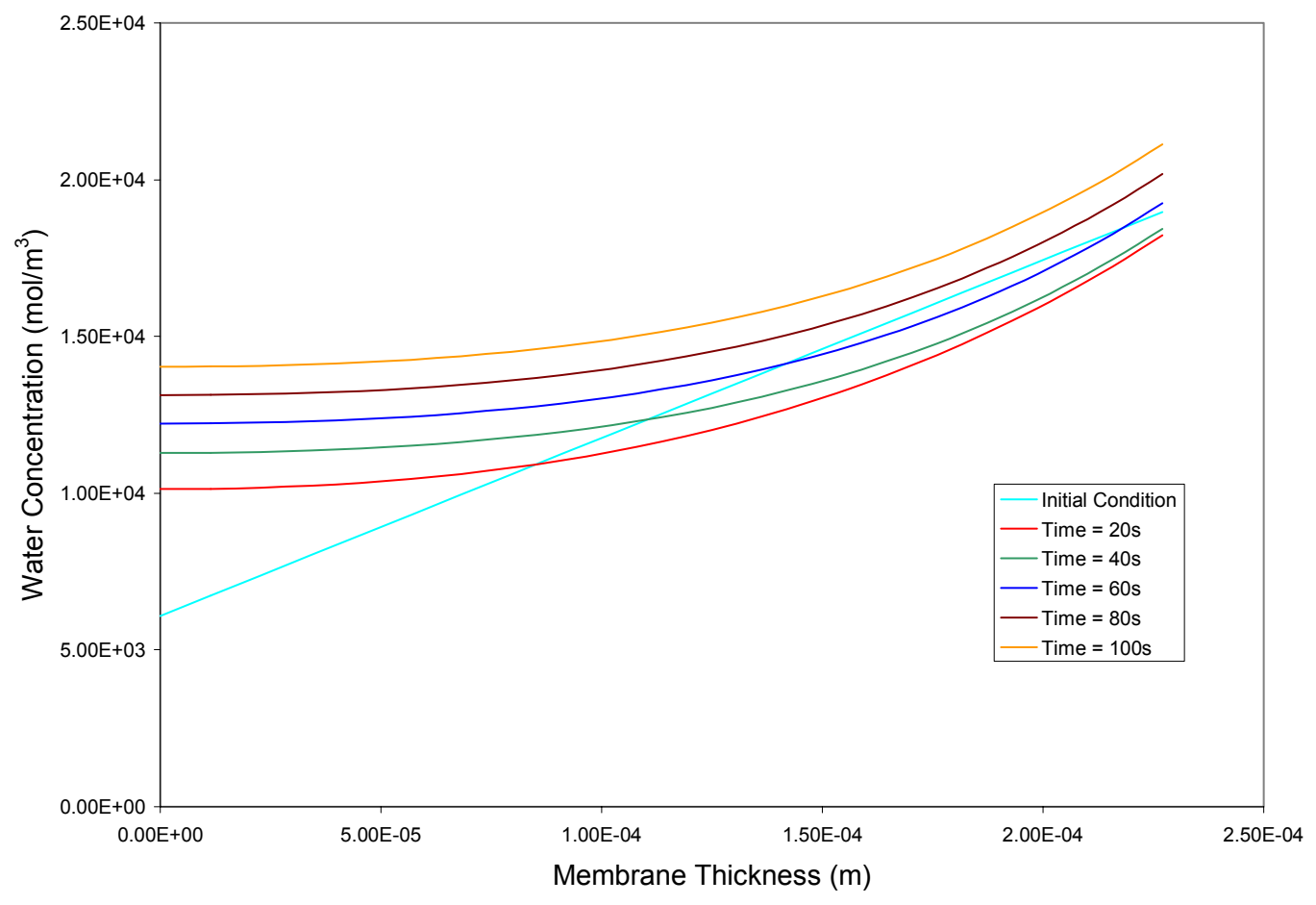

Figure 5.3a Tendency towards flooding in the membrane.

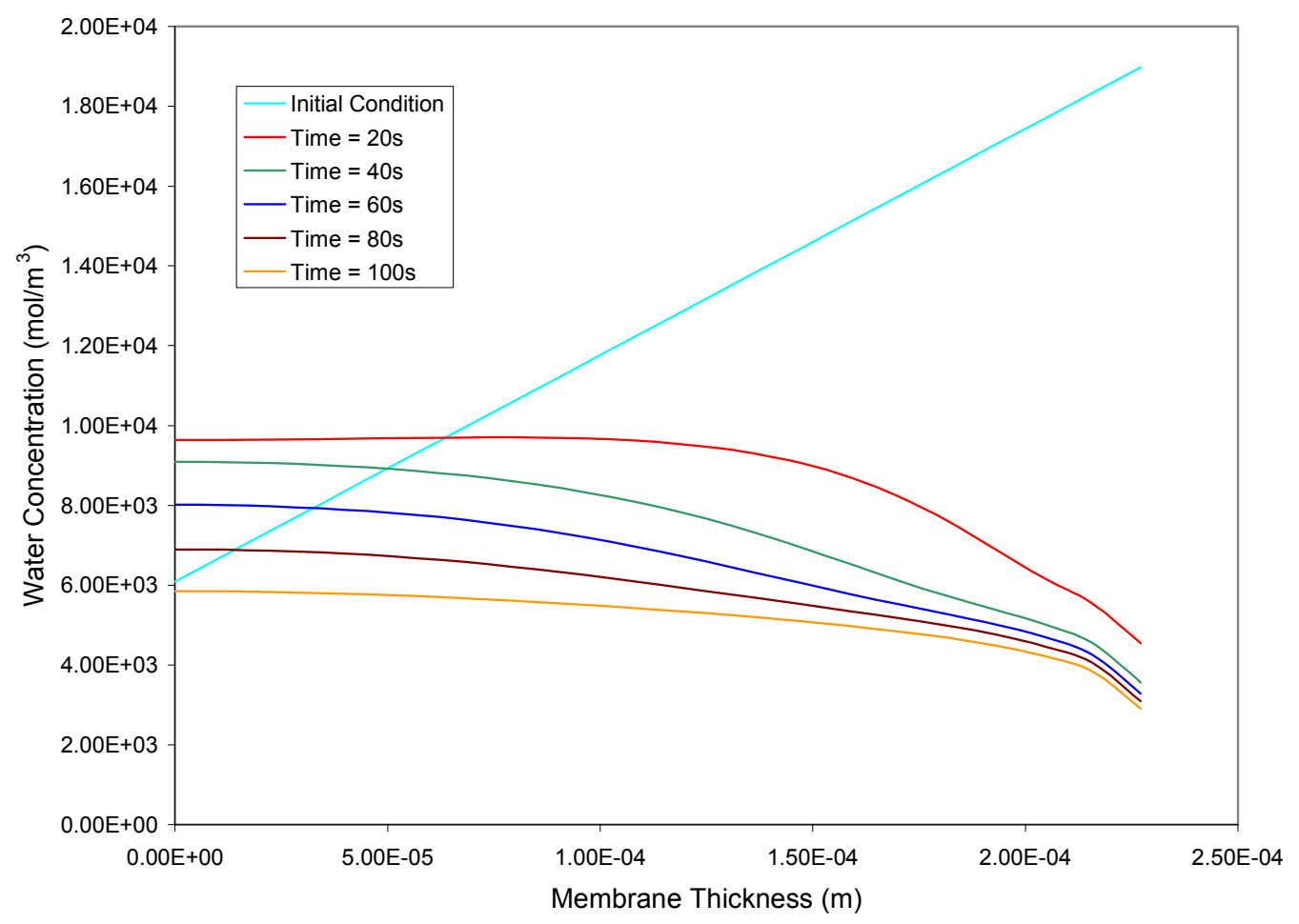

Figure 5.3b Tendency towards drying of the membrane. 
In Figure 5.3a, a zero flux condition is applied at the anode and a positive flux condition is applied at the cathode. This positive flux represents a flux of water into the membrane. The trend demonstrated in Figure 5.3a is one that may eventually lead to "flooding" in the membrane. If water continues to flow into the membrane the overall water content within the membrane will continue to increase until the membrane is saturated and can no longer hold water. Any water produced would then fill the pores of the catalyst layer on the cathode side and cause "flooding." Figure 5.3a demonstrates the importance of removing excess water from the cathode membrane interface through the cathode and collector plate gas channels.

Figure 5.3b shows the opposite extreme to Figure 5.3a. In this case, a zero flux is applied at the anode and a negative flux at the cathode. Figure 5.3b shows that too much water can be removed from the cathode, resulting in a decrease in overall water content in the membrane. If water content becomes too low, the proton conductivity of the membrane could suffer and permanent damage could result at any hot spots on the membrane.

In Figure 5.3b, as the profiles for water concentration approach the cathode an interesting variation in the profile occurs. This can be attributed to the change in diffusion coefficient resulting from transitions from one region of water content to another in the definition of $D^{\prime}$ (Eq. (3.7)). Another test was run with the same boundary conditions as for Figure 5.3b using only Eq. (3.7c) to define $D^{\prime}$. The result was smoother water concentration profiles demonstrating that the original fluctuation was the result of material properties and not numerical errors. Figure 10.9 in Appendix C shows these results. 


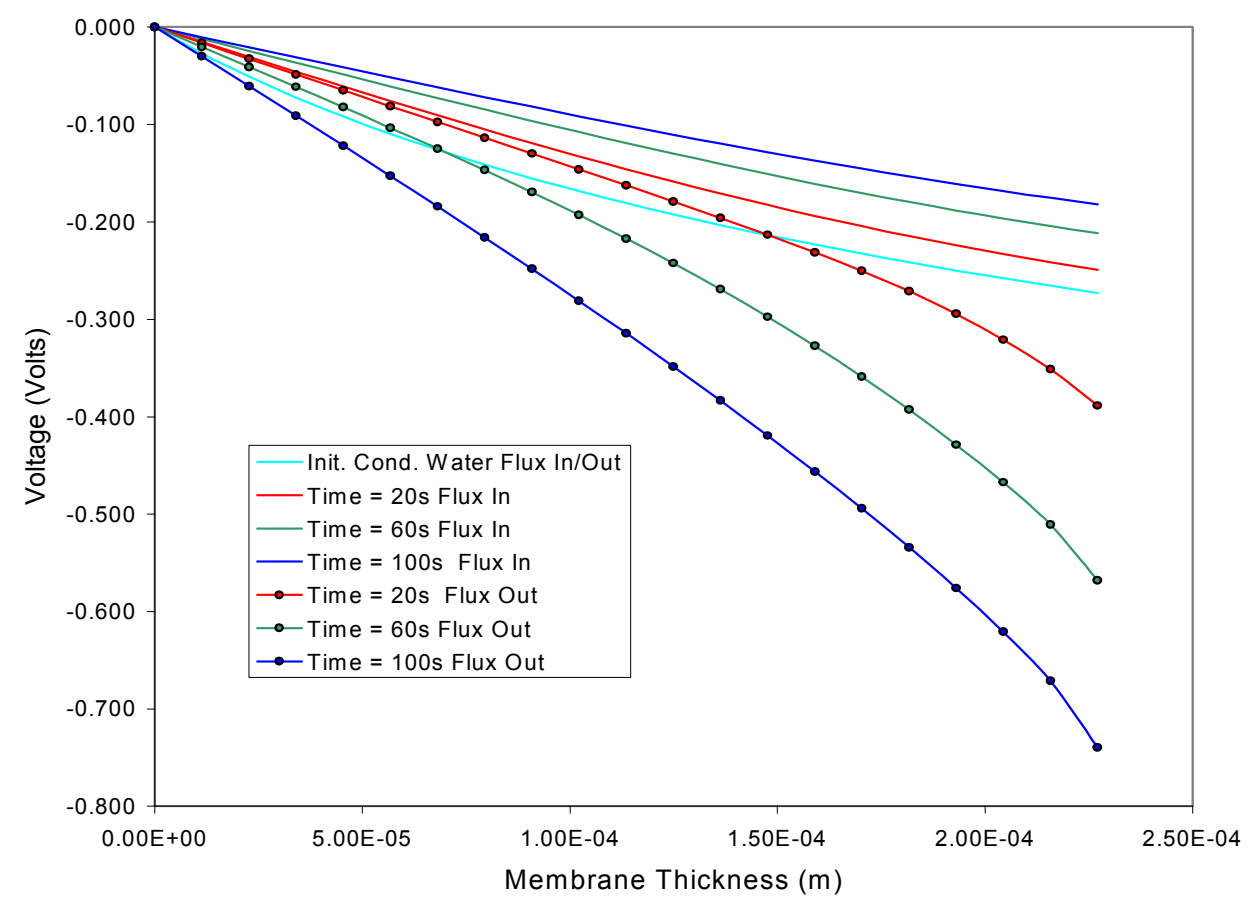

Figure 5.4 Effect of membrane hydration on voltage losses.

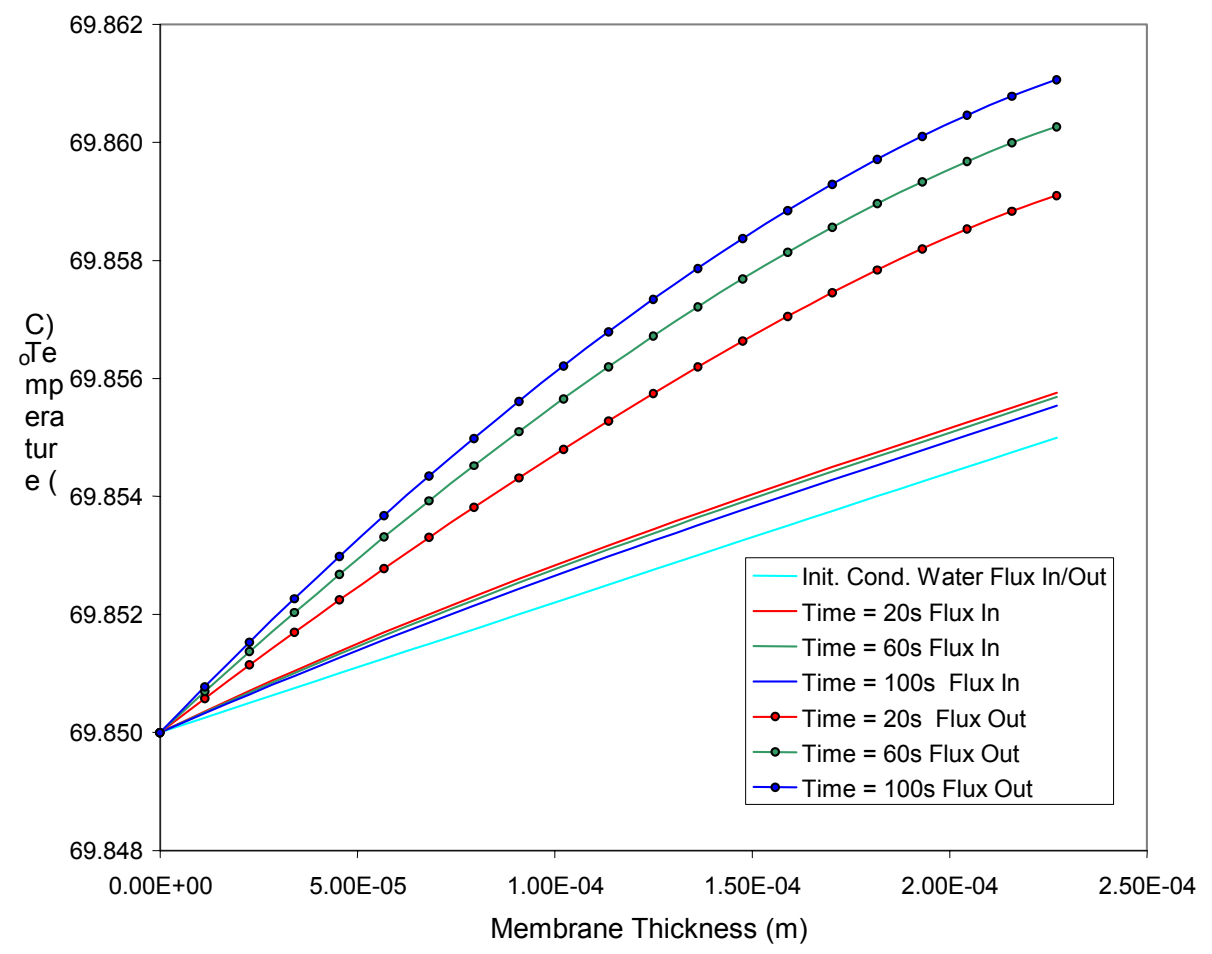

Figure 5.5 Effect of membrane hydration on temperature. 
Figures 5.4 and 5.5 show the effect that water content has on voltage losses and heating of the membrane, illustrating the coupling of water concentration, temperature, and voltage that occurs within the membrane.

Figure 5.4 and 5.5 show the voltage and temperature across the membrane when either there is a water flux into (Figure 5.3a) or out of (Figure 5.3b) the membrane. When water flows into the membrane, the water content increases and membrane conductivity increases. As a result the voltage drop $\left(\Phi_{m, a}-\Phi_{m, c}\right)$ and ohmic heating in the membrane decrease. The voltage drop decrease can be seen in the solid lines of Figure 5.4. The decrease in ohmic heating which is a source term in the thermal energy conservation equation for the membrane is demonstrated by the decrease in temperature inside the membrane, shown as solid lines in Figure 5.5. When water flows out of the membrane the opposite trends are demonstrated. Water content in the membrane decreases and membrane conductivity decreases. As a result, voltage drops across the membrane and ohmic heating and temperatures inside the membrane are greater. These trends are shown with lines in with dots in Figures 5.4 and 5.5.

\subsection{Temperature Profiles within the Membrane}




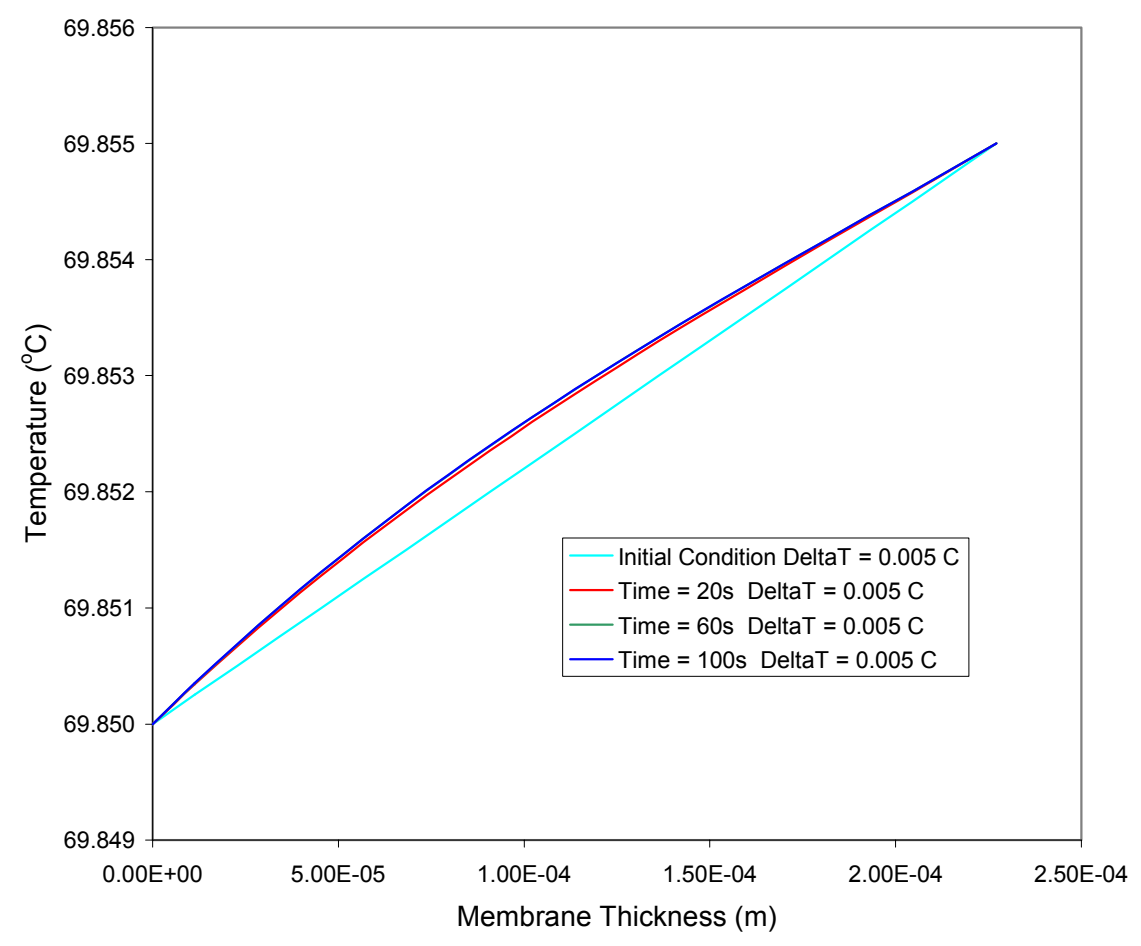

Figure 5.6a Effects of ohmic heating vs convection on the temperature profiles for a $\Delta \mathrm{T}=$ $0.005{ }^{\circ} \mathrm{C}$ across the membrane.

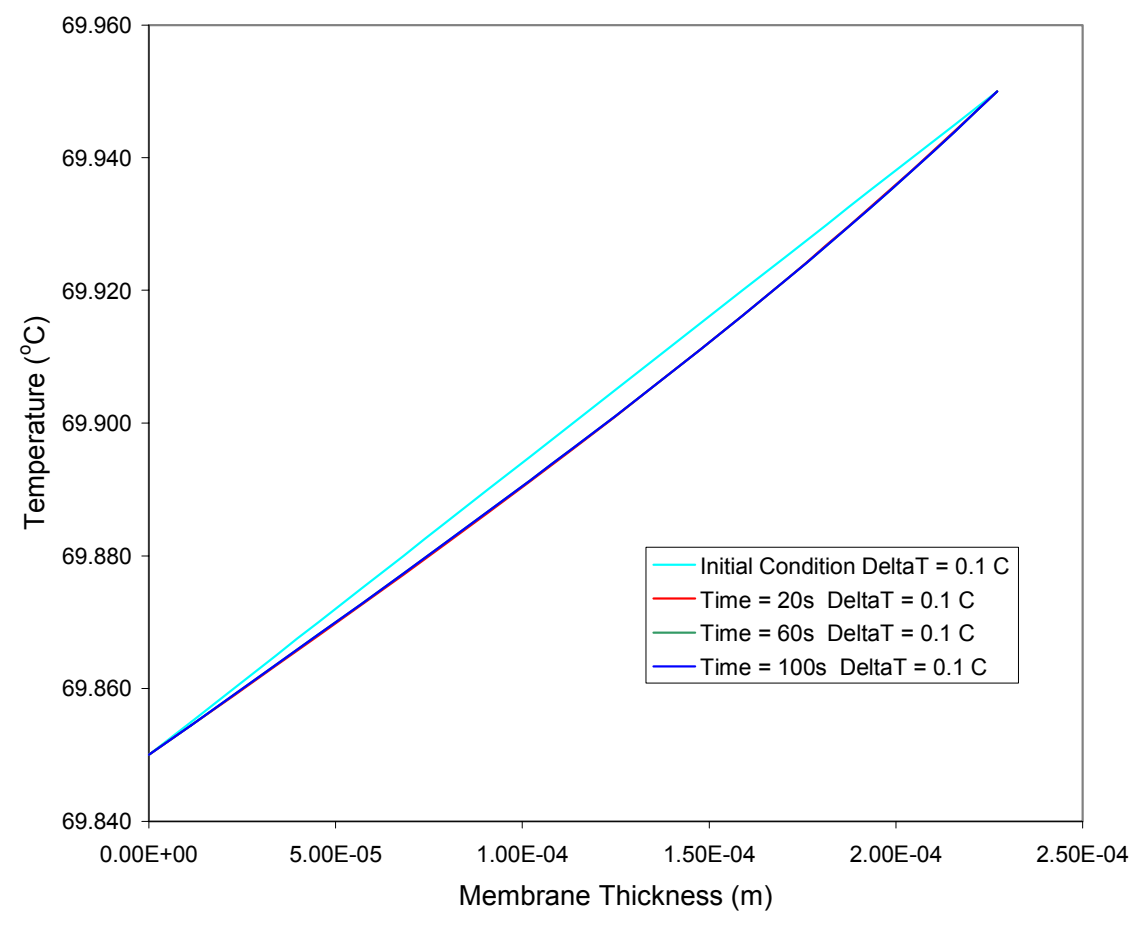

Figure 5.6b Effects of ohmic heating vs convection on the temperature profiles for a $\Delta \mathrm{T}=$ $0.01{ }^{\circ} \mathrm{C}$ across the membrane. 
Figures 5.6a and 5.6b demonstrate boundary conditions that result in different terms in the thermal energy conservation equation dominating. Figure 5.6a shows transient temperature profiles in the membrane when a small temperature gradient $\left(0.005{ }^{\circ} \mathrm{C}\right)$ is established across the membrane. Under such conditions, the source term (ohmic heating) in the temperature conservation equation dominates. This results in a temperature increase across the membrane from the initial conditions established.

Figure 5.6b shows transient temperature profiles in the membrane when a much larger temperature gradient $\left(0.1{ }^{\circ} \mathrm{C}\right.$ as compared to $\left.0.005{ }^{\circ} \mathrm{C}\right)$ is established across the membrane. In this case, convective effects begin to dominate. Even though the source term is still present and supplying energy to the system, the convective effects dominate and temperature decreases across the membrane.

\subsection{Simulated Start-up of a Fuel Cell}

Perhaps the most useful results that can be generated using the transient membrane model are results that demonstrate how water concentration, temperature, and voltage change inside the membrane while boundary conditions change greatly over the time period studied. Such a scenario would illustrate the ability of the model to handle transient boundary conditions. To simulate this scenario boundary conditions that approximate a vehicle start-up were applied to the membrane model. 


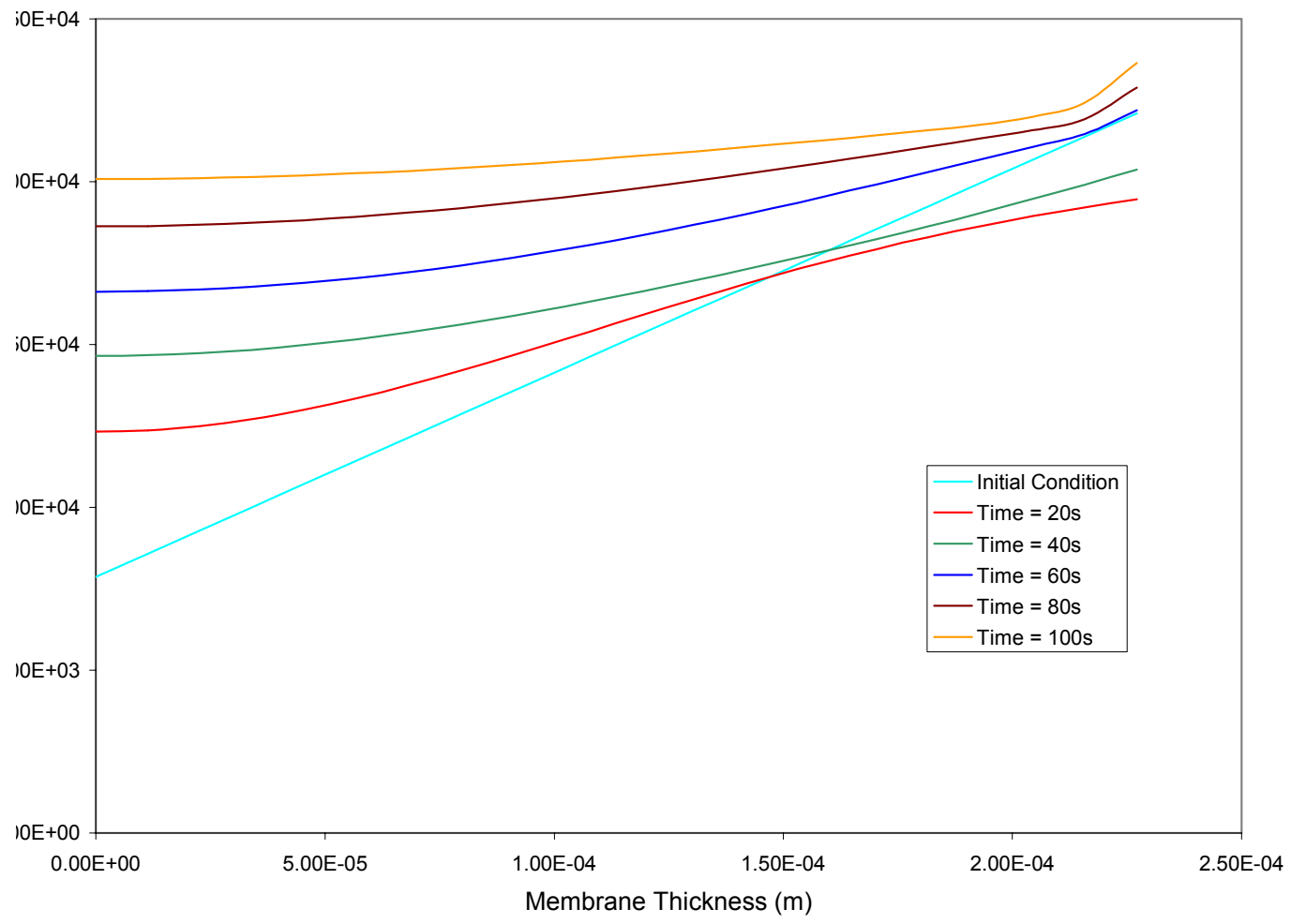

Figure 5.7a Water concentration during start-up.

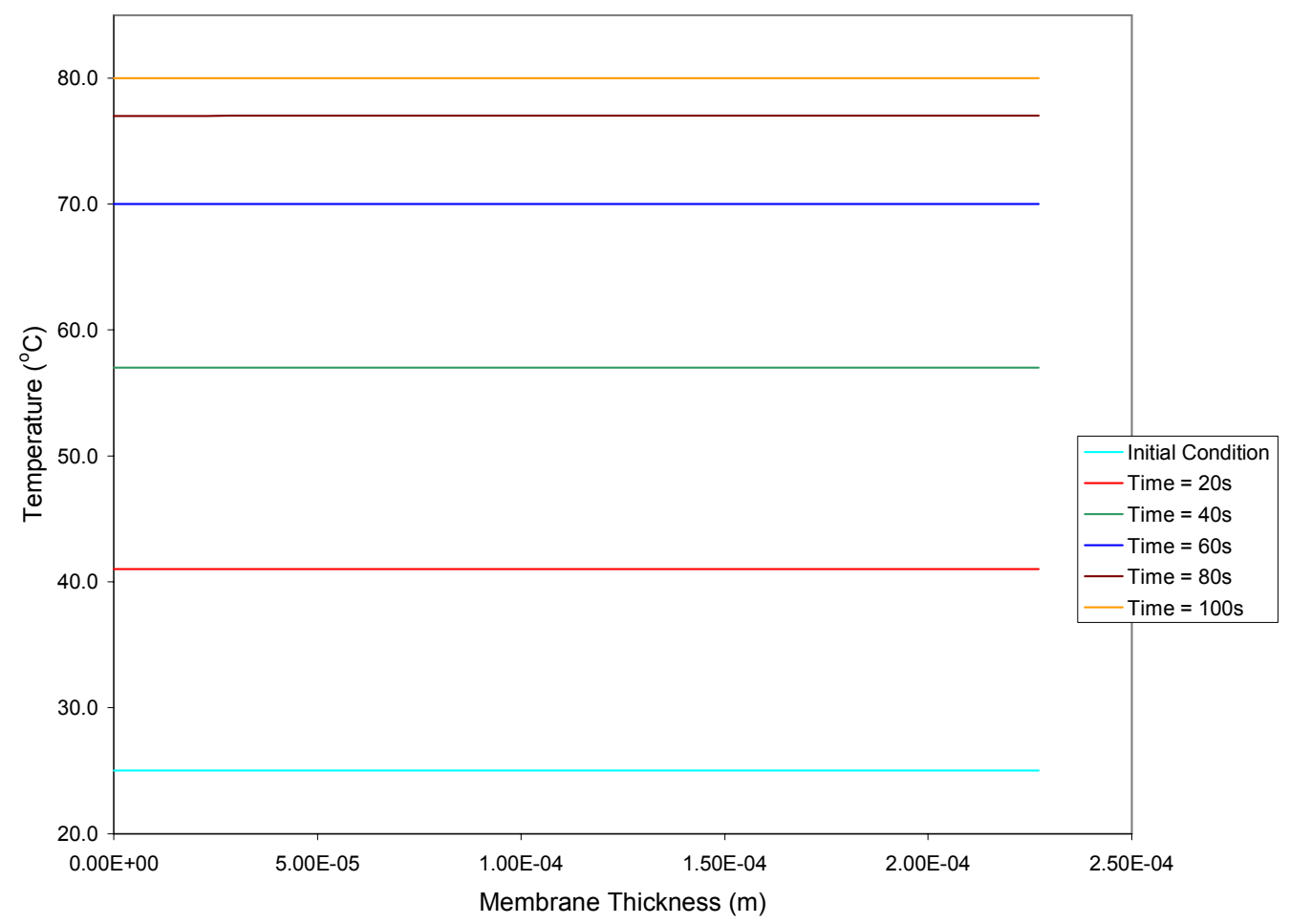

Figure 5.7b Temperature during start-up. 


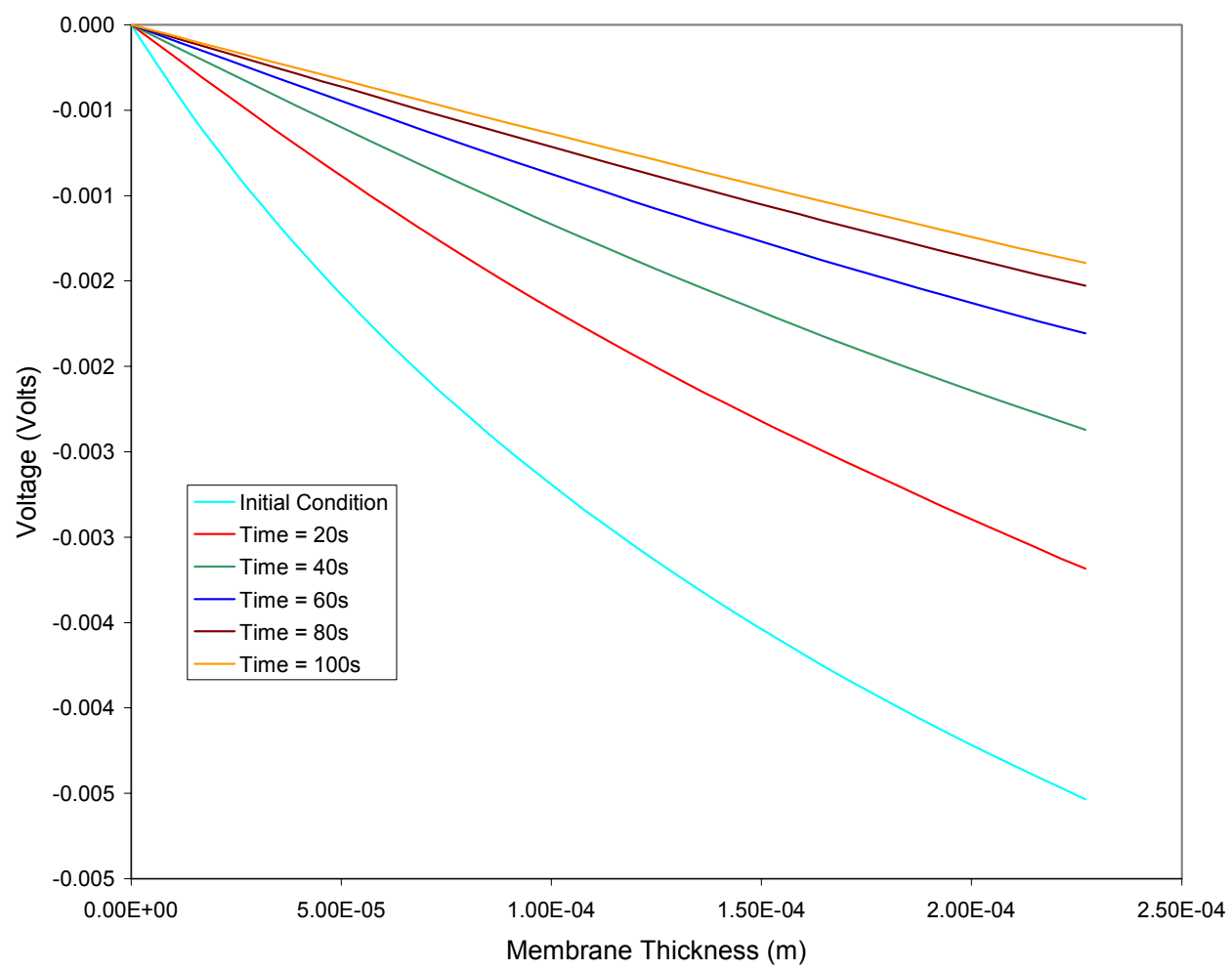

Figure 5.7c Voltage during start-up.

To simulate a vehicle start-up time varying flux boundary conditions at the anode and cathode were used for water concentration while a time varying fixed temperature at the anode as well as and a time varying heat flux at the cathode were used. The exact boundary conditions are specified in Table 5.1. The uniqueness of these boundary conditions relative to the boundary conditions for other results presented in this chapter are that the specified temperature at the anode is varied to approximate the fuel cell stack warming up from $25{ }^{\circ} \mathrm{C}$ to $80{ }^{\circ} \mathrm{C}$ and the water flux into the membrane at the cathode is varied linearly from 0 to $9.27 \mathrm{E} 7 \mathrm{~mol} \mathrm{H}_{2} \mathrm{O} / \mathrm{m}^{4}$. Figures $5.7 \mathrm{a}, 5.7 \mathrm{~b}$, and $5.7 \mathrm{c}$ illustrate the results.

The same trend demonstrated in Figure 5.4 is shown again in Figure 5.7c. As water concentration in the membrane increases, voltage drop across the membrane decreases. As explained earlier this is due to the increase in membrane conductivity brought about by the increase in water concentration in the membrane. An interesting result is that although less water flows into the membrane over the same time period as in the case 
shown in Figure 5.3a, the final water content in the membrane is higher for the simulated start-up. This is the result of a lower specified current density for the simulated start-up compared to the case shown in Figure $5.3 \mathrm{a}\left(0.2 \mathrm{~A} / \mathrm{cm}^{2}\right.$ compared to $\left.0.6 \mathrm{~A} / \mathrm{cm}^{2}\right)$ and the much wider range over which the temperature varies. This result was not expected, but is easily explained when one considers that for the lower current density, less water is removed from the membrane due to the electric drag of protons on the water molecules. In addition, the membrane starts with higher water content in the case shown in Figure 5.7c compared to the case shown in Figure 5.3a. The steep rise in concentration just before the boundary on the cathode side shown in Figure 5.7a is the result of the mathematical model attempting to satisfy an unrealistic boundary condition. This boundary condition was decreased by a factor of three and the test was run again. The result was smoother concentration profiles similar to those shown in Figure 5.3a. 


\section{Chapter 6. Conclusions and Recommendations}

\subsection{Conclusions}

Based on my research on membrane performance and the time spent studying the governing equations and closure relations developed by Olsommer (2000) for a PEMFC in general and its membrane in particular, a clearer understanding of the phenomena occurring in a PEMFC and its membrane was obtained. In addition, developing the transient, finite difference model for the mathematical model of the membrane itself required a much deeper, more detailed understanding of the derivation and use of numerical approximation schemes. In particular, the difficulties encountered due to the presence of extremely small spatial dimensions as well as variable coefficients required many changes to the numerical approximations employed, resulting in a much better understanding of finite difference schemes in general for partial differential equations. All finite difference schemes developed were validated using generic equations while the species conservation equation for water and the thermal energy conservation equation were programmed into a transient finite difference scheme for variable coefficients and validated among other things by comparing the output against both in-house results (Excel spreadsheets) and published results (Springer, 1992).

In analyzing the results obtained, it is apparent that the model developed for the membrane can be a very powerful future design tool. The model solutions demonstrated many of the phenomena observed in proton exchange membranes and permitted more detailed analyses of each. In particular, the following effects were observed:

- $\quad$ The effect of an applied current density on water concentration demonstrated that the higher the current density, the more water is driven from the anode to the cathode and out of the membrane.

- $\quad$ The effect of an applied pressure gradient on water concentration was to show that a positive pressure gradient from anode to cathode could be used to drive water toward the anode, hydrating the anode side which is more likely to dry out. 
- The effect of water flux into and out of the membrane illustrated that if too much water flows into the membrane, flooding may occur, whereas, if too much water is removed from the membrane drying may occur. These results seem obvious, but the value of the membrane model is that it allows these phenomena and their effect on temperature and voltage to be quantified and studied in detail.

Finally, the results showed that the model is capable of predicting transient water concentration, voltage, and temperature profiles for transient boundary conditions. This capability will prove useful when attempting to develop a control strategy for the fuel cell and when investigating highly transient processes such as fuel cell start-up on a vehicle. When linked with the other component models for a PEMFC developed by Olsommer (2000), it should prove a powerful design tool for anyone interested in developing new fuel cell stack designs.

\subsection{Recommendations}

A few recommendations come to mind when considering improvements that could be made to the governing equations and closure relations used to describe the phenomena in the membrane. The first would be to clarify the relationship between saturation ratio and water activity at the catalyst-membrane interface. Many of the equations used in Olsommer's (2000) membrane model come directly from Springer et al. (1992), but Springer does not use saturation ratio in his equations. By including saturation ratios in his model, Olsommer (2000) has enabled the model to predict liquid water behavior in the catalyst pores and, thus, predict flooding. This is very important when attempting to predict fuel cell performance; but it is equally important that all of the equations containing saturation ratio properly reflect phenomena in the membrane.

A second recommendation would be the development of a variable hydrogen diffusion coefficient, $D_{H^{+}}$, for the membrane. Currently the value used is a constant measured at $80{ }^{\circ} \mathrm{C}$ by Bernardi and Verbrugge (1992). Because this variable is a function of 
membrane age and temperature, it might be worthwhile investigating its relative effect on fuel cell behavior and incorporating a variable coefficient for $D_{H^{+}}$if such a relation exists.

I would also suggest that whoever moves forward with this project obtain a better understanding of the way current is treated in the membrane. Presently, current is treated as an independent variable and specified as a boundary condition at each time step. Perhaps a more fundamental variable could be used as a boundary condition, and current could be calculated as a function of all the phenomena taking place in the membrane. The effect of convective proton flow in the membrane is especially interesting and should be investigated.

There are also a few recommendations that may improve the transient finite difference model for the membrane. First, the model should be tested against any known solutions for similar problems. There are likely to be many equations with known solutions that can be compared to the equations developed in Olsommer (2000). Time prohibited testing for this thesis, but more testing should be done. The governing equations could also be normalized in order to reduce error that may occur because a very small spatial time scale is used. In the past, this proved difficult due to the variable coefficients in the governing equations.

In addition, research should be done into how to treat the drag term in Eq. (3.3). Currently, it is removed from the diffusive flux term, $J_{\mathrm{H} 2 \mathrm{O}}$, and treated as a source term in the water species conservation equation, Eq. (3.9). Other suggestions include possibly investigating the best way to approximate the ohmic source term in Eq. (3.16) as well as improving the method used to numerically approximate Eqs. (4.21a,b). At present, a simple trapezoidal approximation is used. 


\section{Bibliography}

Adjerid, S. 2000, MATH 5474: Finite Difference Method, Class Notes, Virginia Polytechnic and State University, Blacksburg, VA, Spring.

Bernardi D.M., Verbrugge M.W., 1991, Mathematical Model of a Gas Diffusion Electrode Bonded to a Polymer Electrolyte, AICHE J., Vol. 37, No. 8, pp. 1151-1163.

Bernardi D.M., Verbrugge M.W., 1992, A Mathematical Model of the Solid-PolymerElectrolyte Fuel Cell, J. Electrochem. Soc., Vol. 139, No. 9, pp. 2477-2491.

Broka K., Ekdunge P., 1997, Modelling the PEM fuel cell cathode, J. Applied Electrochemistry, Vol. 27, pp 281-289.

Derouin C., Springer T.E., Uribe F., Valerio J., Wilson M.S., Zawodzinski T.A., and Gottesfeld S., 1992, 1992 Fuel Cell Seminar Program and Abstracts, Tucson AZ, November 29 - December 2, 1992, sponsored by Fuel Cell Organizing Committee, 615, 1992.

Divisek-J; Mosig-J; Steffen-B; Stimming-U, 1995, "Proton Exchange Membrane Fuel Cell Model," Electrochemical Engineering and Energy, Plenum Press, NY, pp 187-196.

Divisek-J; Eikerling-M; Mazin-V; Schmitz-H; Stimming-U; Volfkovich-YuM, 1998, Study of capillary porous structure and sorption properties of Nafion proton-exchange membranes swollen in water, J. Electrochem. Soc., v 145 n 8, p 2677-2683, 1998.

Eikerling M.; Kharkats YuI.; Kornyshev A.A.; Volfkovich YuM., 1998, Phenomenological theory of electro-osmotic effect and water management in polymer electrolyte proton-conducting membranes, J. Electrochem. Soc., v 145 n 8, p 2684-2699.

Energy Partners, 2001, "Fuel Cells 101”, www.energypartners.net, April 10.

Fuller T.F., Newman J., 1993, Water and thermal management in solid-polymerelectrolyte fuel cells, J. Electrochem. Soc., Vol. 140, No. 5, p 1218-1225.

Gurau V.; Kakac S.; Liu H., 1998, Mathematical Model for Proton Exchange Membrane Fuel Cells, AES-Vol. 38, Proc. of the ASME Advanced Energy Systems Division, pp. 205-214, ASME.

Hinatsu J.T.; Mizuhata M.; Takenaka H., 1994, Water Uptake of Perfluorosulfonic Acid Membranes from Liquid Water and Water Vapor, J. Electrochem. Soc., Vol. 141, No. 6, pp 1493-1498.

Kjelstrup S., Okada T., and Ottoy M., 1999, Water, Ion and Entropy transport in IonExchange Membranes, Surface Chemistry and Electrochemistry of Membranes, pp. 455481, Marcel Dekker, Inc., NY. 
Mitchell A.R., Griffiths D.F., 1980, The Finite Difference Method in Partial Differential Equations. John Wiley \& Sons, NY.

Mosdale R., 1992, Ph. D. Thesis, INPG, Grenoble, France.

Mosdale R., Srinivasan S., 1995, Analysis of Performance and of Water and Thermal Management in Proton Exchange Membrane Fuel Cells, Electrochimica Acta, Vol. 40, No. 4, pp 413-421.

Nguyen T.V., R.E. White, 1993, A Water and Heat Management Model for ProtonExchange-Membrane Fuel Cells, J. Electrochem. Soc., Vol. 140, No. 8, pp. 2178-2186.

Nguyen T.V., Vanderborgh-Nicholas, 1998, The Rate of isothermal hydration of polyperfluorosulfonic acid membranes, Journal-of-Membrane-Science, Vol. 143, No. 1$2, \mathrm{p} 235-248$.

Olsommer, Benoit, 2000, Mathematical Model for a PEM Fuel Cell, Internal Document, Energy Management Institute, Mechanical Engineering, Virginia Polytechnic and State University, Blacksburg, VA.

Rho Y.W., Velev O.A., Srinivasan S., Kho Y.T., 1994, Mass Transport Phenomena in Proton Exchange Membrane Fuel Cells Using $\mathrm{O}_{2} / \mathrm{He}, \mathrm{O}_{2} / \mathrm{Ar}$, and $\mathrm{O}_{2} / \mathrm{N}_{2}$ Mixtures: I. Experimental Analysis, J. Electrochem. Soc., Vol. 141, No. 8, pp.2084-2088.

Rho Y.W., Velev O.A., Srinivasan S., Kho Y.T., 1994, Mass Transport Phenomena in Proton Exchange Membrane Fuel Cells Using $\mathrm{O}_{2} / \mathrm{He}, \mathrm{O}_{2} / \mathrm{Ar}$, and $\mathrm{O}_{2} / \mathrm{N}_{2}$ Mixtures: II. Theoretical Analysis, J. Electrochem. Soc., Vol. 141, No. 8, pp.2089-2096.

Thirumalai D., White R.E., 1997, Mathematical Modeling of Proton Exchange Membrane Fuel Cell Stacks, J. Electrochem. Soc., Vol 144, No. 5, pp. 1717-1723.

Springer T.E., Zawodzinski T.A., and S. Gottesfeld, 1991, Polymer Electrolyte Fuel Cell Model, J. Electrochem. Soc., Vol. 138, No. 8, pp. 2334-2342, (a).

Springer T.E., Gottesfeld S., 1991, Pseudohomogeneous Catalyst Layer for Polymer Electrolyte Fuel Cells, Proc. of the Symposium on Modeling of Batteries and Fuel Cells, R.E. White, M.W. Verbrugge, and J.F. Stockel, Editors, PV 91-10, pp. 197-208, The Electrochemical Society Softbound Proceedings Series, Pennington, NJ, (b).

Springer T.E., M.S. Wilson, and Gottesfeld S., 1993, Modeling and Experimental Diagnostics in Polymer Electrolyte Fuel Cells, J. Electrochem. Soc., Vol 140, No. 12, pp. 3513-3526. 
Springer T.E , Zawodzinski T.A., Wilson M.S., and Gottesfeld S., 1996, Characterization of Polymer Electrolyte Fuel Cells Using AC Impedance Spectroscopy, J. Electrochem.

Soc., Vol 143, No. 2, pp. 587-599.

U.S. Fuel Cell Council, 1999, Fuel Cell Glossary. August 19.

Verbrugge M.W., Hill R.F., 1990, Ion and Solvent Transport in Ion-Exchange

Membranes, J. Electrochem. Soc., Vol. 137, No. 3, pp. 886-893.

van Bussel H.P.L.H, Koene F.G.H, Mallant R.K.A.M, 1998, Dynamic Model of Solid Polymer Fuel Cell Water Management, J. of Power Sources, Vol. 71, pp. 218-222.

Nguyen T.V., Vanderborgh-Nicholas, 1998, The Rate of isothermal hydration of polyperfluorosulfonic acid membranes, Journal of Membrane-Science, Vol. 143, No. 1-2, p 235-248.

von Spakovsky, M.R., Olsommer, B., 1999, "Fuel Cell Systems and System Modeling and Analysis Perspectives for Fuel Cell Development," Efficiency, Costs, Optimization, Simulation and Environ-mental Aspects of Energy Systems (ECOS'99), Tokyo Institute of Technology, ASME, Tokyo, pp 100-104, June.

von Spakovsky M.R., Nelson D.J, and Ellis M.W., 2000, ME 5984: Fuel Cell Systems, Class Notes, Virginia Polytechnic and State University, Blacksburg, VA, Spring.

Weisbrod K.R., Grot S.A., and Vanderborgh N.E., 1995, Through the Electrode Model of a Proton Exchange Membrane Fuel Cells, Proc. Electrochemical Soc. Meeting, Chicago, IL, Vol. 95-23, pp. 152-166.

Weisbrod K.R., Vanderborgh N.E., and Grot S.A., 1996, Modeling of Gaseous Flows within Proton Exchange Membrane Fuel Cells, Proc. 1996 Fuel Cell Seminar, Orlando, FL, pp. 635-638.

Wilson M.S., Springer T.E., Zawodzinski T.A., Gottesfeld S., 1991, $26^{\text {th }}$ Intersociety Energy Conversion Engineering Conference Proceedings, Vol. 3, Conversion Technologies/Electrochemical Conversion, Boston, Massachussets, August 4-9.

Yi J.S., Nguyen, T.V., 1999, Multicomponent Transport in Porous Electrodes of Proton Exchange Membrane Fuel Cells Using Interdigitated Gas Distributors, J. Electrochem. Soc., Vol 146, No. 1, pp. 38-45. 


\section{Appendix A. Nomenclature}

a

$\mathrm{c}_{\mathrm{i}}$

$\mathrm{c}_{\mathrm{i}}^{\alpha}$

$\mathrm{c}_{\mathrm{pi}}$

$\mathrm{D}_{\mathrm{i}}$

$\mathrm{D}^{\prime}$

F

g

$i_{\mathrm{m}}$

$(i)_{\mathrm{x}},(i)_{\mathrm{y}},(i)_{\mathrm{z}}$

$\mathrm{J}_{\mathrm{i}}$

$\mathrm{k}_{\mathrm{r}}^{\alpha}$

K

$\mathrm{L}_{\mathrm{v}}$

$\mathrm{M}_{\mathrm{i}}$

$\mathrm{M}^{\mathrm{m}}$

$\mathrm{N}_{\mathrm{H}^{+}}, \mathrm{N}_{\mathrm{H}_{2} \mathrm{O}}^{m}$

$\mathbf{N}_{\mathrm{i}}$

$\mathrm{n}_{\text {drag }}$

$\mathrm{p}_{0}$

$\mathrm{p}^{\alpha}$

$p^{\alpha}{ }_{i}$

$\mathrm{p}_{\mathrm{sat}}$

$\mathrm{R}_{\mathrm{m}}$

$\mathrm{R}$

$\mathrm{S}$ activity

concentration of species $\mathrm{i}, \mathrm{mol} / \mathrm{m}^{3}$

concentration of species $\mathrm{i}$ in phase $\alpha, \mathrm{kg} / \mathrm{m}^{3}$

specific heat at constant pressure of species $i$,

$\mathrm{J} / \mathrm{kgK}$

diffusion coefficients of species $\mathrm{i}, \mathrm{cm}^{2} / \mathrm{s}$

diffusion coefficient at constant temperature and in coordinates

moving with the swelling membrane, $\mathrm{m}^{2} / \mathrm{s}$

Faraday's constant, 96,485 C/mol

gravitational acceleration, $9.8062 \mathrm{~m} / \mathrm{s}^{2}$

protonic current density in the x-direction within the polymer

membrane, $\mathrm{A} / \mathrm{m}^{2}$

current density in the $\mathrm{x}-, \mathrm{y}-$, and $\mathrm{z}$-directions, $\mathrm{A} / \mathrm{m}^{2}$

diffusive flux of species $\mathrm{i}, \mathrm{mol} / \mathrm{m}^{2} \mathrm{~s}$

relative permeability of phase $\alpha$

absolute permeability, $\mathrm{m}^{2} / \mathrm{s}$

liquid-gas enthalpy of vaporization, $\mathrm{J} / \mathrm{kgK}$

molecular mass of species $\mathrm{i}, \mathrm{kg} / \mathrm{mol}$

molecular mass of the membrane, $\mathrm{kg} / \mathrm{mol}$

electro-osmotic-convective molar flux of $\mathrm{H}^{+}$or $\mathrm{H}_{2} \mathrm{O}$ species within the membrane, $\mathrm{mol} / \mathrm{m}^{2} \mathrm{~s}$

molar flux of species $\mathrm{i}, \mathrm{mol} / \mathrm{m}^{2} \mathrm{~s}$

drag coefficient

reference saturation pressure, $\mathrm{Pa}$

pressure of phase $\alpha, \mathrm{Pa}$

partial pressure of species i in phase $\alpha, \mathrm{Pa}$

saturation pressure, $\mathrm{Pa}$

membrane ohmic source, $\mathrm{W} / \mathrm{m}^{3}$

universal gas constant, $8.3144 \mathrm{~J} / \mathrm{molK}$

saturation ratio 
$\mathrm{T}_{0}$

$\Phi_{\mathrm{m}}$

$\lambda$

$\lambda_{\mathrm{H}_{2} \mathrm{O} / \mathrm{SO}_{3}}$

$\lambda^{\text {eff }}$

$\mu$

$v$

$\rho$

$\rho_{\text {dry }}{ }^{m}$

$\sigma$ time, sec

absolute temperature, $\mathrm{K}$

reference saturation temperature, $\mathrm{K}$

electric potential in the membrane, $\mathrm{V}$

thermal conductivity, $\mathrm{W} / \mathrm{mK}$

water content of the membrane, $\mathrm{mol}_{\mathrm{H} 2 \mathrm{O}} / \mathrm{mol}_{\mathrm{SO} 3}$

effective thermal conductivity, $\mathrm{W} / \mathrm{mK}$

dynamic viscosity, $\mathrm{kg} / \mathrm{ms}$

kinematic viscosity

density, $\mathrm{kg} / \mathrm{m}^{3}$

density of the dry membrane, $\mathrm{kg} / \mathrm{m}^{3}$

electrical conductivity, $\mathrm{S} / \mathrm{m}$

Superscripts, subscripts:

a

app

c

g

1

$\mathrm{m}$

$\mathrm{X}, \mathrm{y}, \mathrm{z}$

0

$\alpha$ anode side

apparent

cathode side, catalyst layer

gas channel, gas phase

liquid phase

membrane

axis directions

reference

phase (s, 1, g, m) 


\section{Appendix B. Mathematical Model}

\section{DIFFERENTIAL EQUATIONS:}

Mass conservation for $\mathbf{H}_{\mathbf{2}} \mathbf{O}$ (constitutive variable: $c_{\mathrm{H}_{2} \mathrm{O}}^{m}$ ):

$\frac{\partial c_{H_{2} O}^{m}}{\partial t}=-\frac{\partial}{\partial x} J_{H_{2} O}-\frac{\partial}{\partial x}\left(c_{H_{2} O}^{m} u^{m}\right)$

Mass conservation for the protons (constitutive variable: $\mathrm{c}_{\mathrm{H}_{+}}$):

$c_{H^{+}}=$cste

Energy conservation (constitutive variable: T):

$\overline{\rho c_{p}} \frac{\partial T}{\partial t}=\lambda_{m} \frac{\partial^{2} T}{\partial x^{2}}-\overline{M c_{p} N} \frac{\partial T}{\partial x}+R_{m}$

Potential (constitutive variable: $\Phi_{\mathrm{m}}$ ):

$\frac{\partial^{2} \Phi_{m}}{\partial x^{2}}=f(x)=\left(\mathrm{Fc}_{\mathrm{H}+} u^{m}-i_{m x}\right) \frac{\partial}{\partial x}\left(\frac{1}{\sigma_{m}}\right)$ 


\section{CLOSURE RELATIONS:}

Diffusive Flux for Water (dependent variable: $J_{\mathrm{H}_{2} \mathrm{O}}$ )

$$
J_{\mathrm{H}_{2} \mathrm{O}}=-D_{c_{\mathrm{H}_{2} \mathrm{O}}, \mathrm{T}} \frac{\partial c_{\mathrm{H}_{2} \mathrm{O}}^{m}}{\partial x}+2.5 \frac{\frac{\lambda_{\mathrm{H}_{2} \mathrm{O}}}{\mathrm{SO}_{3}}}{22} \frac{i_{m_{x}}}{F}
$$

Diffusive Flux for Hydrogen (dependent variable: $J_{H+}$ )

$$
J_{H^{+}}=-\frac{F}{R T} D_{H^{+}} c_{H^{+}} \frac{\partial \Phi_{m}}{\partial x}
$$

Density for the mixture (dependent variable: $\rho$ )

$$
\rho=M_{\mathrm{H}^{+}} c_{\mathrm{H}^{+}}+M_{\mathrm{H}_{2} \mathrm{O}} c_{\mathrm{H}_{2} \mathrm{O}}^{m}
$$

Molar velocity for the mixture: Darcy: (dependent variable: $u^{m}$ )

$$
u^{m}=-K \frac{k_{r}^{g}}{\mu}\left[\frac{\partial p}{\partial x}-\rho g \cos \theta\right]
$$

Dynamic Viscosity of the Mixture (dependent variable: $\mu$ ):

$$
\mu=\frac{M_{H^{+}}{ }^{c} H^{+}}{\rho} \mu_{H^{+}}+\frac{M_{H_{2} O^{c}}{ }_{H_{2} O}}{\rho} \mu_{H_{2} O}
$$

Diffusion coefficient (dependent variable: $D_{c_{H_{2} O}, T}$ ):

$$
D_{c_{H_{2} O}, T}=D^{\prime}\left\{\exp \left[2416\left(\frac{1}{303}-\frac{1}{T}\right)\right] \lambda_{\frac{H_{2} O}{S O_{3}}} \frac{1}{a} \frac{1}{17.81-78.9 a+108 a^{2}}\right\}
$$

Diffusion coefficient at 303 (K) (dependent variable: $D^{\prime}$ ):

$$
\begin{aligned}
& D^{\prime}=2.642276 e(-13) \frac{\lambda_{\frac{\mathrm{H}_{2 O}}{\mathrm{SO}_{3}}}}{} \\
& \text { for } \lambda_{\frac{\mathrm{H}_{2 O}}{\mathrm{SO}_{3}}} \leq 1.23 \\
& D^{\prime}=7.75 e(-11) \frac{\lambda_{\frac{H_{2 O} O}{S O_{3}}}}{S^{\prime}}-9.5 e(-11) \\
& \text { for } 1.23<\lambda_{\frac{\mathrm{H}_{2 O}}{\mathrm{SO}_{3}}} \leq 6 \\
& D^{\prime}=2.5625 e(-11) \frac{\lambda_{\frac{\mathrm{H}_{2 O} \mathrm{O}}{\mathrm{SO}_{3}}}}{}+2.1625 e(-10) \\
& \text { for } 6<\lambda_{\frac{\mathrm{H}_{2 O}}{\mathrm{SO}_{3}}} \leq 14
\end{aligned}
$$

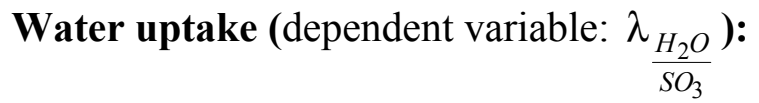

$$
\lambda_{\frac{\mathrm{H}_{2} \mathrm{O}}{S \mathrm{O}_{3}}}=\frac{c_{\mathrm{H}_{2} \mathrm{O}}^{m}}{\frac{\rho_{d r y}^{m}}{M^{m}}-b c_{\mathrm{H}_{2} \mathrm{O}}^{m}}
$$


Proton potential (dependent variable: $\frac{\partial \Phi_{m}}{\partial x}$ ):

$$
\frac{\partial \Phi_{m}}{\partial x}=-\frac{i_{m_{x}}}{\sigma_{m}}+\frac{F}{\sigma_{m}} c_{H^{+}} u^{m}
$$

Heat capacity of the phase mixture (dependent variables: $\overline{\rho c_{p}}, \overline{M c_{p} N}$ ):

$$
\begin{aligned}
& \overline{\rho c_{p}}=\rho_{d r y}^{m} c_{p_{m}}+M_{\mathrm{H}_{2} \mathrm{O}} c_{\mathrm{H}_{2} \mathrm{O}}^{m} c_{p_{\mathrm{H}_{2} \mathrm{O}}}+M_{\mathrm{H}^{+}} c_{H^{+}} c_{p_{H^{+}}} \\
& \overline{M c_{p} N}=M_{\mathrm{H}_{2} \mathrm{O}} c_{p_{\mathrm{H}_{2} \mathrm{O}}}\left(c_{\mathrm{H}_{2} \mathrm{O}}^{m} u^{m}-D_{c_{\mathrm{H}_{2} O}, T} \frac{\partial c_{\mathrm{H}_{2} \mathrm{O}}^{m}}{\partial x}+2.5 \frac{\lambda_{\mathrm{H}_{2} \mathrm{O}}}{2 O_{3}} \frac{i_{m_{x}}}{F}\right) \\
& +M_{H^{+}} c_{p_{H^{+}}}\left(c_{H^{+}} u^{m}-\frac{F}{R T} D_{H^{+}} c_{H^{+}} \frac{\partial \Phi_{m}}{\partial x}\right)
\end{aligned}
$$

Pressure for the water molecules (dependent variable: $\mathrm{p}_{\mathrm{H} 2 \mathrm{O}}$ ):

$$
p_{H_{2} O}=\left\{p^{g}\right\}_{c-}+\frac{\left\lfloor\{s\}_{c+}\left\{p_{H_{2} O}^{l}\right\}_{c+}+\left(1-\{s\}_{c+}\right)\left\{p^{g}\right\}_{c+}\right\rfloor-\left\{p^{g}\right\}_{c-}}{x_{m+}-x_{m-}}\left(x-x_{m-}\right)
$$

Activity of the water molecules (dependent variable: $a$ ):

$$
\begin{array}{rlr}
a & =1 / 2160\left(c_{1}+c_{2} \lambda_{\mathrm{H}_{2} \mathrm{O} / \mathrm{SO}_{3}}+216\left(c_{3}-c_{4} \lambda_{\mathrm{H}_{2} \mathrm{O} / \mathrm{SO}_{3}}\right.\right. \\
& \left.\left.+c_{5} \lambda_{\mathrm{H}_{2} \mathrm{O} / \mathrm{SO}_{3}}{ }^{2}\right)^{(1 / 2)}\right)^{(1 / 3)}-134183 / 2160 / & \text { for }\left(\frac{\lambda_{\mathrm{H}_{2} \mathrm{O}}}{\mathrm{SO}_{3}}\right) \leq 14 \\
& \left(c_{1}+c_{2} \lambda_{\mathrm{H}_{2} \mathrm{O} / \mathrm{SO}_{3}}+216\left(c_{3}-c_{4} \lambda_{\mathrm{H}_{2} \mathrm{O} / \mathrm{SO}_{3}}\right.\right. & \\
& \left.\left.+c_{5} \lambda_{\mathrm{H}_{2} \mathrm{O} / \mathrm{SO}_{3}}{ }^{2}\right)^{(1 / 2)}\right)^{(1 / 3)}+797 / 2160 &
\end{array}
$$

\begin{tabular}{|l|l|}
\hline$c_{1}$ & $-41956 \mathrm{e} 4$ \\
\hline$c_{2}$ & $139968 \mathrm{e} 3$ \\
\hline$c_{3}$ & $382482 \mathrm{e} 6$ \\
\hline$c_{4}$ & $251739 \mathrm{e} 3$ \\
\hline$c_{5}$ & $419904 \mathrm{e} 6$ \\
\hline
\end{tabular}

$a=0.7143\left(\frac{\lambda_{\frac{\mathrm{H}_{2} \mathrm{O}}{\mathrm{SO}_{3}}}}{}\right)-9.0021$

for $14 \leq\left(\frac{\lambda_{\mathrm{H}_{2} \mathrm{O}}}{\mathrm{SO}_{3}}\right) \leq 16.8$

$a=3$

$$
\text { for } 16.8 \leq\left(\frac{\lambda_{\mathrm{H}_{2} \mathrm{O}}}{\mathrm{SO}_{3}}\right)
$$


Ohmic loss (dependent variable: $\mathrm{R}_{\mathrm{m}}$ ):

$$
R_{m}=\frac{i_{m_{x}}{ }^{2}}{\sigma_{m}}
$$

Electrical conductivity (dependent variable: $\sigma_{\mathrm{m}}$ ):

$$
\begin{aligned}
& \sigma_{m}=\exp \left[1268\left(\frac{1}{303}-\frac{1}{T}\right)\right]\left[0.5139 \lambda_{\frac{\mathrm{H}_{2} \mathrm{O}}{\mathrm{SO}_{3}}}-0.326\right], \quad \text { for } \lambda_{\frac{\mathrm{H}_{2} \mathrm{O}}{\mathrm{SO}_{3}}} \geq 1 \\
& \sigma_{m}=\sigma_{m}\left(\frac{\lambda_{\frac{H_{2} O}{S O_{3}}}}{S O_{3}}\right)=1 \quad \text { for } 0<\lambda_{\frac{\mathrm{H}_{2} O}{\mathrm{SO}_{3}}}<1
\end{aligned}
$$

Thermal conductivity tensor (constant: $\lambda_{\mathrm{m}}$ ):

$$
\lambda_{\mathrm{m}}=\text { cste }
$$


SUMMARY OF NOTATIONS APPEARING IN EOS 1-20:

\begin{tabular}{|c|c|c|c|c|}
\hline Notation & $\begin{array}{l}\text { Constitutive } \\
\text { variables }\end{array}$ & $\begin{array}{l}\text { Dependent } \\
\text { variables }\end{array}$ & Constants & Units \\
\hline$c_{\mathrm{H}_{2} \mathrm{O}}^{m}$ & Eq 1 & & & mol.m ${ }^{-3}$ \\
\hline$c_{H^{+}}$ & Eq 2 & & $1.2 \mathrm{e} 3$ & mol.m ${ }^{-3}$ \\
\hline$T$ & Eq 3 & & & $\mathrm{~K}$ \\
\hline$\Phi_{m}$ & Eq 4 & & & Volt \\
\hline$J_{\mathrm{H} 2 \mathrm{O}}$ & & Eq 5 & & mol.m $\mathrm{m}^{-2} \cdot \mathrm{s}^{-1}$ \\
\hline$J_{H^{+}}$ & & Eq 6 & & $\mathrm{~mol} \cdot \mathrm{m}^{-2} \cdot \mathrm{s}^{-1}$ \\
\hline$\rho$ & & Eq 7 & & kg.m ${ }^{-3}$ \\
\hline$u^{m}$ & & Eq 8 & & $\mathrm{~m} \cdot \mathrm{s}^{-1}$ \\
\hline$\mu$ & & Eq 9 & & $\mathrm{~kg} \cdot \mathrm{m}^{-1} \cdot \mathrm{s}^{-1}$ \\
\hline$D_{c_{H_{2} O}, T}$ & & Eq 10 & & $\mathrm{~m}^{2} \cdot \mathrm{s}^{-1}$ \\
\hline$D^{\prime}$ & & Eq 11(a,b,c) & & $\mathrm{m}^{2} \cdot \mathrm{s}^{-1}$ \\
\hline$\lambda_{\frac{\mathrm{H}_{2} \mathrm{O}}{\mathrm{SO}_{3}}}$ & & Eq 12 & & $\mathrm{~mol}_{\mathrm{H}_{2} \mathrm{O}} \cdot\left(\mathrm{mol}_{\mathrm{SO}_{3}}\right)^{-1}$ \\
\hline$b$ & & & 0.0126 & - \\
\hline$\frac{\partial \Phi_{m}}{\partial x}$ & & Eq 13 & & Volt.m ${ }^{-1}$ \\
\hline$\overline{\overline{\rho c_{p}}}$ & & Eq 14 & & $\mathrm{~J} \cdot \mathrm{m}^{-3} \cdot \mathrm{K}^{-1}$ \\
\hline$\overline{M c_{p} N}$ & & Eq 15 & & $\mathrm{~W} \cdot \mathrm{m}^{-2} \cdot \mathrm{K}^{-1}$ \\
\hline$D_{H^{+}}$ & & & $4.5 \mathrm{e}-5\left(\mathrm{~cm}^{2} \mathrm{~s}^{-1}\right)$ & $\mathrm{cm}^{2} \mathrm{~s}^{-1}$ \\
\hline$\rho_{d r y}^{m}$ & & & 2000.0 & $\mathrm{~kg} \cdot \mathrm{m}^{-3}$ \\
\hline$M^{m}$ & & & 1.1 & $\mathrm{~kg} \cdot\left(\mathrm{mol}_{\mathrm{SO}_{3}}\right)^{-1}$ \\
\hline$c_{p_{m}}$ & & & 852.63 & $\mathrm{~J} \cdot \mathrm{kg}^{-1} \cdot \mathrm{K}^{-1}$ \\
\hline$M_{\mathrm{H}_{2} \mathrm{O}}$ & & & $18 \mathrm{e}-3$ & $\mathrm{~kg} \cdot \mathrm{mol}^{-1}$ \\
\hline$c_{p_{\mathrm{H}_{2} \mathrm{O}}}$ & & & 4190 & $\mathrm{~J} \cdot \mathrm{kg}^{-1} \cdot \mathrm{K}^{-1}$ \\
\hline$M_{H^{+}}$ & & & $1 e-3$ & kg.mol ${ }^{-1}$ \\
\hline$c_{p_{H^{+}}}$ & & & 20630.0 & $\mathrm{~J} \cdot \mathrm{kg}^{-1} \cdot \mathrm{K}^{-1}$ \\
\hline$\mu_{H^{+}}$ & & & $98.8 \mathrm{e}-7$ & $\mathrm{~kg} \cdot \mathrm{m}^{-1} \cdot \mathrm{s}^{-1}$ \\
\hline$p_{\mathrm{H}_{2} \mathrm{O}}$ & & Eq 16 & & $\mathrm{~Pa}$ \\
\hline$x_{m+}$ & & & $2.271 \mathrm{e}-4$ & $\mathrm{~m}$ \\
\hline$x_{m-}$ & & & 0 & $\mathrm{~m}$ \\
\hline$\rho_{\mathrm{H}_{2} \mathrm{O}}$ & & & 972 & $\mathrm{~kg} \cdot \mathrm{m}^{-3}$ \\
\hline$a$ & & Eqs $17(a, b, c)$ & & - \\
\hline
\end{tabular}




\begin{tabular}{|l|l|l|l|l|}
\hline$R_{m}$ & & Eq 18 & & W. $\mathrm{m}^{-3}$ \\
\hline$\sigma_{m}$ & & Eqs 19(a,b) & & $\Omega^{-1} \cdot \mathrm{m}^{-1}$ \\
\hline$K k_{r}^{g}$ & & & $1.8 \mathrm{e}-18$ & $\mathrm{~m}^{2}$ \\
\hline$\theta$ & & & 90 & Degrees \\
\hline$\mu_{H_{2} O}$ & & & $8.91 \mathrm{e}-4$ & $\mathrm{~kg} \cdot \mathrm{m}^{-1} \cdot \mathrm{s}^{-1}$ \\
\hline$g$ & & & 9.81 & $\mathrm{~m} \cdot \mathrm{s}^{-2}$ \\
\hline$F$ & & & 96485 & $\mathrm{C} \cdot \mathrm{mol}^{-1}$ \\
\hline$\lambda_{m}$ & & Eq 20 & 100.0 & $\mathrm{~W} \cdot \mathrm{m}^{-1} \cdot \mathrm{K}^{-1}$ \\
\hline
\end{tabular}

\begin{tabular}{|l|l|l|l|l|}
\hline Notation & $\begin{array}{l}\text { Constitutive } \\
\text { variables }\end{array}$ & $\begin{array}{l}\text { Dependent } \\
\text { variables }\end{array}$ & Constant & Unit \\
\hline$\left\{p^{g}\right\}_{c-}$ & & & $\begin{array}{l}\text { see boundary } \\
\text { conditions }\end{array}$ & $\mathrm{Pa}$ \\
\hline$\left\{p_{\mathrm{H}_{2} \mathrm{O}{ }_{c+}}\right\}$ & & & $\begin{array}{l}\text { see boundary } \\
\text { conditions }\end{array}$ & $\mathrm{Pa}$ \\
\hline$\left\{p^{g}\right\}_{c+}$ & & $\begin{array}{l}\text { see boundary } \\
\text { conditions }\end{array}$ & $\mathrm{Pa}$ \\
\hline$\{s\}_{c+}$ & & $\begin{array}{l}\text { see boundary } \\
\text { conditions }\end{array}$ & - \\
\hline$i_{m_{x}}$ & & $\begin{array}{l}\text { see boundary } \\
\text { conditions }\end{array}$ & A.m-2 \\
\hline
\end{tabular}




\section{INITIAL/BOUNDARY CONDITIONS}

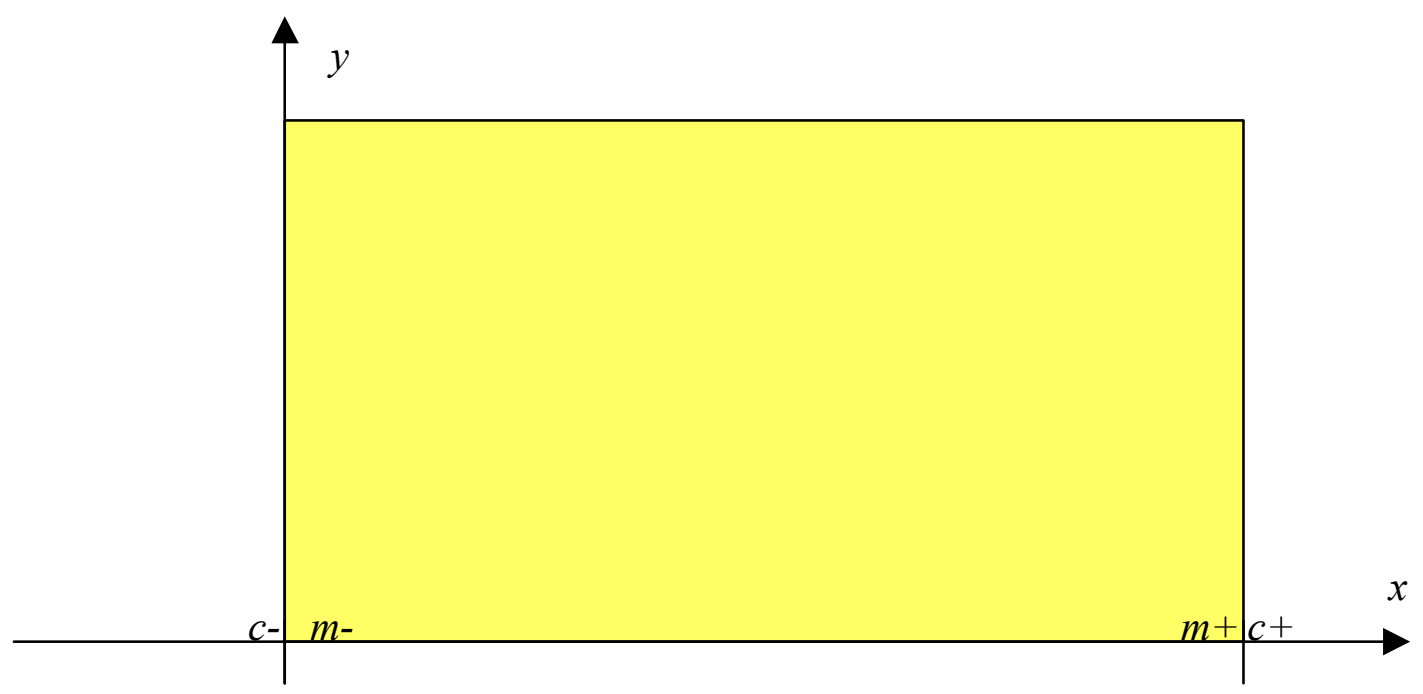

\section{Water concentration $\left(c_{\mathrm{H}_{2} \mathrm{O}}(t, x)\right)$}

Water concentration, function of the water uptake (used only with the boundary cond.) $\left(c_{\mathrm{H}_{2} \mathrm{O}}^{m}(t, x)\right)$ :

$$
\left\{c_{\mathrm{H}_{2} \mathrm{O}}^{m}=\lambda_{\frac{\mathrm{H}_{2} \mathrm{O}}{\mathrm{SO}_{3}}} \frac{\rho_{d r y}^{m}}{M^{m}} \frac{1}{1+b \lambda_{\frac{\mathrm{H}_{2} \mathrm{O}}{\mathrm{SO}_{3}}}}\right\}_{\substack{t, x=x_{m-} \\ t, x=x_{m+} \\ t=0, x}}
$$

Water uptake, function of the activity (used only with the bound. cond.) $\left(\lambda_{\frac{\mathrm{H}_{2} \mathrm{O}}{\mathrm{SO}_{3}}}(t, x)\right)$ :

$$
\begin{aligned}
& \left\{\frac{\lambda_{\mathrm{H}_{2} \mathrm{O}}}{\mathrm{SO}_{3}}=0.043+17.81(a)-39.85(a)^{2}+36(a)^{3}\right\}_{\substack{t, x=x_{m-} \\
t, x=x_{m+} \\
t=0, x}} \text { for } a<1 \\
& \left\{\lambda_{\frac{\mathrm{H}_{2} \mathrm{O}}{\mathrm{SO}_{3}}}=14+1.4(a-1)\right\}_{\substack{t, x=x_{m-} \\
t, x=x_{m+} \\
t=0, x}} \quad \text { for } 1 \leq a \leq 3 \\
& \left\{\lambda_{\frac{\mathrm{H}_{2} \mathrm{O}}{\mathrm{SO}_{3}}}=16.8\right\}_{\substack{t, x=x_{m-} \\
t, x=x_{m+} \\
t=0, x}} \quad \text { for } 3 \leq a
\end{aligned}
$$


Water activity, function of the thermodynamic conditions within the catalyst layer $\left(\mathrm{c}_{-}, \mathrm{c}^{+}\right)$(used only with the boundary cond.) $(a(t, x))$ :

$$
\begin{aligned}
& a\left(t, x=x_{m-}\right)=\left\{\frac{R T}{p_{s a t}(T)} \quad c_{H_{2} O}^{g}+2 s\right\}_{c-} \\
& a\left(t, x=x_{m+}\right)=\left\{\frac{R T}{p_{s a t}(T)} \quad c_{H_{2} \mathrm{O}}^{g}+2 s\right\}_{c+} \\
& a(t=0, x)=\left\{a\left(t=0, x=x_{m-}\right)+\frac{a\left(t=0, x=x_{m+}\right)-a\left(t=0, x=x_{m-}\right)}{x_{m+}-x_{m-}}\left(x-x_{m-}\right)\right\}
\end{aligned}
$$

Clapeyron relation $\left(p_{\text {sat }}(T)\right)$ :

$$
p_{\text {sat }}(T)=p_{0} \exp \left(\frac{\left(\frac{1}{T_{0}}-\frac{1}{T}\right) L_{v} M_{H_{2} O}}{R}\right)
$$

Temperature $(T(t, x))$

$$
\begin{aligned}
& T\left(t, x=x_{m-}\right)=\{T\}_{c-} \\
& T\left(t, x=x_{m+}\right)=\{T\}_{c+} \\
& T(t=0, x)=\left\{T\left(t=0, x=x_{m-}\right)+\frac{T\left(t=0, x=x_{m+}\right)-T\left(t=0, x=x_{m-}\right)}{x_{m+}-x_{m-}}\left(x-x_{m-}\right)\right\}
\end{aligned}
$$

Electrical potential $\left(\Phi_{m}(t, x)\right)$

$$
\Phi_{\mathrm{m}}\left(t, x=x_{m^{-}}\right)=\left\{\Phi_{\mathrm{m}}\right\}_{t, c^{-}}
$$


SUMMARY OF NOTATIONS APPEARING IN EOS 21-30:

\begin{tabular}{|l|l|l|l|l|}
\hline Notation & $\begin{array}{l}\text { Constitutive } \\
\text { variables }\end{array}$ & $\begin{array}{l}\text { Dependent } \\
\text { variables }\end{array}$ & Constant & Unit \\
\hline$c_{H_{2} O}^{m}$ & Eq 21 & & & $\mathrm{mol} \cdot \mathrm{m}^{-3}$ \\
\hline$T$ & Eqs 27-29 & & & $\mathrm{K}$ \\
\hline$\Phi_{\mathrm{m}}$ & Eq 30 & & & Volt \\
\hline$\lambda_{\frac{H_{2} O}{S O_{3}}}$ & & Eqs 22(a,b,c) & & mol $_{H_{2} O} \cdot\left(\mathrm{mol}_{\mathrm{SO}_{3}}\right)^{-1}$ \\
\hline$a$ & & Eqs 23-25 & & - \\
\hline$R$ & & & 8.314 & $\mathrm{~J} . \mathrm{mol}^{-1} \mathrm{~K}^{-1}$ \\
\hline$\{T\}_{c^{-}}$ & & & Catalyst layer & $\mathrm{K}$ \\
\hline$\{T\}_{c^{+}}$ & & & Catalyst layer & $\mathrm{K}$ \\
\hline$\left\{\Phi_{\mathrm{m}}\right\}_{c^{-}}$ & & & Catalyst layer & $\mathrm{Volt}$ \\
\hline$\left\{p^{g}\right\}_{c^{-}}$ & & & Catalyst layer & $\mathrm{Pa}$ \\
\hline$\left\{p_{H_{2} O}^{l}\right\}_{c+}$ & & & Catalyst layer & $\mathrm{Pa}$ \\
\hline$\left\{p^{g}\right\}_{c+}$ & & & Catalyst layer & $\mathrm{Pa}$ \\
\hline$\{s\}_{c^{+}}$ & & & Catalyst layer & - \\
\hline$p_{s a t}(T)$ & & Eq 26 & & $\mathrm{Pa}$ \\
\hline$\rho_{H_{2} O}^{l}$ & & & 972 & $\mathrm{~kg} . \mathrm{m}^{-3}$ \\
\hline$p_{0}$ & & & $1 \mathrm{e} 5$ & $\mathrm{~Pa}$ \\
\hline$T_{0}$ & & & 298.16 & $\mathrm{~K}$ \\
\hline$L_{v}$ & & & $2310 \mathrm{e} 3$ & $\mathrm{~J} . \mathrm{kg}^{-1}$ \\
\hline
\end{tabular}




\section{Appendix C. Additional Figures}

Temperature and Voltage Profiles for Results presented in Figures 5.1 and 5.2 and Water Concentration and Voltage Profiles for Figures 5.6a,b

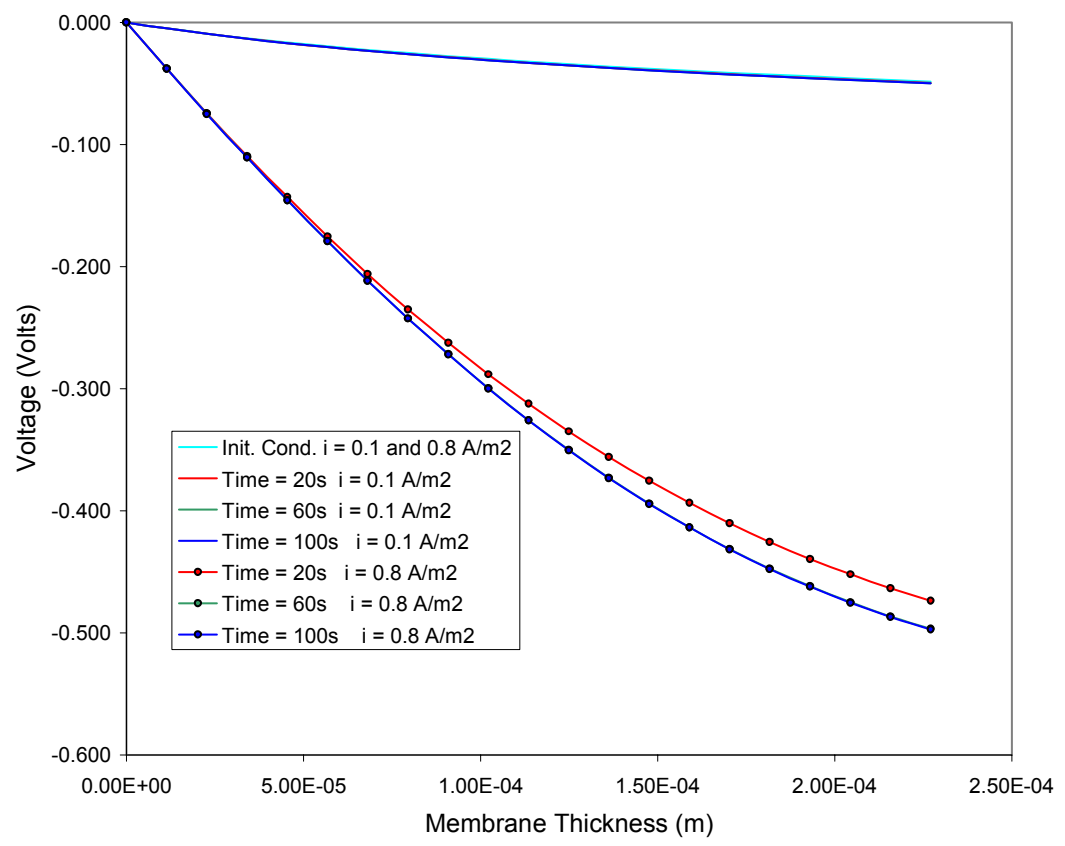

Figure 10.1 Effect of current density on voltage. 


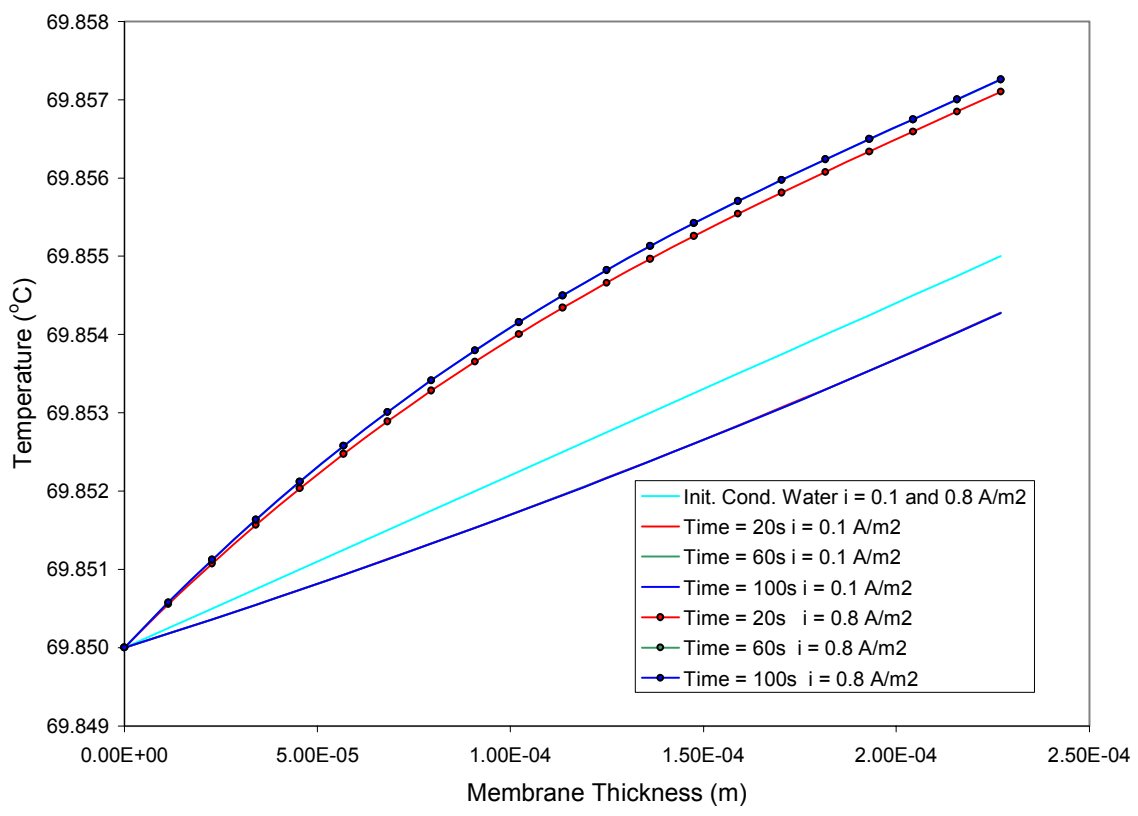

Figure 10.2 Effect of current density on temperature.

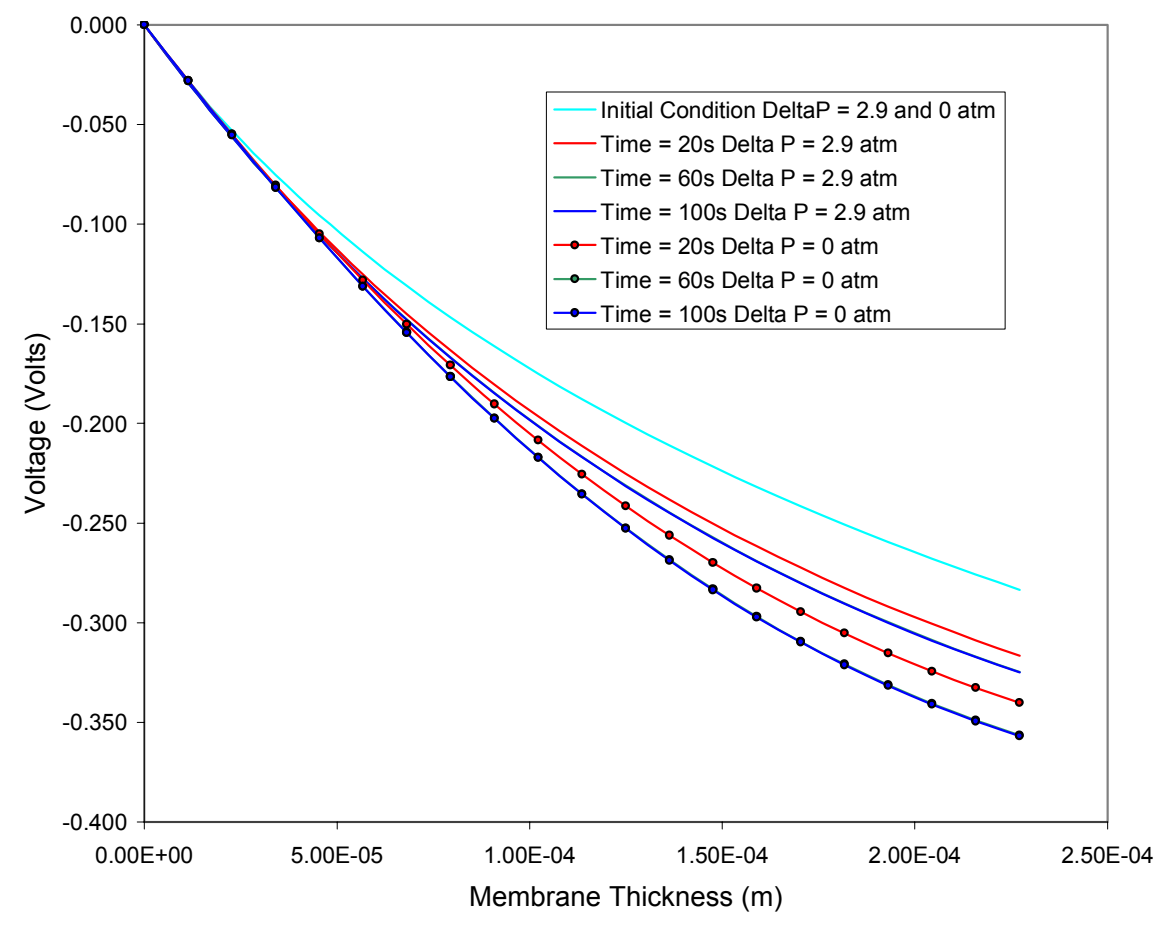

Figure 10.3 Effect of pressure gradient on voltage. 


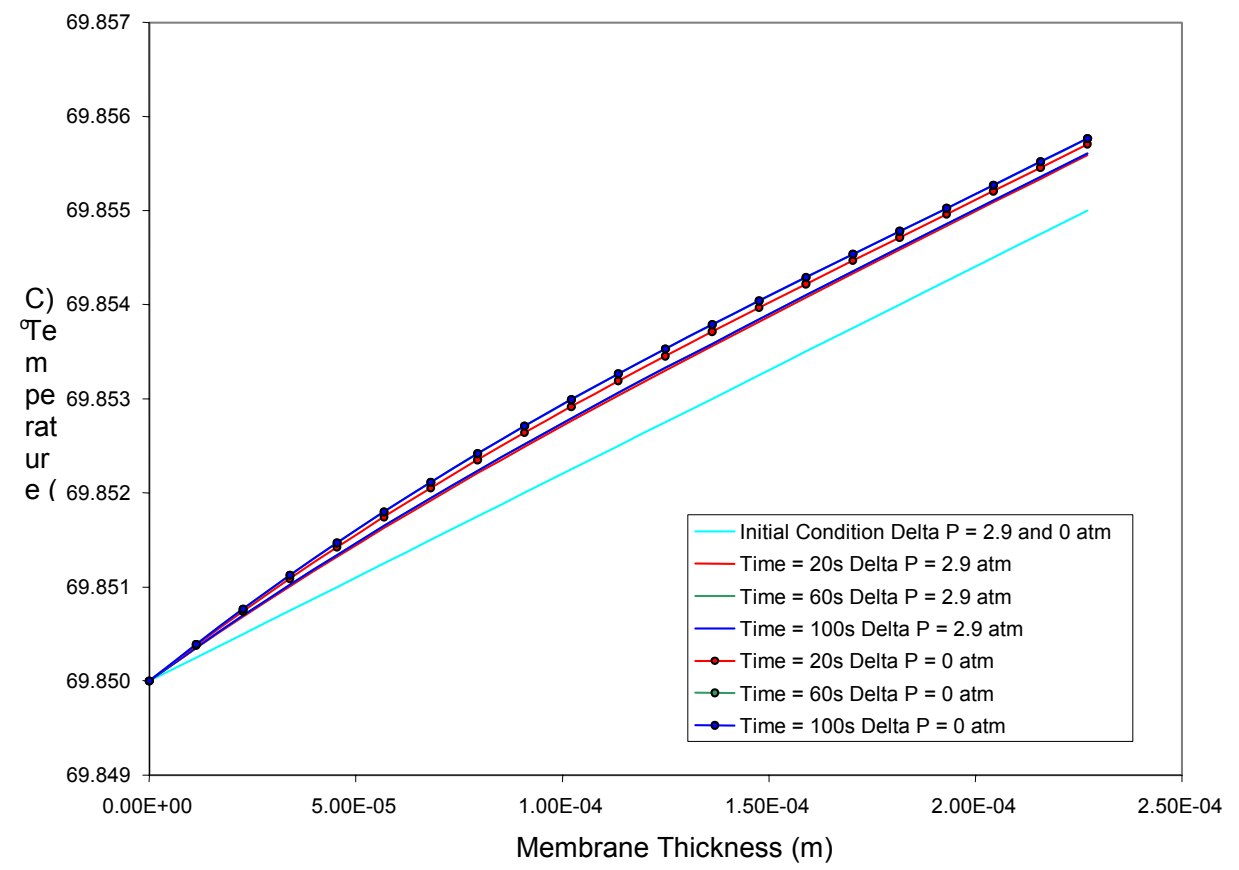

Figure 10.4 Effect of pressure gradient on temperature.

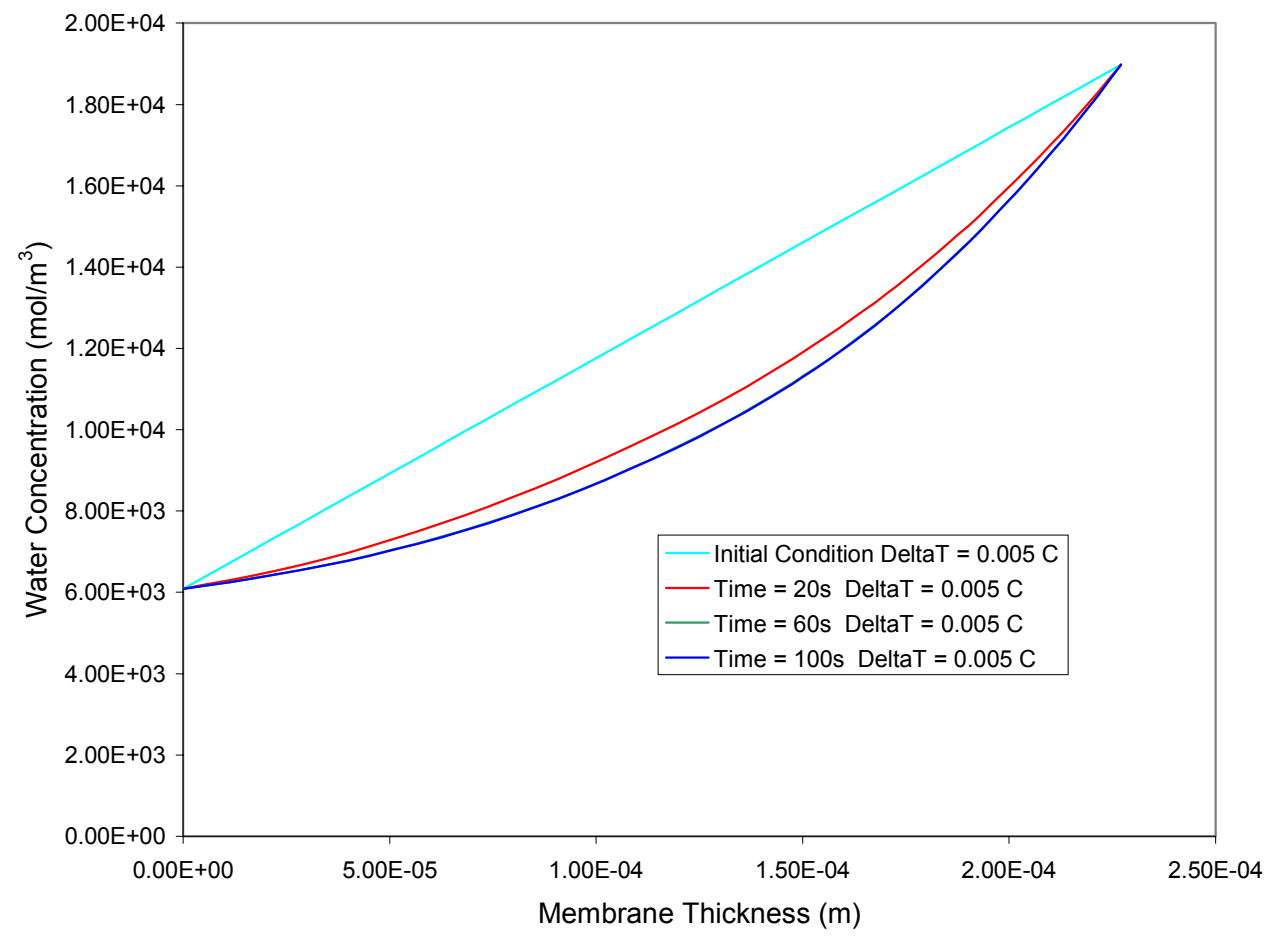

Figure 10.5 Effects of ohmic heating vs convection on the water concentration profiles for a $\Delta \mathrm{T}=0.005{ }^{\circ} \mathrm{C}$ across the membrane. 


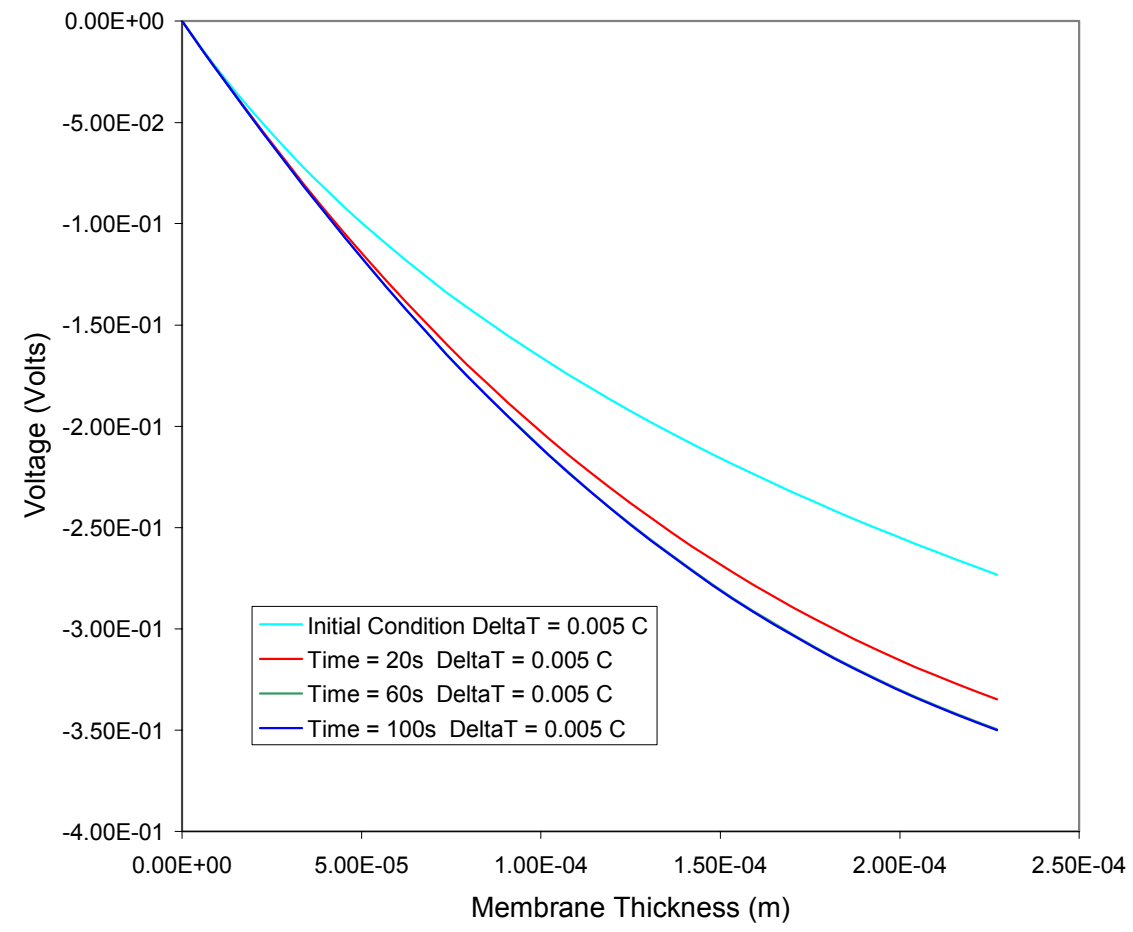

Figure 10.6 Effects of ohmic heating vs convection on the voltage profiles for a $\Delta \mathrm{T}=$ $0.005{ }^{\circ} \mathrm{C}$ across the membrane.

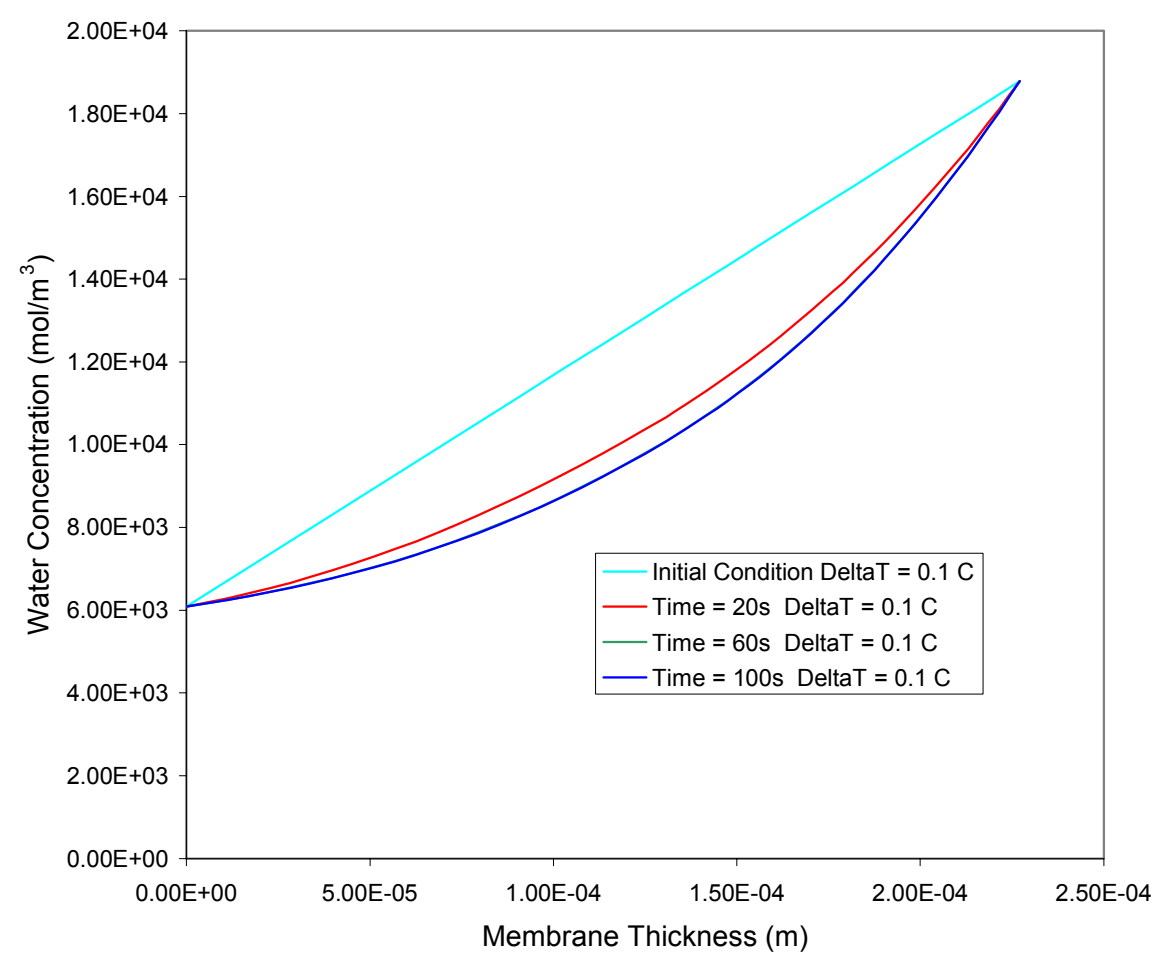

Figure 10.7 Effects of ohmic heating vs convection on the water concentration profiles for a $\Delta \mathrm{T}=0.1{ }^{\circ} \mathrm{C}$ across the membrane. 


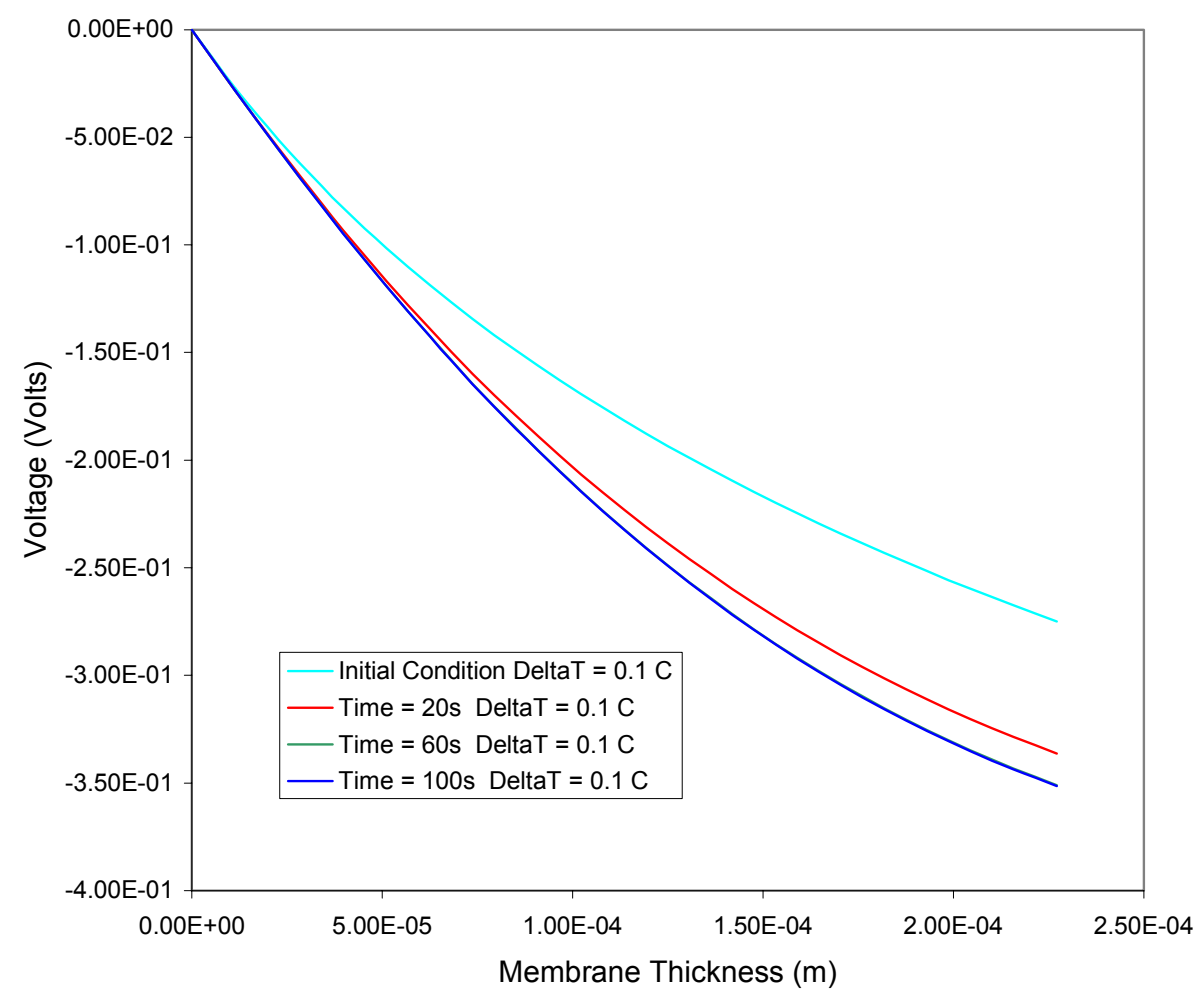

Figure 10.8 Effects of ohmic heating vs convection on the voltage profiles for a $\Delta \mathrm{T}=$ $0.1{ }^{\circ} \mathrm{C}$ across the membrane.

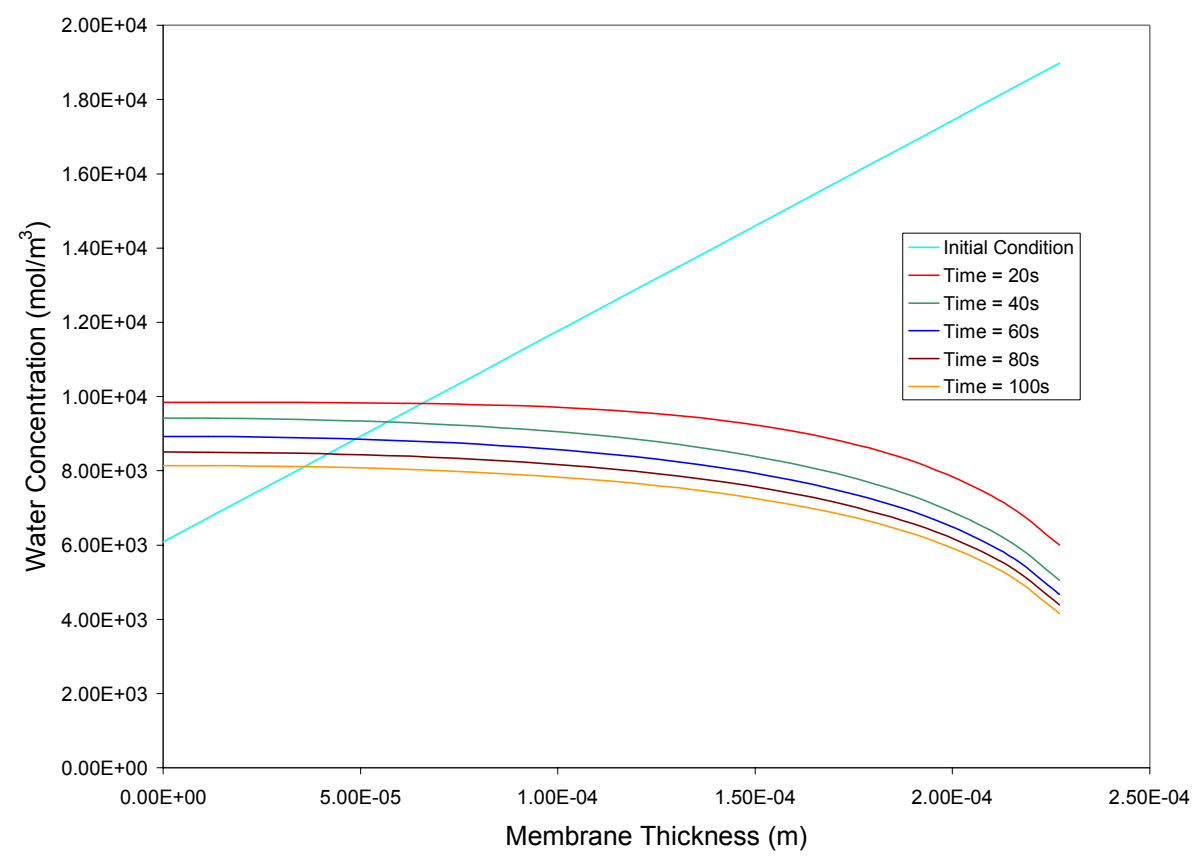

Figure 10.9 Results for boundary condition used to generate Figure 5.3b with $D^{\prime}$ defined using only Eq. (3.7c). 


\section{Vita}

\section{B R A N D O N M EATON}

\section{EDUCATION}

VIRGINIA POLYTECHNIC INSTITUTE AND STATE UNIVERSITY Blacksburg, VA B.S., Mechanical Engineering, with Mathematics minor May 1999

Major GPA: 3.6/4.0, Overall: 3.6/4.0

M.S., Mechanical Engineering May 2001

Overall GPA: 3.6/4.0

\section{EXPERIENCE}

9/99-Present Virginia Polytechnic Institute and State University

Graduate Research Assistant

- Developed Finite Difference Solution for Fuel Cell Membrane Model.

- Assisted in Development of Finite Element Solution for Fuel Cell Membrane Model.

5/99-8/99 ABB Daimler-Benz Transportation Prattelin, Switzerland

Praktikant System Engineer

- Conducted Vibration and Strain Tests on High-Speed Passenger Trains.

- Evaluated Motor Housing Design Variations.

9/98 - 5/99 Virginia Polytechnic Institute and State University

Student Assistance Center Tutor

- Tutored Engineering Students in All Freshman and Sophomore Classes.

5/97-8/97, 5/98-8/98 Unisys Corporation McLean, Va

Intern

- Trained Other Interns.

- Developed More Efficient Methods for Data Manipulation.

- Designer 2000 Application Management.

- Tested Developing Business Applications.

\section{HONORS}

Golden Key National Honor Society

Seay, G.L. \& L.C. Scholarship

Gilbert Associates Scholarship
Virginia Tech Honors Program

Dean's List with Distinction

Gate Fellowship 